\title{
Characterisation of a Novel Benzopyran Library Using

\author{
High-Throughput
}

\section{Microscopy}

\author{
by \\ Jeffrey Patrick Christopher Sheridan
}

\begin{abstract}
A thesis
submitted to the Victoria University of Wellington in fulfilment of the requirements for the degree of Master of Science

in Cell and Molecular Biosciences.
\end{abstract}

Victoria University of Wellington 



\begin{abstract}
Drug discovery is a multi-disciplinary field incorporating both chemistry and biology to create novel pharmaceuticals. Nature synthesizes a diverse range of chemical entities that can demonstrate a wide range of biological interactions, though often produces these compounds in small amounts. Using natures structural diversity as a template, organic synthetic chemistry can tap into the structures of natural products and provide novel structures as well as overcome supply issues through large-scale synthetic chemical processes. A novel benzopyran library was synthesised by Sandile Simelane by reacting $3,4,6$,-tri-O-acetyl-D-galactal with various phenols to create a novel focused library of bridged benzopyrans. Each molecule has unique functional groups at defined points in the structure due to varying the functional groups on the phenol, allowing for variation within the library whilst retaining the core scaffold. In this thesis, the bioactivity of this novel benzopyran library was explored using a phenotypic screen measuring growth inhibition. A compound, S13, was determined to be the most potent in the library, therefore genome-wide screening was performed using S13. High-throughput microscopy of 4,100 strains, each with a different GFP-tagged protein, was utilized to determine proteins that increased in abundance or changed localization in response to perturbation with S13. Following treatment with S13, the yeast vacuole increased in size due to an aggregation of proteins in the vacuolar lumen. The increase in vacuole size was coincident with a decrease in vacuolar
\end{abstract}


acidity, potentially disrupted autophagy and the upregulation of several proteins involved in ergosterol biosynthesis. Together, these results reveal a novel bridged benzopyran that increases vacuolar size and $\mathrm{pH}$ through an epistatic mechanism involving ergosterol biosynthesis. 


\section{Acknowledgments}

I would like to begin by thanking my supervisor Dr. Andrew Munkacsi, thank you for your constant support and allowing me to following whichever path I deemed best. To my secondary supervisor Dr. Simon Hinkley, thank you for all your help with the chemistry side of things. To Dr. Bradley Williams and Dr. Sandile Simelane and the whole Ferrler institute, thank you for giving me the opportunity to work on these novel compounds.

To the chemical genetics group, thanks for being a "unique" bunch of individuals. Thanks to Namal for your constant insight into scientific methods and critiquing all aspects of my work. Thanks to Dinindu for all your help with OPERA work, image analysis and just general wisdom. Thanks to Tamayanthi for the late nights powering through trying to make sense of my results, may your passion for science always BURN strong. Shaun, it was good to have a fellow zaibatsu to share the "lovely" experience of Masters with. Timothy, may the lighting ever be in your favour. Liam, may there be lots of metal gardens in your future. Aidan, one day you will be the very best like no one ever was. Richard, Richard.

Thanks to my friends and family for your never ending support through this harrowing ordeal. Thanks to David for your coding abilities that made my life that much easier. Thanks to mum for the putting up with 
my hours and making sure I had everything I needed. I can finally sleep now. 


\section{Contents}

1 Literature Review 1

1.1 Drug Discovery . . . . . . . . . . . . . . . . . . . . 1

1.1 .1 Drug Screening . . . . . . . . . . . . . . . 3

1.1.2 Medicinal Chemistry . . . . . . . . . . . . 4

1.1.3 Natural Products . . . . . . . . . . . . . . . . 6

1.1 .4 Privileged Scaffolds . . . . . . . . . . . . . . . . . . 8

1.1 .5 Benzopyrans . . . . . . . . . . . . . 9

1.2 Saccharomyces cerevisiae as a model for drug discovery . 11

1.2.1 Homozygous Deletion Collection . . . . . . . . . . 13

1.2.2 Synthetic Genetic Array Methodology . . . . . . . . 14

1.2.3 Green Fluorescent Protein Collection . . . . . . . . 16

1.2 .4 Aims . . . . . . . . . . . . . . . 18

$2 \quad 19$

2.1 Introduction . . . . . . . . . . . . . . . . . . . . . 19

2.2 Matarials and Methods . . . . . . . . . . . . . . . 21

2.2 .1 Strains . . . . . . . . . . . . . 21

2.2 .2 Materials . . . . . . . . . . . . . 21

2.2.3 Compound preparation . . . . . . . . . . . 23

2.2.4 Liquid-Based Bioactivity Assays . . . . . . . . . . . 23

2.2 .5 Cytoxicity assay . . . . . . . . . . . . . . . 24 
2.2.6 Agar-Based Bioactivity Assays . . . . . . . . . . . . 25

2.2 .7 PCR amplification $\ldots \ldots \ldots \ldots$

2.2 .8 Yeast Transformations . . . . . . . . . . . . . . . . . 27

2.2.9 Transformant Functional Validation . . . . . . . . . . 29

2.2.10 Synthetic Genetic Array Methodology . . . . . . . . 29

2.2.11 Genomic Extraction . . . . . . . . . . . . . . 32

2.2.12 Plasmid Extraction . . . . . . . . . . . . . . . 32

2.2.13 PCR confirmation . . . . . . . . . . . 33

2.2.14 High-throughput microscopy . . . . . . . . . . . 34

2.2.15 Automated image analysis . . . . . . . . . . . 34

2.2.16 Filipin staining of ergosterol microscopy . . . . . . . 36

2.2.17 Calcofluor white staining of chitin . . . . . . . . . 36

2.2.18 GFP-ATG8 as a marker for autophagy . . . . . . . . 36

2.2.19 Chloroquine staining of vacuolar $\mathrm{pH}$. . . . . . . 37

2.2.20 MUP1 localisation assay $\ldots . . \ldots 37$

2.2.21 FM4-64 staining of the vacuole . . . . . . . . . . 38

2.3 Results . . . . . . . . . . . . . . . . . . . . . 39

2.3.1 Phenotypic screen shows $\mathrm{S} 13$ is the most potent compound from focused benzopyran library . . . . . 39

2.3.2 $\mathrm{S} 13$ is a pdr5 substrate . . . . . . . . . . . 40

2.3.3 The benzopyran compound library is cytostatic . . . 42

2.3.4 S13 treatment induces upregulation of ergosterol biosynthesis proteins . . . . . . . . . . 45

2.3.5 S13 treatment increases vacuole size . . . . . . . 49

2.3.6 S13 treatment does not alter cell wall or membrane morphology . . . . . . . . . . . . . 5 56 
2.3.7 S13 treatment induces GFP-Atg8 localisation to the vacuole but autophagy is not required for inhibition . 58

2.3.8 S13 treatment does not induce ER stress . . . . . 61

2.3.9 $\mathrm{S} 13$ induces an increase in vacuolar $\mathrm{pH} \ldots$. . . . . 63

2.3.10 S13 does not inhibit endocytosis but potentially inhibits vesicle fusion at the vacuole . . . . . . . . 67

2.4 Discussion . . . . . . . . . . . . . . . . . . . 70

2.4.1 Summary of Focused Compound Phenotypic Screen 70

2.4.2 Chlorination as a means of increasing potency . . . 70

2.4.3 Vacuolar deacidification as a mechanism of action . 71

2.4 .4 S13 induced autophagy . . . . . . . . . . . . . 72

2.4.5 Ergosterol's involvement in vacuolar $\mathrm{pH} \ldots$. . . . 72

2.4 .6 Potential uses . . . . . . . . . . . . . . . . . . . 74

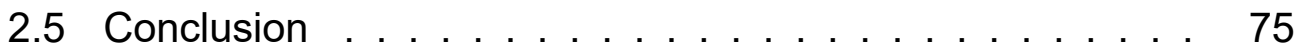

2.6 Future Directions . . . . . . . . . . . . . . . . . . . . 77

2.6.1 Quantifying vacuolar $\mathrm{pH}$ increase . . . . . . . . . 77

2.6.2 Measuring autophagic flux . . . . . . . . . 77

2.6.3 Quantifying ergosterol and its intermediates . . . . . 78

2.6.4 Determining a target of $\mathrm{S} 13 \ldots \ldots \ldots$

2.6.5 Translation into mammalian cell lines . . . . . . 79

2.6.6 Further structure activity relationship research $\ldots 79$

3 Appendix $\quad 81$ 


\section{List of Figures}

1.1 Drug discovery timeline. . . . . . . . . . . . . . 3

1.2 Benzopyran structure $\ldots \ldots \ldots 11$

1.3 Synthetic lethality . . . . . . . . . . . . . . . . 16

2.1 Transformation Confirmation Primers . . . . . . . . . . . . 35

2.2 S13 is the most potent compound in a bridged benzopyran compound library . . . . . . . . . . . . . . . . . . . . . 41

$2.3 \mathrm{~S} 13$ is bioactive in solid media . . . . . . . . . . . . . 42

$2.4 \mathrm{~S} 13$ is pdr5p substrate . . . . . . . . . . . . . . . 43

$2.5 \mathrm{~S} 13$ treatment is cytostatic . . . . . . . . . . . . . . . . . 44

2.6 Control-Treated GFP intensity . . . . . . . . . . . . . . . . 47

2.7 S13 and S12 show high concordance between upregulated genes ........................... 49

2.8 S13 treatment induced upregulation of ergosterol biosynthesis genes . . . . . . . . . . . . . . . . . 50

2.9 Ergosterol biosynthesis pathway showing genes upregulated in $\mathrm{S} 13$ treatment $\ldots \ldots \ldots$. . . . . . . . 51

$2.10 \mathrm{~S} 13$ and $\mathrm{S} 12$ treatment upregulates genes involved in ergosterol biosynthesis . . . . . . . . . . . . . 53

2.11 Network summaries of $\mathrm{S} 13$ screen . . . . . . . . . . . . . . 54 
$2.12 \mathrm{~S} 13$ and $\mathrm{S} 12$ treatment increases prominence of the vacuole

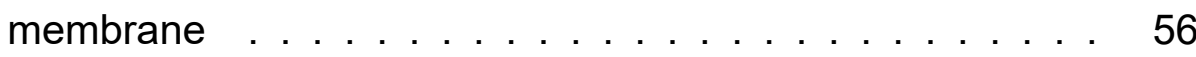

$2.13 \mathrm{~S} 13$ and $\mathrm{S} 12$ treatment increases localisation of membrane transporters to vacuole lumen . . . . . . . . . . . . . 57

$2.14 \mathrm{~S} 13$ has no affect on ergosterol or chitin distribution . . . 58

2.15 Ergosterol biosynthesis genes are invovled in the mechanism for $\mathrm{s} 13 \ldots \ldots$

$2.16 \mathrm{~S} 13$ treatment induces increased localisation of GFP-Atg8 to the vacuole . . . . . . . . . . . . . . . . . . . . 61

2.17 Deletion of genes involved with vacuolar vesicle fusion rescues growth of cells treated with $\mathrm{S} 13 \ldots \ldots 2$

2.18 Deletion of ATG genes has no affect on S13 sensitivity . . . 62

$2.19 \mathrm{~S} 13$ does not induce ER stress . . . . . . . . . . . . . 64

$2.20 \mathrm{~S} 13$ treatment increases vacuolar $\mathrm{pH} \ldots \ldots 6$

$2.21 \mathrm{~S} 13$ is more potent at a neutral $\mathrm{pH} \ldots \ldots 6$

$2.22 \mathrm{~S} 13$ treatment partially inhibits MVB fusion at the vacuole . 67

2.23 S13 inhibits FM4-64 localisation to the vacuole . . . . . . . 68

$2.24 \mathrm{~S} 13$ mechanism of action $\ldots \ldots \ldots \ldots$

3.1 RFP and GFP channel for Ypq1-GFP and Cot1-GFP . . . . 82

3.2 Secondary image analysis . . . . . . . . . . . . . . 83 


\section{List of Tables}

1.1 Summary of studies that screen libraries of benzopyrans . . 10

2.1 S. cerevisiae strains used in this report. . . . . . . . . . 21

2.2 Primers used in this study . . . . . . . . . . . . . . . 26

2.3 PCR reaction $\operatorname{mix} \ldots \ldots \ldots \ldots$

2.4 Transformation reaction $\operatorname{mix} \ldots \ldots . . \ldots 28$

2.5 Strains used for SGA . . . . . . . . . . . . . . . . . . . . . 29

2.6 High-throughput microscopy parameters and settings. . . . 35

2.7 Table of genes upregulated due to $\mathrm{S} 13$ treatment . . . . . . 52 


\section{Abbreviations}

\begin{tabular}{|c|c|}
\hline $\mathrm{ABC}$ & ATP-Binding Cassette \\
\hline ATP & Adenosine Triphosphate \\
\hline cDCFDA & 5(6)-Carboxy-2',7'-dichlorofluorescein diacetate \\
\hline BCECF & 2,7-bis(carboxyethyl)-5(6)-carboxyfluorescein \\
\hline DMA & Deletion Mutant Array \\
\hline DMSO & Dimethyl Sulfoxide \\
\hline ER & Endoplasmic Reticulum \\
\hline GFP & Green Fluorescent Protein \\
\hline HTS & High-Throughput Screen \\
\hline LB & Lysogeny Broth \\
\hline ORF & Open Read Frame \\
\hline $\mathrm{PE}$ & phosphatidylethanolamine \\
\hline PDR & pleiotropic drug resistance \\
\hline SAR & Structure activity relationship \\
\hline SC & Synthetic Complete \\
\hline SD & Synthetic Dropout \\
\hline SGA & Synthetic Genetic Array \\
\hline UPR & Unfolded Protein Response \\
\hline UPRE & Unfolded Protein Response Element \\
\hline V-ATPase & Vacuolar-Type H+ -ATPase \\
\hline YPD & Yeast Extract Peptone Dextrose \\
\hline
\end{tabular}




\section{Chapter 1}

\section{Literature Review}

\subsection{Drug Discovery}

The earliest recorded use of medicine by humans is from a 5,000 year old Sumerian clay slab. The slab described 12 recipes for medicinal concoctions utilising over 250 plants, including poppy and mandrake, which are still used in medicine today (Petrovska, 2012). Other examples of ancient medicines taken from nature include descriptions found in the Indian holy books Vedas and traditional Chinese medicines that mention numerous plants that were used to treat various pathologies (Cheng, 2000; Petrovska, 2012). The pursuit of new medicines continued throughout history, such as the discovery of vaccines by Edward Jenner and the serendipitous finding of penicillin by Alexander Fleming (Fleming, 1929; Jenner, 1801).

Modern drug discovery is a multi-disciplinary field incorporating both chemistry and biology to create novel pharmaceuticals. Pharmaceuticals are a billion dollar industry with \$150bn USD spent on research and development in 2015 alone and is expected to increase to \$182bn USD by 2022 (World Preview 2016, Outlook to 2022 n.d.). 
Although a record number of products were approved by the FDA in 2015, few drugs are available to effectively treat an array of common diseases including neurodegenerative disease, metabolic diseases, cardiovascular diseases, and cancer. Therefore there is still a requirement for novel drugs to be brought to market.

Developing a new drug takes on average 14 years to get from the initial compound discovery (e.g., a hit in a screen) to a commercial product (Fig. 1.1). The process begins with screening candidates to determine "hits", which are compounds that fulfil all screening parameters. Hits are modified to form "lead" compounds that are optimised to give more drug like properties and increase efficacy. Phase 0 animal studies are carried out after lead optimisation is finished to determine toxicity and estimate dosages for human trials. From there clinical trials are carried out starting with phase 1 trials in a select group of healthy volunteers to determine tolerable doses for humans. Phase 2 and 3 trials involve testing the drug in patients that are afflicted with the target disease. If by the end of phase 3 trials the drug proves efficacious and safe for human consumption, then the approval agency will consider the application for release to the general population. Each step of the drug discovery process sees drug candidates fail due to various reasons, though generally due to a lack of efficacy or toxicity (Harrison, 2016).

Clinical trials are the most costly aspect of the drug discovery process. The length of Phase II and phase III clinical trial are increasing, with the median trial length increasing by 7 months in phase II and 6 for phase III in the 2013-2015 period compared to the 2006-2008 period (Martin et al., 2017). Returns on R\&D investment are continuing to decline, having dropped more than 50\% from 2010 to 2016 (Mullard, 


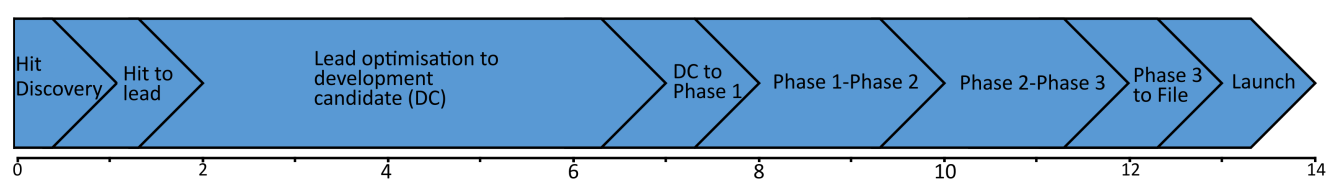

Figure 1.1: Drug discovery time-line. Approximate time-line for drug discovery from hit discovery to product launch. Redrawn from (Payne et al., 2007)

2016). Due to this increase in time and expenditure, robust screening methods are required earlier in the drug discovery process to create high quality leads for drug development.

\subsubsection{Drug Screening}

There are two main approaches for drug screening: target-based and phenotypic drug discovery platforms. Target-based or reverse drug discovery takes an isolated drug target and screens drug candidates for binding affinity in vitro (Takenaka, 2001). Reverse drug discovery was popularised following the sequencing of the human genome allowing for rapid cloning and synthesis of proteins (Bauer et al., 2010). Protein targets are generally critical for disease function whereby knocking out the protein inhibits disease progression (Takenaka, 2001). Using a predefined target means little work is required to determine the compounds mechanism of action, out of all possible mechanisms. Knowing the drug target also allows for easier post-screen modifications due to rapid screening of modified molecules. However, target-based drug screens require prior knowledge about disease dynamics in order to determine potential targets. Computer algorithms can be used to help determine potential drug targets, however off target effects cannot be determined (Khurana et al., 2015). Cells are also not static, having dynamic responses to environmental and xenobiotic perturbation. It is 
thus nearly impossible to determine how a living cell will compensate when exposed to a drug.

Phenotypic drug discovery involve unbiased screening of live cells to determine compounds that give a desired phenotype. Such a method offers a number of advantages to target-based screening. For instance each hit in a phenotypic screen is active in vivo and cellular compensation is determined early in screening. Each compound is also screened against a library of mutants, meaning potentially "undruggable" proteins are also screened. It's estimated that $50 \%$ of drugs target the same four classes of proteins: nuclear receptors, G-protein coupled receptors, and voltage- and ligand-gated ion channels. Having limited target variation in commercial drugs can bias researchers to these protein types when designing screens (Adams et al., 2012; Overington et al., 2006). However, as the target is unknown in phenotypic screens, researchers need to manually determine the cellular target. Structure activity relationships (SARs) also become more difficult due to more confounding factors such as drug metabolism. The phenotype chosen must be robust enough to screen for drug candidates but simple enough to be screened in high-throughput. This means much work needs to be put into choosing a cell based assay or model organism to screen for potential phenotypes (Khurana et al., 2015).

\subsubsection{Medicinal Chemistry}

Medicinal chemistry plays a crucial role in hit to lead development, involving the identification, modification and synthesis of novel bioactive compounds utilising both chemistry and medicinal biology. Once hits are identified modifications are made to develop hits into what's known as a "lead compound". Lead compounds have improved chemical 
properties such as binding affinity, potency, half-life and toxicity compared to hits. SARa are used to determine structural changes for lead optimisation. SAR is the relationship between a compound's structure such as functional groups and biological activity. SAR is vital for determining structural modifications that improve chemical properties whilst simultaneously retaining bioactivity. Quantitative structure-activity relationships QSAR is a method that involves using computer models to predict variables that affect the potency of a compound (Perkins et al., 2003). Other methods involve generating libraries of compounds with slight modifications and determining constituents that modify or enhance activity (Ballard et al., 2008). The ideal end result for each method is a more efficacious compound for pre-clinical and clinical trials.

Combinatorial chemistry involves chemically synthesising thousands of compounds using a single process. Molecules found in compound libraries synthesised via combinatorial chemistry typically follow absorption, distribution, metabolism, excretion and toxicity (ADMET) characteristics in order to exhibit "lead-like" properties (Lipinski et al., 2001). The benefit of a compound library approach is that a high proportion molecules will be cell permeable and orally available due to being designed according to the ADMET criteria. In theory the ideal compound libraries for drug discovery would be synthesised. However, compound libraries generated via combinatorial chemistry are under-represented in distinct bioactive structures found in natural products. For instance, $83 \%$ of core ring scaffolds represented in natural products are absent in commercial screening libraries (Hert et al., 2009). This covers a large area of biologically relevant chemical space, which is not investigated with commercial libraries. It has been theorised that 
including natural products with such scaffolds into compound screening would likely increase hit rates over purely synthetic libraries (Hert et al., 2009).

\subsubsection{Natural Products}

Natural products are compounds produced by living organisms. The use of natural products in medicine has persisted from ancient times to modern pharmaceuticals. The utilisation of natural products as a source for novel drugs is significant; natural products either directly (as natural products) or indirectly (as drugs based on natural products) accounted for $42 \%$ of drugs released between 1981 and 2014 in the USA (D. J. Newman and Cragg, 2016). In 2008 only 35\% of all FDA-approved drugs were from natural sources, whereas in 2010 natural products or naturally derived products accounted for $80 \%$ of approved drugs that year. These data show that natural products and naturally derived products are still highly prevalent in drug discovery and a continuous source of new molecular entities.

Natural products contain biologically relevant molecular scaffolds that have evolved over millennia to elicit biological activity such as compounds involved in allelopathy. Allelopathy is a natural defence mechanism found in many organisms involving the release of molecules that target specific pathways in neighbouring organisms, giving a competitive fitness advantage (Song et al., 2017). Studying allelopathy has lead to important breakthroughs in the field of medicine, such as the discovery of penicillin, and offers a wealth of information due to the diversity and structural differences natural products offer over purely synthetic compounds (Ligon, 2004). Nature produces compounds that differ from those readily accessed through synthetic methods in many key 
areas; e.g., a high number of chiral centres, low nitrogen content, slightly higher oxygen content and enrichment for aliphatic compounds over aromatic rings (Lee and Schneider, 2001)(Henkel et al., 1999).

Natural products have contributed some of the most important drugs of the last century, such as antibiotics, statins, anticancer agents, immunosuppressants and pain relievers (Harvey et al., 2015). A number of such drugs came from microbial sources, for example the antibiotic penicillin, which was isolated from Penicillium notatum in 1928 (Fleming, 1929) or the immunosuppressant rapamycin (Sirolimus) from Streptomyces hygroscopicus (Vezina et al., 1975). In addition to microbes, natural product drugs have been derived from other organisms such as the chemotherapy drug paclitaxel, isolated from the Pacific yew Taxus brevifolia (Wani et al., 1971), or the analgesic ziconotide isolated from the snail Conus magus (Mclntosh et al., 1982).

Much like molecules from synthetic libraries, natural products may also undergo lead optimisation via medicinal chemistry. Semi-synthetic drugs are natural products that have been modified post-isolation giving altered chemical properties compared to the original natural product. Tetracycline describes a group of protein synthesis inhibitors sharing a four hydrocarbon ring system (Charest, 2005). Chlorotexacycline was the first tetracycline isolated from Streptomyces aureofaciens and has undergone numerous modifications creating a number of different commercial drugs termed tetracycline antibiotics (M. L. Nelson and Levy, 2011). Doxycycline is a tetracycline antibiotic used for the treatment of a wide range of bacterial infections including acne, chlamydia and cholera (Alam et al., 1990; Nilsen et al., 1992; Skidmore et al., 2003). Doxycycline differs from chlorotetracycline in only 
three functional groups that increased both the efficacy and stability of doxycycline compared to chlorotexacycline (M. L. Nelson and Levy, 2011; Stephens et al., 1963).

Natural products often demonstrate unique biological activity that has recently been difficult to replicate through wholey synthetic libraries; however, abundance and availability are limiting factors for their use as pharmaceuticals. For example, the Pacific yew that produces paclitaxel faced extinction due to over-harvesting of the much needed chemotherapeutic (Mayor, 2011). Whilst it is possible to synthesise paclitaxel in a laboratory, the same is not possible for all natural products. Through organic synthesis or semi-synthesis abundance issues can be overcome and lead to large scale production. However, as stated, libraries generated through purely synthetic means often lack the diversity seen in natural products. The bridge between natural products is to harvest the "privileged scaffolds" of nature and optimise these through synthetic means.

\subsubsection{Privileged Scaffolds}

Privileged scaffolds are molecular frameworks with inherent bioactivity capable of binding different proteins due to slight structural changes (Duarte et al., 2007; Welsch et al., 2010). Privileged scaffolds are not to be confused with promiscuous inhibitors, which are groups of molecules that create false positives during High throughput screening (HTS) due to binding large numbers of targets without specificity (Feng and Shoichet, 2006). The idea of privileged scaffolds was first presented in 1988, when it was discovered that varying affinities for CCK receptors were achieved by altering functional groups on a core benzodiazepine structure (Evans et al., 1988). Another reported that 32 structures 
accounted for more than $50 \%$ of compound variability, out of 5,120 drugs (Bemis and Murcko, 1996). Therefore, privileged scaffolds offer an ideal starting point for drug discovery, due to their ability to bind a wide range of proteins.

Privileged scaffolds have been discovered with the ability to bind a wide variety of proteins. For instance, the class of molecule benzodiazepines, are able to mimic $\beta$-turn structures found in many biological ligands (Hata and G. R. Marshall, 2006). Another example are non-steroidal anti-inflammatory drugs used to treat pain and inflammation. A key target of non-steroidal anti-inflammatory drugs is the cyclooxygenase enzyme COX2, which catalyses the formation of prostaglandin $\mathrm{H}_{2}$ from arachadonic acid (Corcoran et al., 1992; Pentland et al., 1995). Two types of privileged structures, indole rings and indomethacin have proven to be effective inhibitors of COX-2 (Hu et al., 2003). Determining priveleged scaffolds that specifically bind proteins of interest allows researchers to focus compound libraries on specific sets of molecular structures to treat specific diseases.

\subsubsection{Benzopyrans}

Benzopyrans are a privileged scaffold consisting of a benzene ring fused to a pyran ring (Fig. 1.2) (Welsch et al., 2010). Benzopyrans are found in a wide variety of biologically active compounds and have been used for decades in the pharmaceuticals industry to treat a range of different pathologies. For example Nebivolol is a $\beta$-blocker, used to treat hypertension and left ventricular failure (de Boer et al., 2007). Flavoxate is used to treat urinary bladder spasms as well as a number of other pathologies (Bradley and Cazort, 1970 Jan-Feb). Phenprocoumon is a vitamin $\mathrm{K}$ antagonist that acts as an anticoagulant by inhibiting synthesis 


\begin{tabular}{lll}
\hline Publication & Library size & Brief description of findings \\
\hline $\begin{array}{l}\text { (Staats et al., 500 } \\
\text { 2013) }\end{array}$ & $\begin{array}{l}\text { Found molecules that act as a mast } \\
\text { cell activator to be used as a vaccine } \\
\text { adjuvants. Determined a class of } \\
\text { benzopyrans that were capable of } \\
\text { degranulating mast cells }\end{array}$ \\
$\begin{array}{l}\text { (Nicolaou et 10,000 } \\
\text { al., 2001) }\end{array}$ & $\begin{array}{l}\text { The library showed enrichment in } \\
\text { molecules involved in reported gene } \\
\text { activation under hypoxic conditions }\end{array}$ \\
$\begin{array}{l}\text { (Ko et al., 22 } \\
\text { 2006) }\end{array}$ & $\begin{array}{l}\text { Synthesised benzopyran library and } \\
\text { determined bioactivity in an A549 lung } \\
\text { carcinoma cell line. }\end{array}$ \\
(Kumar et al., Not stated \\
$2011)$
\end{tabular}

Table 1.1: Summary of studies that screened libraries of benzopyrans.

of various coagulation factors (Hirsh et al., 1992).

Much work has been performed into utilising benzopyrans as a core structure for library generation and screening. Chemists are increasingly using benzopyrans as core structures in the design of novel focused compound libraries. A study by Tan et al. created a benzopyran library consisting of 10,000 unique molecules and found enrichment in compounds involved in reporter gene activation under hypoxic conditions due to the targeting of hypoxia inducible factor-1 (Ferguson et al., 2017; Tan et al., 2005). Other studies have found that benzopyrans have diverse mechanisms of action with activities such as mast cell activation as well as antitubercular and anti-cancer activity (Table. 1.1). Due to these robust activities, benzopyrans offer great potential for novel compounds to treat a number of pathologies. 


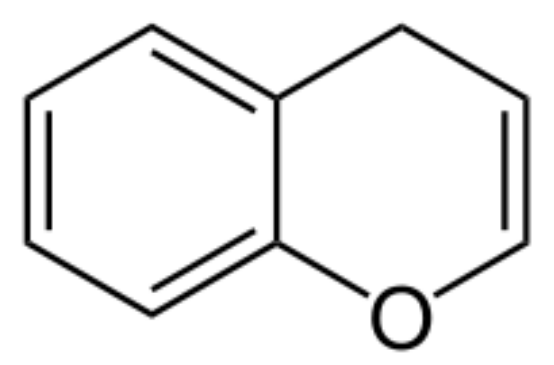

Figure 1.2: Benzopyran structure. Figure showing the core structure of a benzopyran.

\subsection{Saccharomyces cerevisiae as a model for drug discovery}

Saccharomyces cerevisiae is a single cell eukaryote colloquially known as "Baker's yeast" that is widely used as a model for various cellular processes (Botstein and Fink, 2011). Yeast is inexpensive, grows on simple media, has a doubling time of only 90 minutes and was the first organism to have its whole genome sequenced, with the initial genome map published in 1996 (Goffeau et al., 1996; Simon and Bedalov, 2004). The yeast genome is small, comprising 16 chromosomes and contains just over 6,000 open reading frames (ORFs) (Gavin et al., 2006). Approximately $45 \%$ of yeast genes have an orthologous human gene (Hughes, 2002) including 950 human genes implicated in disease (Heinicke et al., 2007). Protein functions and amino acid sequences have been conserved to such an extent that gene function can be inferred between yeast and other eukaryotes, including humans (Botstein and Fink, 2011).

Homology to higher eukaryotes extends to a number of key cellular processes, such as the secretory pathway and autophagy. Pioneering work performed using yeast shaped our knowledge of the 
secretory system. Using S. cerevisiae, Randy Schekman and Peter Novick created 23 temperature-sensitive "sec" mutants that helped form the basis for our understanding of the secretory pathway (Novick and Schekman, 1979; Novick, Field, et al., 1980). Their work earned the Nobel prize in 2013 in Physiology or Medicine (Rothman et al., 2017). Yeast was also used as a model organism by Yoshinori Ohsumi in the 1990's for the discovery of 15 genes required for autophagy. The elucidation of these genes then allowed for the identification of the major regulator of autophagy, the mammalian the target of rapamycin (mTOR) (Kamada et al., 2000). The pioneering work of Ohsumi's earned him the Nobel Prize in Physiology or Medicine in 2016 (Ohsumi, 2017).

Due to conservation of genes and processes the Gene Ontology (GO) Consortium was established to create a set of terms that transfer functional information between species (Ashburner et al., 2000). GO has three highly structured and controlled levels of classification: biological process, cellular components (localisation) and molecular function. Each GO term is described in a species independent manner allowing for translation between species. A large proportion of proteins with GO annotations were characterised in $S$. cerevisiae and translated into higher eukaryotes (Heinicke et al., 2007). With GO annotations $S$. cerevisiae is a well positioned organism for translating genetic data to higher organisms, as $85 \%$ of protein coding genes in yeast have assigned biological functions (Botstein and Fink, 2011). A major reason for $S$. cerevisiae having such a well characterised genome and its use in drug screens are the numerous tools available to researchers. The versatility of $S$. cerevisiae has fuelled the development of a number of genome-wide libraries. These include protein over expression, yeast two 
hybrid and tandem affinity purification libraries (Ghaemmaghami et al., 2003; Sopko et al., 2006; Uetz et al., 2000). Of particular interest to this study are the homozygous deletion collection and the yeast green fluorescent protein (GFP) collection.

\subsubsection{Homozygous Deletion Collection}

Each of the 6,000 ORFs in yeast's genome was systematically deleted creating a library of haploid deletion mutants (Giaever and Nislow, 2014; Giaever, Chu, et al., 2002; Winzeler, 1999). Deletions were created by inserting a "deletion cassette" into each ORF. Deletion cassettes contain a kanamycin resistance marker that allows gene deletion mutants to grow in the presence of the antibiotic kanamycin. Each cassette also contained a unique synthetic barcode sequence to identify individual mutants. From these deletions, 1000 were determined to be essential for viability on nutrient rich media (Giaever, Chu, et al., 2002). The non-essential genes were used to create a deletion mutant array (DMA) containing approximately 4,800 strains (Giaever, Chu, et al., 2002; A. H. Y. Tong, 2004).

The DMA is a powerful genomic tool for characterising the bioactivity of novel compounds. Exposure to various stressors causes changes in gene and protein expression in order to effectively handle the stress, making different genes essential (Hillenmeyer et al., 2008; Parsons, Lopez, et al., 2006). This is related to the principle of synthetic lethality whereby the deletion of each individual gene is viable but the deletion of both causes death (Dobzhansky, 1946; Nijman, 2011). Gene deletions can be substituted for drugs, that inhibit the function of a gene, thereby inducing synthetic lethality upon treatment in relevant deletion strains (Fig. 1.3). Synthetic lethality or synthetic sick interactions form the 
basis for probing the yeast DMA with xenobiotics.

The unique barcode found in each mutant strain in the DMA allows for pooling of each mutant in liquid media (Smith, Ammar, et al., 2010). Cells are treated with an inhibitory concentration of a compounds and the barcodes are quantified using microarray or next-generation sequencing to determine strains that are under or over represented in each pool (Pierce et al., 2006). Under-represented strains are considered hyper-sensitive or synthetic lethal. Strains that are over-represented are considered resistant to treatment. Each deletion strain can also be pinned onto agar and grown in the presence of a bioactive compound and hypersensitivity or resistance to compound treatment is determined by measuring colony size in relation to untreated colonies (Parsons, Brost, et al., 2004). In summary, determining strains with altered sensitivity gives insight into the genes and pathways required for viability in the presence of an inhibitory compound (Smith, Heisler, et al., 2009).

\subsubsection{Synthetic Genetic Array Methodology}

Synthetic Genetic Array (SGA) methodology involves high-throughput en mass mating of a query strain with a yeast library. SGA methodology exploits the ability of yeast to grow in both a haploid and diploid life cycle. Query MAT $\alpha$ strains are mated into a library of MATa strains forming diploids containing the genetic material from both parents. Diploids are then induced to sporulate via growth under starvation conditions, forming haploids. As the haploids formed have various genotypes, a number of selection steps are undertaken to sequentially select for each desired genotype. The outcome of an SGA is a library of strains consisting of the starting strains with the addition of a selectable trait such as a gene deletion or GFP tagged protein 
(A. H. Y. Tong and Boone, 2006; A. H. Tong et al., 2001).

SGA methodology is traditionally used to study genetic interactions between genes by mass mating a query gene deletion into the DMA (A. H. Y. Tong and Boone, 2006; A. H. Tong et al., 2001). Genetic interactions can either be positive or negative. Positive interactions are when two gene deletions rescue or buffer the phenotype caused by the individual gene deletion. Negative interactions are induced when two gene deletions have greater than expected fitness defects than each of the single gene deletions. Positive and negative interactions can also be looked at in terms of gene knock-down in the case of essential genes, where the knock-down of a gene induces synthetic lethality when paired with another gene deletion. In a powerful investigation of yeast genetic interactions Costanzo et al. used SGA methodology to construct over 23 million double mutants, which resulted in the identification of 555,000 negative and 350,000 positive interactions (Costanzo et al., 2016).

SGA methodology proves useful in the addition of new selectable traits into already established libraries. Such matings allow for the creation of new $S$. cerevisiae libraries containing novel insertions to study various phenotypes at a genome-wide level. Coorey et al. constructed a library of strains hypersensitive to xenobiotics by mass mating two gene deletions, $p d r 1 \Delta$ and $p d r 3 \Delta$ into the yeast DMA (Coorey et al., 2015). PDR1 and PDR3 encode transcription factors for a number of drug efflux pumps, therefore their deletions increase sensitivity to drugs (Mamnun et al., 2002). Another study introduced a reporter for length dependent mRNA accumulation into the yeast DMA to discover gene deletions that act as elongation factors (Milln-Zambrano et al., 2013). 


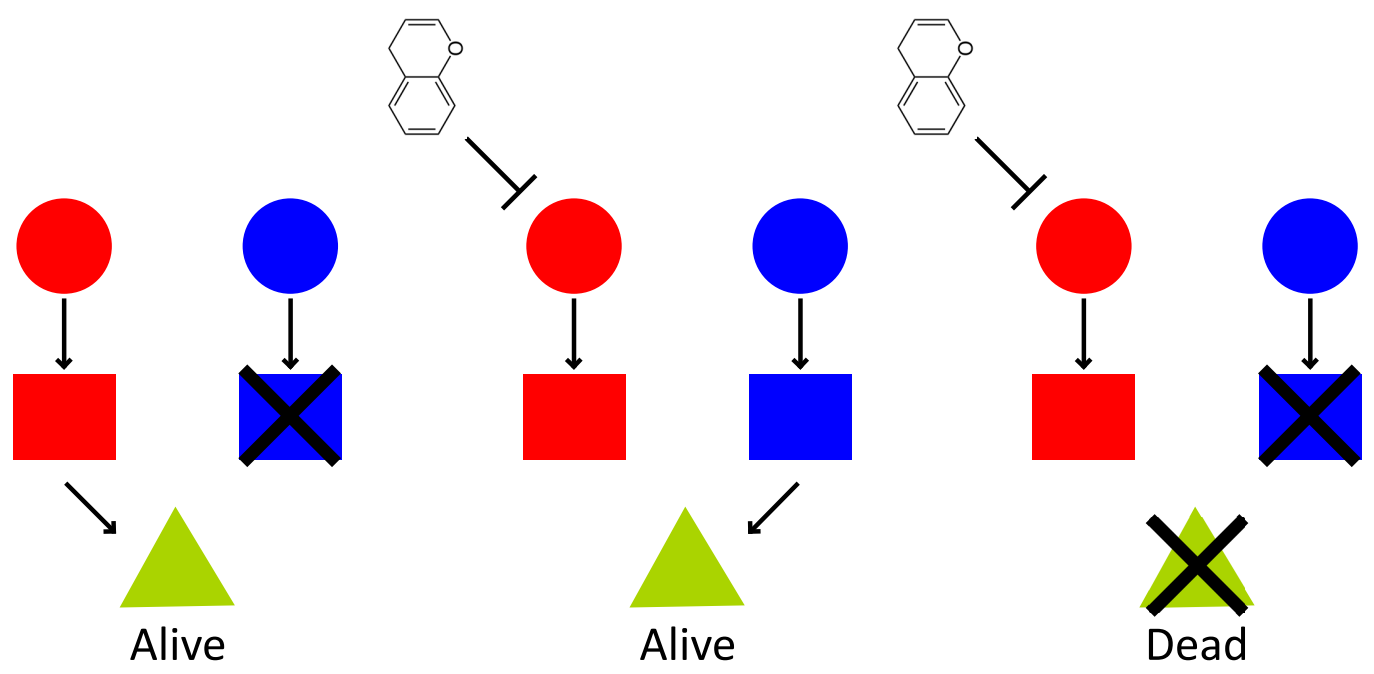

Figure 1.3: Synthetic lethality. A drug-gene interaction whereby a drug treatment or single gene deletion by themselves are viable but when when in conjunction, the cell is no longer viable. Circles and squares represent proteins and the triangle represents the end result of both pathways. Red and blue indicate two separate biological pathways that lead to the same end result (green triangle).

\subsubsection{Green Fluorescent Protein Collection}

Living cells express thousands of proteins at any given time. Protein expression and localisation change in response to various stimuli such as nutrient availability, temperature, $\mathrm{pH}$ and other stressors (Brett et al., 2011; Gasch et al., 2000). GFPs are a group of proteins that fluoresce green when excited with light with a wavelength of $488 \mathrm{~nm}$ (Heim et al., 1995). GFPs can be attached to either the carboxyl- or amino-terminus of a protein with minimal altering of protein function or localisation (Breker et al., 2013; Landgraf et al., 2012).

Introducing fluorescent tagged proteins via plasmids has been extensively used in research to study protein localisation (Eugster, 2004; Stringer and Piper, 2011). Plasmids containing GFP-tagged proteins have especially been used in the study of autophagy and vesicular trafficking in S. cerevisiae (Estrada et al., 2015; Reggiori, 2004). However, GFP-tagged 
proteins expressed via plasmids are not controlled by their endogenous promoter meaning it is not possible to extrapolate expression data from such assays.

GFPs are commonly incorporated into ORFs, usually just before the stop codon (Huh et al., 2003). ORF incorporation of GFPs in the genome allows for the visualisation of natural protein localisation and abundance levels. A library of 4,156 genome integrated S. cerevisiae GFP strains was created by GFP tagging at the carboxyl terminus (Huh et al., 2003). Each GFP tagged protein remains attached to its natural promoter allowing GFP fluorescence to be used as a proxy for protein abundance as well as localisation (J. R. S. Newman et al., 2006). S. cerevisiae is currently the only organism in which such a library has been constructed. This library has been used to study protein localisation (Huh et al., 2003), protein abundance through flowcytometry (J. R. S. Newman et al., 2006) and high-throughput microscopy (Breker et al., 2013; Y. Chong et al., 2015; Tkach et al., 2012).

S. cerevisiae is a model candidate for high-throughput microscopy due to ease of growth, genetic tractability and the aforementioned GFP collection (Y. T. Chong et al., 2012). High-throughput microscopy used in conjunction with the yeast GFP collection allows for proteomic level studies of protein localisation and abundance in response to chemical perturbation (Tkach et al., 2012). High-throughput microscopy screens when used in tandem with multi-parametric image analysis are referred to as high-content screens due to the enormous amounts of data generated at the single cell level (Mattiazzi Usaj et al., 2016).

The large amounts of data generated by high-throughput 
assays are uninformative without robust analysis tools to extract relevant information. High-content screens generate large quantities of images, which are impractical to analyse by eye due to time constraints and inherent human biases. Researchers have thus adopted automated image analysis software, capable of recognising and measuring GFP signals at the individual cell level. A common method to identify single cells is to utilise fluorescent markers of specific cellular compartments such as the nucleus or cytoplasm (Bircham et al., 2011; Handfield et al., 2013). RFPs are often used to label nuclei and cytoplasm due to their separation from GFPs in both the emission and excitation spectra, thus minimising crosstalk. The ability to recognise single cells and analyse both localisation and abundance changes allows for the study chemical perturbation at the proteome level.

\subsubsection{Aims}

A novel benzopyran library was synthesised by Dr. Sandile Simelane by reacting 3,4,6,-tri-O-acetyl-D-galactal with various phenols to create a novel focused library of bridged benzopyrans (Simelane et al., 2014). Each molecule has unique functional groups at defined points in the structure due to varying the functional groups on the phenol, allowing for variation within the library whilst retaining the core scaffold. This compound library was kindly gifted by the Ferrier Institute for the use in this thesis. The bioactivity of the compound library is unknown, therefore using chemical genetics this thesis aims to:

1. Determine the bioactivity of a novel focused compound library using a phenotypic screen for growth inhibition.

2. Determine the mechanism of action for a single compound using chemical genetics. 


\section{Chapter 2}

\subsection{Introduction}

Medicinal chemicals derived from natural products has been a mainstay of human therapeutic treatments from ancient times until the modern day. Natural products contain biologically relevant molecular scaffolds that have evolved over millennia to elicit biological activity. A number of core structures are found on natural products and have been described as "privileged scaffolds"; molecular frameworks with inherent bio-activity capable of binding different proteins due to slight structural changes (Duarte et al., 2007). Benzopyrans are a privileged scaffold consisting of a benzene ring fused to a heterocyclic pyran ring (Welsch et al., 2010).

A novel benzopyran library was synthesised by Sandile Simelane by reacting 3,4,6,-tri-O-acetyl-D-galactal with a number of phenols to create a novel focused library of bridged benzopyrans (Simelane et al., 2014). By varying the functional groups on the phenol each molecule could have unique constituents whilst conserving the core structure. Therefore a novel bridged benzopyran library could be created by reacting the same 3,4,6,-tri-O-acetyl-D-galactal compound with a number of substituted phenols. 
Chemical genetics serves to bridge the gap between chemistry and biology. The chemical genetic tool set in S. cerevisiae allows for the determination of a compound's mechanism of actions through the use of various libraries such as the deletion mutant array and GFP library (Huh et al., 2003; Parsons, Brost, et al., 2004). The GFP collection consists of over 4,000 strains each with a different carboxyl-terminal GFP tagged protein. The GFP collection has been used successfully to help elucidate the mechanism of action for a number of different compounds or deletions (Bircham et al., 2011; Breker et al., 2013; Y. Chong et al., 2015; Tkach et al., 2012). Such methods use the are able to measure protein abundance and localisation at the single cell level, giving insight into cellular responses to chemical perturbation.

Herein the bioactivity of a novel focused bridged benzopyran library was determined and one of the molecules, S13, was determined to be the most potent in the library, therefore genome wide screening was performed using S13. High-throughput microscopy using 4,100 strains, each with a different GFP-tagged protein, was utilized to determine proteins that increased in abundance or changed localization in response to perturbation with $\mathbf{S 1 3}$. Following treatment with $\mathrm{S} 13$ yeast's vacuole appeared to increase in size due to an aggregation of proteins in the vacuolar lumen. The increase in vacuole size was in parallel with a decrease in vacuolar acidity and the upregulation of several proteins involved in ergosterol biosynthesis. These findings show a novel bridged benzopyran that increases vacuolar size and $\mathrm{pH}$ through an epistatic mechanism involving ergosterol biosynthesis. 


\subsection{Matarials and Methods}

\subsubsection{Strains}

\begin{tabular}{|c|c|}
\hline Strain & Genotype \\
\hline Y7092 & $\begin{array}{l}\text { MAT } \alpha, \text { can } 1 \Delta:: \text { STE2pr-HIS5, lyp } 1 \Delta, \text { his } 3 \Delta, \text { leu } 2 \Delta 0, \\
\text { ura } 3 \Delta 0, \text { met } 15 \Delta 0, \text { Lys } 2+\end{array}$ \\
\hline$p d r 1 \Delta p d r 3 \Delta$ & 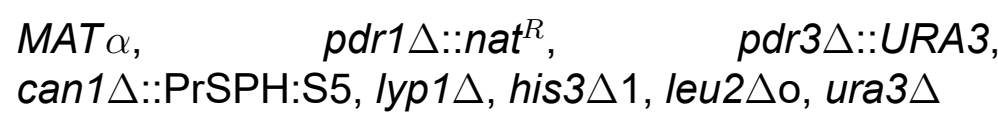 \\
\hline$p d r 1 \Delta p d r 3 \Delta$ & $\begin{array}{l}\text { MAT } \alpha, \text { pdr1 } \Delta:: \text { nat }^{R}, \text { pdr3 } \Delta:: \text { kan }^{R}, \text { can1 } \Delta:: P r S P H: S 5, \\
\text { lyp1 } \Delta, \text { his } 3 \Delta 1, \text { leu } 2 \Delta \text { o, ura3 } \Delta\end{array}$ \\
\hline$p d r 1 \Delta p d r 3 \Delta$ & $\begin{array}{l}\text { MAT } \alpha, \quad p d r 1 \Delta:: K_{a n}^{R}, \quad p d r 3 \Delta:: U R A 3, \\
\text { can1 } \Delta:: \operatorname{PrSPH}: S 5, \text { lyp1 } \Delta, \text { his3 } \Delta 1, \text { leu2 } \Delta \text { o, ura3 } \Delta\end{array}$ \\
\hline$x x x-G F P$ & pdr1 $1 \Delta::$ nat $^{R}$, \\
\hline$p d r 1 \Delta p d r 3 \Delta$ & 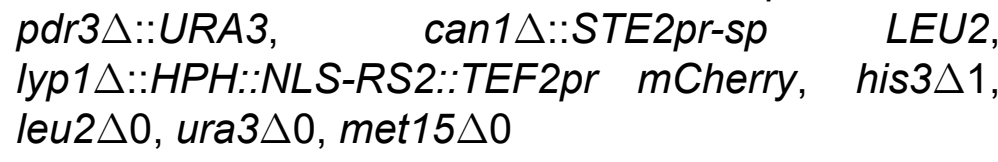 \\
\hline $\begin{array}{l}\mathrm{xxx} \Delta \\
\operatorname{pdr1} \Delta p d r 3 \Delta\end{array}$ & $\begin{array}{l}\text { MATa, pdr1 } \Delta:: \text { nat }^{R}, \quad \text { pdr3 } \Delta:: U R A 3, \quad \text { xxx } \Delta:: K a^{R} \text {, } \\
\text { can1 } \Delta:: \text { STE2pr-sp HIS5, lyp1 } 1, \text { his } 3 \Delta 1 \text {, leu2 } \Delta 0 \text {, } \\
\text { ura3 } \Delta 0, \text { met15 } \Delta 0, \text { LYS2 }\end{array}$ \\
\hline
\end{tabular}

Table 2.1: S. cerevisiae strains used in this report.

\subsubsection{Materials}

\section{SC media amino acid mixture:}

$3 \mathrm{~g}$ adenine, $2 \mathrm{~g}$ alanine, $2 \mathrm{~g}$ asparagine, $2 \mathrm{~g}$ aspartic acid, $2 \mathrm{~g}$ cysteine, 2 $\mathrm{g}$ glutamic acid, $2 \mathrm{~g}$ glutamine, $2 \mathrm{~g}$ glycine, $2 \mathrm{~g}$ histidine, $2 \mathrm{~g}$ inositol, $2 \mathrm{~g}$ isoleucine, $10 \mathrm{~g}$ leucine, $2 \mathrm{~g}$ lysine, $2 \mathrm{~g}$ methionine, $0.2 \mathrm{~g}$ paraaminobenzoic acid, $2 \mathrm{~g}$ phenylalanine, $2 \mathrm{~g}$ proline, $2 \mathrm{~g}$ serine, $2 \mathrm{~g}$ threonine, $2 \mathrm{~g}$ tryptophan, $2 \mathrm{~g}$ tyrosine, $2 \mathrm{~g}$ uracil and $2 \mathrm{~g}$ valine.

\section{HEPES:}

1M HEPES with a $\mathrm{pH}$ of 8.0 . 


\section{SC broth:}

$0.1 \%(\mathrm{w} / \mathrm{v})$ monosodium glutamate $\mathrm{W} / \mathrm{O}$ acids or ammonium sulphate (Sigma-Life Sciences), 0.17\% (w/v) Yeast Nitrogen Base (Formedium), $0.2 \%(\mathrm{w} / \mathrm{v})$ amino acid mixture to suit (Formedium), 2\% (w/v) glucose (Sigma-Aldrich), 20 mM pH 8 HEPES (Formedium).

\section{SC agar media:}

$0.1 \%(\mathrm{w} / \mathrm{v})$ monosodium glutamate $\mathrm{W} / \mathrm{O}$ acids or ammonium sulphate (Sigma-Life Sciences), 0.17\% (w/v) Yeast Nitrogen Base (Formedium), $0.2 \%(w / v)$ amino acid mixture to suit (Formedium), 2\% (w/v) glucose (Sigma-Aldrich), 2\%, $20 \mathrm{mM} \mathrm{pH} 8$ HEPES (Formedium) (w/v) agar granulated bacteriological grade (Formedium).

\section{Synthetic dropout (SD) broth:}

Same as with SC broth but with appropriate amino acid(s) missing.

\section{Synthetic dropout (SD) agar:}

Same as with SC agar but with appropriate amino acid(s) missing.

\section{Yeast extract peptone dextrose (YPD) media:}

$2 \%(\mathrm{w} / \mathrm{v})$ yeast extract (Formedium), 2\% (w/v) peptone (Formedium), $0.012 \% \quad(\mathrm{w} / \mathrm{v})$ adenine (Formedium), 2\% (w/v) agar granulated bacteriological grade (Formedium) and 2\% glucose (Sigma-Aldrich).

\section{YB broth:}

$0.5 \%(\mathrm{w} / \mathrm{v})$ yeast extract (Formedium), 1\% (w/v) tryptone (Formedium), 0.5\% (w/v) NaCl (Thermo Fisher Scientific). 


\section{YB agar:}

$0.5 \%(\mathrm{w} / \mathrm{v})$ yeast extract (Formedium), 1\% (w/v) tryptone (Formedium), $0.5 \%(\mathrm{w} / \mathrm{v}) \mathrm{NaCl}$ (Thermo Fisher Scientific), 2\% (w/v) agar granulated bacteriological grade (Formedium).

\section{Sporulation media:}

$1 \%(\mathrm{w} / \mathrm{v})$ potassium acetate (Sigma Aldrich), $0.1 \%(\mathrm{w} / \mathrm{v})$ yeast extract (Formedium), $0.05 \%(w / v)$ glucose (Sigma-Aldrich), $0.2 \%(w / v)$ amino acid mixture to suit (Formedium), 2\% (w/v) agar (Formedium).

\subsubsection{Compound preparation}

All compounds were dissolved in dimethyl sulfoxide (DMSO) (Sigma-Aldrich) to make a $200 \mathrm{mM}$ stock solution, which was stored at $-20^{\circ} \mathrm{C}$

\subsubsection{Liquid-Based Bioactivity Assays}

Bioactivity for the focused compound library was determined by measuring yeast's growth in the presence and absence of each compound. Growth was measured in two strains, Y7092 and a pdr1 $\Delta p d r 3 \Delta$ strain. Y7092 and $p d r 1 \Delta p d r 3 \Delta$ were inoculated into a $2 \mathrm{~mL}$ synthetic complete with HEPES (SC) broth from YPD agar and grown at $30^{\circ} \mathrm{C}$ in a rotating drum overnight. Optical density (OD) was measured at $660 \mathrm{~nm}$ using a Jenway Genova MK3 spectrophotometer. Each culture's cell density was determined using an OD to cell count conversion. Y7092 and $p d r 1 \Delta p d r 3 \Delta$ cultures were then diluted in $10 \mathrm{~mL}$ of SC media to a final cell concentration of $5 \times 10^{5}$ cells $/ \mathrm{mL}$. $100 \mu \mathrm{L}$ of the diluted culture was added into a Biofill 96well tissue culture plate. $1 \mu \mathrm{L}$ of relevant compound was added to each well in triplicate to give a final concentration of both $100 \mu \mathrm{M}$ and $10 \mu \mathrm{M}$. The plate was then shaken at $1000 \mathrm{rpm}$ for 60 seconds using a MixMate 
Eppendorf plate shaker. A t0 reading was then taken using the Perkin Elmer Envision 2102 Multilabel plate reader, with software 1.13.3009.1401 at wavelength of $590 \mathrm{~nm}$. Further absorbance readings were taken after 16 hours and every 2 hours after that until an OD of 0.4 was achieved the control wells. OD values were normalised by subtracting the initial at time zero. Residual growth was then calculated for each compound treatment using the following equation

$$
\text { Residual Growth }=\frac{\text { Absorbance }(\text { treated })}{\text { Absorbance }(\text { untreated })} \times 100
$$

\subsubsection{Cytoxicity assay}

pdr1 $1 \Delta$ pdr $3 \Delta$ was cultured overnight in $2 \mathrm{~mL}$ of SC media at $30^{\circ} \mathrm{C}$ with rotation. The culture was diluted to give a final concentration of $5 \times 10^{5}$ cells $/ \mathrm{mL}$. $1: 5$ serial dilutions of $\mathrm{S} 13$ were performed to give final concentrations of $200 \mu \mathrm{M}$ to $0.96 \mu \mathrm{M}$. $1 \mu \mathrm{L}$ of each concentration was added to the relevant well in triplicate. $1 \%$ of DMSO was used as a vehicle control. The plate was incubated at $30^{\circ} \mathrm{C}$ for 16 hours.

The 96 well plate was shaken at 1,000 rpm for 30 seconds and an OD reading was taken as described is Section 2.2.4. The plate was then centrifuged at 2,000 rpm using a Eppendorf centrifuge 5810 for five minutes, the supernatant removed and the cells washed with $100 \mu \mathrm{L}$ water. The wash step was repeated twice to remove all compounds from solution. Cells were suspended in $100 \mu \mathrm{L}$ of water and pinned onto YPD agar plates. Plates were incubated at $30^{\circ} \mathrm{C}$ for 24 hours and pictures taken after 24 hours. Colonies were quantified using gitter, which measures colony size based on pixel count (Wagih and Parts, 2014). 


\subsubsection{Agar-Based Bioactivity Assays}

Using a 24 well Biofill plate, $1 \mathrm{~mL}$ of $\mathrm{SC}$ agar was added to each well followed by $1 \mu \mathrm{L}$ of the respective compound. 1 in 2 serial dilutions were performed. The plates were left to set and dried for 15 minutes under the Holten HB2460 LaminAir After drying the pdr1 $\Delta p d r 3 \Delta$ strain was diluted to give three different concentrations of cells: $1 \times 10^{8}$ cells $/ \mathrm{mL}, 1 \times 10^{4}$ cells $/ \mathrm{mL}$ and $1 \times 10^{4}$ cells $/ \mathrm{mL} .2 \mu \mathrm{L}$ of each yeast concentration was spotted into each well. Plates were incubated at $30^{\circ} \mathrm{C}$ for 48 hours with pictures taken after 24 and 48 hours using a Canon EOS 600D with EOS Utitlity software version 2.10.2.0.

\subsubsection{PCR amplification}

natMX4 and URA3MX4 genes were amplified from the p4339 (kind gift from Charles Boone, University of Toronto) and pAG60 (Euroscarf) plasmids respectively. PCR reagents and volumes are listed in Table 2.3 and the primers used for each amplification are listed in Table 2.2. The PCR protocol used for both reactions is as follows: $105^{\circ} \mathrm{C}$ preheat, $94^{\circ} \mathrm{C}$ initial denaturation $(5 \mathrm{~min}), 94^{\circ} \mathrm{C}$ denaturation (40 sec), $58^{\circ} \mathrm{C}$ annealing $(1 \mathrm{~min}), 68^{\circ} \mathrm{C}$ extension $(2 \mathrm{~min})$ and $72^{\circ} \mathrm{C}$ final extension using an Alphatech Prime thermo cycler.

PCR products were visualised on a $1 \%$ agarose gel with ethidium bromide to stain the DNA. Gels were visualised under an Alphatech Alphalmager mini to ensure the product was the predicted size. 
Primer Name

5' PDR3-UraMX deletion F

3' PDR3-UraMX deletion $\mathrm{R}$

A pdr3 $\Delta:: U R A 3$ confirmation primer forward external

B pdr3 $\triangle:: U R A 3$ confirmation primer reverse internal

C pdr3 $\triangle:: U R A 3$ confirmation primer forward internal

D pdr3 $\triangle:: U R A 3$ confirmation primer reverse external

PDR1 deletion primer forward

PDR1 deletion primer reverse

A pdr1 $1:$ natR confirmation primer forward external

B pdr1 $\Delta::$ natR confirmation primer reverse internal

C pdr1 $\Delta::$ natR confirmation primer forward internal

D pdr1 $::$ natR confirmation CGCCTTTACTGGTGGGCC primer reverse external
Primer Sequence
ACTGCATCAGCAGTTTTATTAATTTTTTC TTATTGCGTGACCGCAACATGGAGGCC CAGAATACCCT

CCATTTACTATGGTTATGCTCTGCTTCCC

TATTTCTTTTGCGTTTCAGTATAGCGACC AGCATTCAC

TACCGCCTAGGTAACCAT

AATTCAACGCGTCTGTGAGG

GACACCTGGAGTTGGATT

TTATGAACACGCACAGGC

CATCTCAGCCAAGAATATACAGAAAAG AATCCAAAAACTGGAAGACATGGAGG CCCAGAATACCCT

AGGAAGGAAGTTTTTGAGAACTTTTATC TATACAAACGTATACGTCAGTATAGCG ACCAGCATTCAC

GCAGGACCATAGCGGCCA

TACGAGACGACCACGAAGC

TGGAACCGCCGGCTGACC

Table 2.2: Primers used in this study 


\begin{tabular}{ll}
\hline PCR Reaction Mix Components & Volume $(\mu \mathrm{L})$ \\
\hline $\mathrm{ddH}_{2} \mathrm{O}$ & 18.38 \\
$\mathrm{dNTP}$ mix & 2 \\
10x extaq buffer & 2.5 \\
forward primer $(10 \mu \mathrm{M})$ & 0.5 \\
reverse primer $(10 \mu \mathrm{M})$ & 0.5 \\
eqTaq & 0.125 \\
Template DNA & 1 \\
\hline
\end{tabular}

Table 2.3: PCR reaction mix. Components and volumes for a $25 \mu \mathrm{L}$ PCR reaction.

\subsubsection{Yeast Transformations}

The starting strain contained a double RFP attached to hygromycin B resistance (lyp1 $\Delta:: H p h R:: m C h e r r y:: R S 2)$. $\mu$ s strain was first transformed with a pAG60 URA3 deletion cassette to generate a pdr3 $\triangle::$ URA3 strain, then subsequently with a NatR deletion cassette to generate a $p d r 1 \Delta::$ NatR $p d r 3 \Delta:: U R A 3$ strain. Both transformations were performed as previously described, with partial alterations (Gietz and Schiestl, 2007; Hill et al., 1991).

Cells were inoculated into a $5 \mathrm{~mL}$ culture of YPD and grown overnight at $30^{\circ} \mathrm{C}$. The culture was then subcultured into $50 \mathrm{~mL}$ 's of YPD with a starting OD of 0.2. $\mu$ s culture was grown for a further 6 hours or until an OD of 0.8 was achieved. Cells were pelleted by centrifugation (get the centrifuge) at 3,000 rpm for five minutes. The supernatant was removed and the cells were washed with $25 \mathrm{~mL}$ of water. The cells were again pelleted by centrifugation at 3,000 rpm for five minutes and wash in $10 \mathrm{~mL}$ of $1 \mathrm{M}$ LiAc TE. The cells were pelleted once more by centrifugation at 3,000 for five minutes and suspended in $1 \mathrm{~mL} 1 \mathrm{M} \mathrm{LiAc} \mathrm{TE}$.

$100 \mu \mathrm{L}$ of the cell suspension was moved to a separate tube and 


\begin{tabular}{lc}
\hline Transformation mix components & Volume \\
\hline & \\
PEG $50 \%$ w/v & $240 \mu \mathrm{L}$ \\
LiAc $1 \mathrm{M}$ & $36 \mu \mathrm{L}$ \\
SS-carrier DNA & $50 \mu \mathrm{L}$ \\
PCR amplified DNA & $34 \mu \mathrm{L}$ \\
or & or \\
Plasmid DNA & $4 \mu \mathrm{L}$ \\
Total volume & $360 \mu \mathrm{L}$ \\
\hline
\end{tabular}

Table 2.4: Transformation reaction mix

\section{Transformation reaction $\mathrm{mix}$}

pelleted by centrifugation at $16,000 \mathrm{rpm}$ for 30 seconds. The supernatant was then removed. $326 \mu \mathrm{L}$ of the transformation reaction mix without DNA (Table 2.4) was added to each pellet followed by the appropriate DNA insert or plasmid. The pellet was resuspended by repeatedly pipetting up and down. The tubes were incubated at $30^{\circ} \mathrm{C}$ for 30 minutes without shaking but were inverted $10 x$ every 10 minutes to stop cells pelleting. The cells were then heat shocked at $42^{\circ} \mathrm{C}$ for 20 minutes again with inversion every 10 minutes. $36 \mu \mathrm{L}$ of DMSO was then added to each tube, which were then incubated at $42^{\circ} \mathrm{C}$ for five minutes.

After the heat shock cells are pelleted and resuspended in $1 \mathrm{~mL}$ of YPD broth and incubated at $30^{\circ} \mathrm{C}$ with rotation. After three hours the cells were pelleted and suspended in $1 \mathrm{~mL} \mathrm{ddH}_{2} O$. For plasmid transformations $20 \mu \mathrm{L}$ of cells was plated onto SD-Ura agar using a cell spreader. For PCR product transformations $150 \mu \mathrm{L}, 300 \mu \mathrm{L}$ and $500 \mu \mathrm{L}$ volumes were plated onto three separate plates of the appropriate selection using a cell spreader. Plates were left for 30 minutes to sit before being incubated at $30^{\circ} \mathrm{C}$ for two days. 


\begin{tabular}{ll}
\hline Query & GFP Library \\
\hline & \\
pdr1 $1::$ NaTR & PDR1 \\
pdr3 $::$ URA3 & PDR3 \\
lyp1 $1::$ HphR:::mCherry::RS2::Ste2pr-LEU2 & LYP1 \\
can1 $1 \Delta$ & CAN1 \\
his3 & xxx-GFP::His5 \\
\hline
\end{tabular}

Table 2.5: Strains used for SGA

\subsubsection{Transformant Functional Validation}

A dose response was performed using cyclohexamide (Sigma Aldrich) as it is more potent in $p d r 1 \Delta p d r 3 \Delta$ mutant strains (Balzi et al., 1987). A starting concentration of $4 \mathrm{mM}$ cyclohexamide was used and serial 1:5 dilutions performed until a concentration of $50 \mathrm{nM}$ was reached.

Transformants were cultured in SD-URA + NAT overnight at $30^{\circ} \mathrm{C}$ with ration. The starting strain as well as a separate $p d r 1 \Delta p d r 3 \Delta$ strain and the $p d r 3 \Delta$ transformant were cultured in SC media overnight at $30^{\circ} \mathrm{C}$ with rotation. $100 \mu \mathrm{L}$ of the overnight culture was added to $2 \mathrm{~mL}$ of SC media and cultured for a further six hours. Cells were then diluted as described in section 2.2.4 and $99 \mu \mathrm{L}$ of each transformant was added to the appropriate well in a 96 well plate. $1 \mu$ of cyclohexamide described above was added to the appropriate wells in triplicate giving final concentrations of $40 \mu \mathrm{M}$ to $0.5 \mathrm{nM}$. The 96 well plates were read as described in section 2.2.4.

\subsubsection{Synthetic Genetic Array Methodology}

For the duration of this SGA the Singer ROTOR HDA (Singer Instruments) was used for all pinning and mating steps. Unless stated all pinning steps were performed in 384 colony format.

The GFP library (Invotrogen) consists of 4,159 MATa yeast 
strains, each with a different protein fused to a GFP protein using a Histadine selection.

A pdr1 $\Delta::$ NatR, pdr3 $\Delta:: U R A 3, \quad$ lyp1 $1:: H p h R:: M c h e r r y:: R S 2$ MAT $\alpha$ was used as a query strain for the SGA (Table 2.5). 384 colony query plates were generated my growing a $6 \mathrm{~mL}$ overnight culture and pouring this onto a YPD Singer plate. Using The Singer ROTOR HDA (Singer Instruments), the query plate was pinned into 384 colony format.

Mating Query with GFP library: Mass mating was achieved by pinning the GFP library onto fresh YPD singer plates and the query pinned directly on top, allowing mating to occur. Plates were incubated at $30^{\circ} \mathrm{C}$ overnight.

Diploid Selection: MATa/ $\alpha$ diploids generated from mating were selected by pinning onto SD - HIS + NAT media to select for genetic markers derived from each parent strains, removing any haploid cells. The plates were incubated at $30^{\circ} \mathrm{C}$ for two days.

Sporulation: Diploids were pinned onto enriched sporulation media, which are deficient in nutrients, which stimulates dipoids to sporulate generating haploid spores. These plates were incubated for seven days at room temperature.

MATa Selection: MATa selection was achieved using the MATa specific promoter STE2 promoter, which controls an attached LEU2 gene. The attached LEU2 genes allows MATa cells to synthesis their own leucine and grow on leucine deficient media.

can1 $\Delta$ and lyp1 1 are another form of haploid selection. CAN1 
and LYP1 encode arganine and lysine permeases respectively, therefore when deleted, cells can't take up arganine and lysine. When treated with arganine and lysine analogues Canavanine (Sigma Aldrich) and $\mu$ alysine (Sigma Aldrich), cells with functioning CAN1 and LYP1 genes can take up these toxic analogues and are killed, whilst cells containing can $1 \Delta$ and lyp1 1 survive.

Cells from sporulation plates were therefore plated onto SD-Leu/His/Arg/Lys + Canavanine + $\mu$ alysine to select for MATa cells with GFP proteins. These plates were grown for two days at $30^{\circ} \mathrm{C}$. $\mu \mathrm{s}$ selection step was repeated again with cells plated back onto SD-Leu/His/Arg/Lys + Canavanine + $\mu$ alysine and grown for one day at $30^{\circ} \mathrm{C}$.

MATa + URA3 Selection: To select for pdr3 $\Delta::$ URA3, cells were grown on SD-Leu/His/Arg/Lys/Ura + Canavanine $+\mu$ alysine for two days at $30^{\circ} \mathrm{C}$.

MATa + URA3 + HphR Selection: To select for lyp1 $1:: H$ phR::mCheery::RLS2, cells were grown on SD-Leu/His/Arg/Lys/Ura + Canavanine + + alysine + Hygromycin B (Formedium) for two days at $30^{\circ} \mathrm{C}$.

MATa + URA3 + HphR + NatR Selection: To select for pdr1 $\Delta::$ NatR, cells were grown on SD-Leu/His/Arg/Lys/Ura + Canavanine $+\mu$ alysine + Hygromycin B (Formedium) + NAT for two days at $30^{\circ} \mathrm{C}$. $\mu \mathrm{s}$ selection step was repeated twice with cells plated back onto SD-Leu/His/Arg/Lys/Ura + Canavanine + + alysine + Hygromycin B 
$($ Formedium $)+$ NAT for one days at $30^{\circ} \mathrm{C}$

\subsubsection{Genomic Extraction}

Each yeast strain was inoculated into $2 \mathrm{~mL}$ of YPD broth and incubated overnight at $30^{\circ} \mathrm{C} .1 .5 \mathrm{~mL}$ of the overnight culture was centrifuged at $16,000 \mathrm{rpm}$ for 30 seconds and the supernatant removed. $50 \mu \mathrm{L}$ of glass beads, $250 \mu \mathrm{L}$ of breaking buffer (2\% Triton, $1 \%$ SDS, 100 $\mathrm{mM} \mathrm{NaCl}, 10 \mathrm{mM}$ TRIS $\mathrm{pH} 8,1 \mathrm{mM}$ EDTA) and $250 \mu \mathrm{L}$ of phenol:chloroform:isoamyl alcohol $(25: 24: 1)$ was added to the pellet and briefly vortexed. The cells were then centrifuged for 10 minutes at 16,000 rpm and the aqueous phase removed and added to a separate tube. 200 $\mu \mathrm{L}$ of chloroform (Fisher Chemicals) was added to the isolate,vortexed for 30 seconds on high and centrifuged for 10 minutes at 16,000 rpm. The aqueous phase was removed and added to a separate tube. $1 \mathrm{~mL}$ of $100 \%$ ethanol (Pure Science) and $40 \mu \mathrm{L}$ of $3 \mathrm{M} \mathrm{NaAC}$ with a $\mathrm{pH}$ of 5.3 was added to the solution. Tubes were then inverted 10x and stored at $-20^{\circ} \mathrm{C}$ for 20 minutes. The solution was then centrifuged for 10 minutes at $16,000 \mathrm{rpm}$ and the supernatant removed. The resulting pellet was then washed in $70 \%$ ethanol and centrifuged at 16,000 rpm for 5 minutes. The ethanol was removed and the pellet dried in a Holten HB2460 LaminAir. Once dry the gDNA was suspended in $1 \mathrm{M}$ TE and incubated at $65^{\circ} \mathrm{C}$ for 10 minutes to disolve the pellet. Extracted gDNA was stored at $-20^{\circ} \mathrm{C}$.

\subsubsection{Plasmid Extraction}

Escherichia coli containing plasmids with an ampR cassette were streaked onto $\mathrm{YB}+\mathrm{Amp}$ agar media and grown overnight at $37^{\circ} \mathrm{C}$. A single colony was inoculated into $2 \mathrm{~mL}$ of $\mathrm{YB}$ broth $+\mathrm{Amp}$ and incubated overnight at $37^{\circ} \mathrm{C}$ with shaking. The culture was then pelleted by centrifugation at $12,000 \mathrm{~g}$ for 30 seconds and the media removed. 
The cell pellet was resuspended in $100 \mu \mathrm{L}$ of ice cold solution I (50 mM glucose (Sigma Aldrich), 25 mM TRIS pH 8.0 (Formedium), 10 mM EDTA pH 8.0 (Aplichem)) by vortexing. $200 \mu \mathrm{L}$ of fresh solution II $(1: 1,0.2$ $\mathrm{M} \mathrm{NaOH}$ (Fisher Chemicals): 1\% SDS (invitrogen)) was then added and the tube was inverted rapidly so that the whole surface came into contact with the solution. $150 \mu \mathrm{L}$ of solution III (60:11.5:28.5, 5 M KAC (Sigma Aldrich): glacial acetic acid: $\left.d_{d H_{2}} \mathrm{O}\right)$ ) was added and mixed in by light vortexing for 10 seconds. The tube was then left to sit on ice for three minutes.

The resulting bactarial lysate was then centrifuged at $16,000 \mathrm{~g}$ for 5 minutes and the supernatant transferred to a new tube. 2 volumes $100 \%$ ethanol was added to precipitate the DNA. The tube was then vortexed and left to sit at $4^{\circ} \mathrm{C}$ for five minutes, before centrifuging at $16,000 \mathrm{~g}$ for five minutes. The supernatant was removed and the pellet washed in $1 \mathrm{~mL}$ of $70 \%$ ethanol and centrifuged at $16,000 \mathrm{~g}$ for 5 minutes. The ethanol was removed and the pellet was left to air dry in a Holten HB2460 LaminAir. The pellet was suspended in $50 \mu \mathrm{L}$ of $1 \mathrm{M} \mathrm{TE} \mathrm{pH} \mathrm{8.0,} \mathrm{vortexed} \mathrm{briefly} \mathrm{and}$ incubated at $37^{\circ} \mathrm{C}$ for 15 minutes to dissolve the pellet. Extracted plasmid DNA was stored at $-20^{\circ} \mathrm{C}$.

\subsubsection{PCR confirmation}

Transformants were confirmed via PCR using $A$ and $D, A$ and $B$, and $C$ and $D$ primers (Table 2.2). $A$ and $D$ primers give a different sized product depending on whether the resistance cassette is inserted. Whereas $A$ and $B$, and $C$ and $D$ primers only amplify if the deletion cassette is inserted into the correct space in the genome (Fig. 2.1). 


\subsubsection{High-throughput microscopy}

The $p d r 1 \Delta p d r 3 \Delta$ GFP library consists of 11 plates and approximately 4,100 strains. The library was pinned in 384 colony format onto SC agar and grown overnight at $30^{\circ} \mathrm{C}$. Plates were then pinned again onto SC media in 384 colony format and grown for 16 hours at $30^{\circ} \mathrm{C}$. Each plate was staggered by 1 hour so that 16 hours of growth was achieved. After precisely 16 hours, cells were pinned into a 384 well Perkin Elmer Cell Carrier, optically clear bottom tissue culture plate with either $1 \%$ DMSO or $10 \mu \mathrm{M} \mathrm{S13}$ using the following settings: using 384 long pin repads cells from the source plate were picked up with a 0.15 $\mathrm{mm}$ offset and inoculated into the 384 well tissue culture plate using a 2D wet mix with 20 rotations. The plates were then shaken for 15 seconds at $2,000 \mathrm{rpm}$ and incubated for 6 hours at $30^{\circ} \mathrm{C}$. After incubating each 384 well plate was run through a Perkin Elmer Opera high-throughput confocal microscope to capture images of each well using the settings listed in Table 2.6.

\subsubsection{Automated image analysis}

Images were analysed using Acapella $^{T M}$ software as previously described (Bircham et al., 2011). Each GFP strain contains two two RFP markers, mcherry, a low intensity cytoplasmic marker and Red. Star2, a nuclear marker. The RFP markers were used to recognise cells by the software as well as normalisation of fluorescence within each cell so that each cell can be compared as each cell should express consistent levels of RFP. Gene enrichment was determined using Gene Mania (Warde-Farley et al., 2010). For secondary analysis the GFP and RFP expression levels were measured as pixel intensity by using a automated quantitative pipeline developed by Senanayake (2017, unpublished). 
A

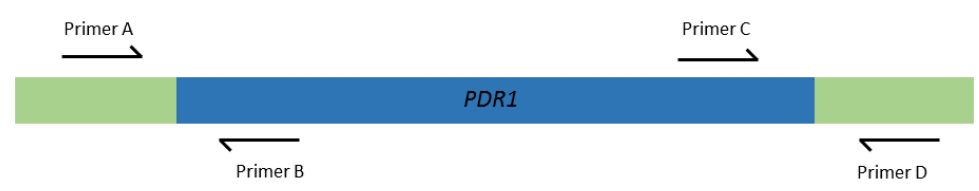

B

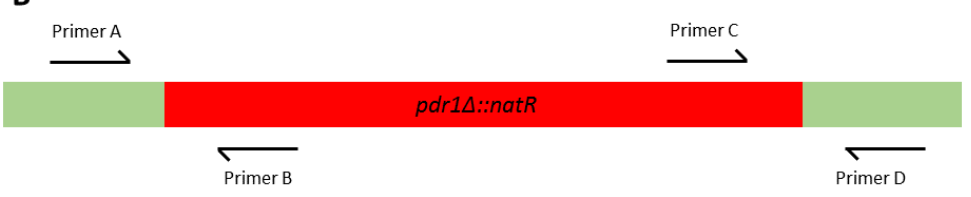

Figure 2.1: Transformation Confirmation Primers. A, B, C and D primers are used to confirm insertion of the resistance cassette into the correct genomic location. Primers $A$ and $D$ are located in the genome whilst primer $B$ and $C$ and unique for the inserted resistance Cassette. Therefore in the wild-type $(\mathbf{A})$, only primers $A$ and $D$ will amplify. Whereas in the deletion mutant (B) primers $A$ and $D$ will amplify as well as $A$ and $B$, and $C$ and $D$. Therefore you can use these primers to determine if the deletion cassette has inserted in the correct location.

\begin{tabular}{ll}
\hline Parameter & Setting \\
\hline Focus height & $4 \mu \mathrm{m}$ \\
Camera 1 and 2 exposure time & $400 \mathrm{~ms}$ \\
Camera 1 and 2 binning & 2 \\
Laser 1 power & $2000 \mu \mathrm{W}$ \\
Laser 2 power & $900 \mu \mathrm{W}$ \\
Laser 1 colour & 488 \\
Laser 2 colour & 561 \\
Filter camera 1 & $520 / 35$ \\
Filter camera 2 & $600 / 40$ \\
Filter detect dichro & 568 \\
Filter primary dichro & $405 / 488 / 561 / 640$ \\
Lens magnification & $60 \mathrm{x}$ \\
\hline
\end{tabular}

Table 2.6: High-throughput microscopy parameters and settings. Perkin Elmer Opera high-throughput confocal microscope settings used for high-throughput GFP microscopy screen. 


\subsubsection{Filipin staining of ergosterol microscopy}

An overnight culture of $p d r 1 \Delta p d r 3 \Delta$ cells was grown and diluted to a starting concentration of $2.55 \times 10^{6}$ cells $/ \mathrm{mL}$. Yeast were grown for 6 hours in $2 \mathrm{~mL}$ of SC broth either treated with $10 \mu \mathrm{M} \mathrm{S13}$ or $1 \%$ DMSO as a vehicle control. $500 \mu \mathrm{L}$ of broth was removed and pelleted by centrifugation at $13,000 \mathrm{rpm}$ for 5 minutes. The pellet was resuspended in YPD broth with $2 \mu \mathrm{L}$ of $25 \mathrm{mg} / \mathrm{mL}$ filipin in DMSO giving a final concentration of 100 $\mu \mathrm{g} / \mathrm{mL}$. Samples were viewed immediately after staining on an Olympus BX63 Upright Microscope under a DAPI filter using cell Sens Dimension version 1.15 .

\subsubsection{Calcofluor white staining of chitin}

Calcofluor white staining was performed as previously described (Lindstrom and Gottschling, 2009). An overnight culture of pdr1 1 pdr3 $\Delta$ cells was grown and diluted to a starting concentration of $2.55 \times 10^{6}$ cells $/ \mathrm{mL}$. Yeast were grown for 6 hours in $2 \mathrm{~mL}$ of SC broth either treated with $10 \mu \mathrm{M}$ S13 or $1 \%$ DMSO as a vehicle control. Cells were stained with $0.1 \mathrm{mg} / \mathrm{mL}$ of calcofluor white (Sigma Aldrich) for 5 minutes and washed 3 times with PBS then visualised. Images were taken on the Olympus BX63 Upright Microscope under a DAPI filter using cell Sens Dimension version 1.15.

\subsubsection{GFP-ATG8 as a marker for autophagy}

pdr1 $\Delta p d r 3 \Delta$ cells were transformed with a plasmid containing a GFP-Atg8 cassette (Addgene). ATG8-GFP was used as a marker for autophagy according to (Klionsky et al., 2016). Overnight cultures of pdr1 1 pdr $3 \Delta$ cells were grown at $30^{\circ} \mathrm{C}$ with rotation. The overnight culture was diluted in $2 \mathrm{~mL}$ of SC broth to a starting culture of $2.55 \times 10^{6}$ cells $/ \mathrm{mL}$ and were treated for 16 hours with $10 \mu \mathrm{M}$ S13 or $1 \%$ DMSO as a 
vehicle control. Cells were then was twice with SD-N and resuspended in $2 \mathrm{~mL}$ of SD-N. $1 \mathrm{~mL}$ of the culture was centrifuged at 13,000 rpm and resuspended in $50 \mu \mathrm{L}$ of SD-N and visualised using a Olympus BX63 Upright Microscope using cell Sens Dimension version 1.15 under a FITC filter. The other $\mathrm{mL}$ was resuspended in $2 \mathrm{~mL}$ of SD-N with or without 10 $\mu \mathrm{M}$ S13 and incubated for a further 4 hours. After 4 hours the culture was centrifuged at $13,000 \mathrm{rpm}$ and resuspended in $50 \mu \mathrm{L}$ of SD-N and visualised as before. Cells were determined to be performing autophagy if ATG-8 localised primarily to the vacuole. Cell counting was performed using the built function in ImageJ. At least 300 cells were counted for each treatment and time-point using the multi-point function in ImageJ. Cells that showed a clearly sick, dead phenotype or lacked any detectable GFP signal were ignored.

\subsubsection{Chloroquine staining of vacuolar $\mathrm{pH}$}

Staining was performed as previously described (Watanabe et al., 2005). pdr1 $\Delta p d r 3 \Delta$ cells were diluted to a starting concentration of $2.55 \times 10^{6}$ cells $/ \mathrm{mL}$ from an overnight culture of $p d r 1 \Delta p d r 3 \Delta$ or the relevant triple deletion mutant. $p d r 1 \Delta p d r 3 \Delta$ was treated with or without $10 \mu \mathrm{M} \mathrm{S13}$ for 6 hours whereas the triple deletions were grown for 6 hours in SC with $1 \%$ DMSO. Cells were centrifuged and resuspended in $0.2 \mathrm{M}$ phosphate buffer containing $2 \%$ glucose and $10 \mathrm{mM}$ chloroquine (Sigma Aldrich) for 20 minutes at $30{ }^{\circ} \mathrm{C}$. Cells were visualised instantly using an Olympus BX63 Upright Microscope using cell Sens Dimension version 1.15.

\subsubsection{MUP1 localisation assay}

pdr1 $\Delta p d r 3 \Delta$ cells were transformed with a plasmid containing a Mup1-GFP (a kind gift from Scott Emr, Cornell University). An overnight culture of $p d r 1 \Delta p d r 3 \Delta$ cells containing a MUP1-GFP plasmid were grown 
at $30^{\circ} \mathrm{C}$ with rotation. The overnight culture was diluted giving $2.55 \times 10^{6}$ cells $/ \mathrm{mL}$, which were grown for 6 hours with or without $10 \mu \mathrm{M} \mathrm{S13.} 1 \%$ DMSO was used as a vehicle control. Cells were visualised using a Olympus BX63 Upright Microscope using cell Sens Dimension version 1.15 under a FITC filter.

\subsubsection{FM4-64 staining of the vacuole}

FM4-64 staining was performed as previously described (Vida and Emr, 1995). From an overnight culture of $p d r 1 \Delta p d r 3 \Delta$, cells were diluted to give a starting concentration of $2.55 \times 10^{6} \mathrm{cells} / \mathrm{mL}$ and were treated with or without $10 \mu \mathrm{M} \mathrm{S} 13$ for either 6 hours at $30^{\circ} \mathrm{C}$. After incubation, cells were centrifuged at $13,000 \mathrm{rpm}$ for 1 minute, the supernatant removed and resuspended in $50 \mu \mathrm{L}$ of YPD. $1.25 \mu \mathrm{L}$ of 1.6 mM FM4-64 (ThermoFisher) was added to each culture, with a final concentration of $25.6 \mu \mathrm{M}$. Cultures were then shaken at $23^{\circ} \mathrm{C}$ for 30 minutes. After 30 minutes cells were washed once with water and resuspended in $30 \mu \mathrm{L}$ of SC broth with or without $10 \mu \mathrm{M} \mathrm{S13}$. Cells were visualised at 20, 60 and 240 minutes after FM4-64 staining. 


\title{
2.3 Results
}

\subsubsection{Phenotypic screen shows $\mathrm{S} 13$ is the most potent compound from focused benzopyran library}

\begin{abstract}
Baker's yeast (S. cerevisiae) was used as a model organism to evaluate bioactivity of a novel benzopyran library. The phenotype screened was growth inhibition of $S$. cerevisiae in a liquid medium. Two strains of S. cerevisiae were used, a wild-type Y7092 strain and a pdr1 $\Delta$ pdr3 $\Delta$ double deletion mutant in the Y7092 background. PDR1 and PDR3 are zinc finger proteins, upregulated during xenobiotic treatment, that function as homodimers or heterodimers and act as transcription factors for ABC transporters (Mamnun et al., 2002; Schuller et al., 2007). $A B C$ transporters are drug efflux pumps that actively pump xenobiotics from the cell. Deletion of PDR1 and PDR3 decreases ABC transporter expression and increase sensitivity to compounds that would normally be pumped out (Balzi et al., 1987; Coorey et al., 2015; Delaveau et al., 1994). Both strains were tested with serial dilutions of each compound in triplicate with $200 \mu \mathrm{M}$ as the highest concentration and $0.8 \mu \mathrm{M}$ as the lowest. Residual growth was calculated by taking the percentage of treated cell growth compared to control (untreated) cells.
\end{abstract}

Most compounds showed residual growth of $100 \%$ at each concentration tested, indicating they elicit no growth inhibition and are not bioactive in yeast (Fig. 2.2). S13 was the most bioactive molecule from the compound library showing growth inhibition at each concentration tested. S13 showed slight growth inhibition in Y7092, with an $I_{20}$ of 200 $\mu \mathrm{M}$. However, $\mathrm{S} 13$ was significantly more potent in the $p d r 1 \Delta p d r 3 \Delta$ mutant compared to $\mathrm{Y} 7092$ with an $\mathrm{IC}_{20}$ of $800 \mathrm{nM}$, a 250-fold decrease 
compared to the concentration required in the wild-type. S12 was the only other compound bioactive at concentrations lower than $10 \mu \mathrm{M}$ with an $\mathrm{IC}_{20}$ between 3-8 $\mu \mathrm{M}$, approximately 10-fold higher than S13. S9 and S33 both showed approximately $50 \%$ inhibition at $100 \mu \mathrm{M}$ in pdr1 $\Delta p d r 3 \Delta$ and about $10 \%$ growth inhibition in Y7092 at $200 \mu \mathrm{M}$. S11, S14, S15, S21 and S23 all showed activity at $200 \mu \mathrm{M}$ in pdr1 $\Delta$ pdr3 $\Delta$ but not in $\mathrm{Y} 7092$. These results indicate the compound library can induce growth inhibition in S. cerevisiae with nine out of 14 showing bioactivity at the tested concentrations.

An S13 dose response was conducted on agar to determine the type of media that exhibited the greatest bioactivity. Cells were treated with serially diluted $\mathrm{S} 13$ starting at $4 \mu \mathrm{M}$, which showed to be inhibitory in the liquid dose response. Cells displayed growth inhibition at concentrations of S13 as low as $0.5 \mu \mathrm{M}$ after 24 hours and $1 \mu \mathrm{M}$ at 48 hours (Fig. 2.3). This result indicates that $\mathrm{S} 13$ has approximately the same bioactivity in agar as it does in liquid broth.

These data indicate that $\mathrm{S} 13$ is the most potent molecule in yeast from a focused benzopyran library and is as active in liquid broth as solid media. Unless stated otherwise all future experiments are conducted using liquid broth.

\subsection{2 $\mathrm{S} 13$ is a pdr5 substrate}

Pdr1p and Pdr3p control the expression of a large number of genes including ABC-transporters (DeRisi et al., 2000). An additional dose response was performed to determine whether $A B C$-transporters mediated the resistance seen in $\mathrm{Y} 7092$ cells. If $A B C$-transporters were involved the efflux of $\mathrm{S} 13$ from the cell then deletion of these genes should cause the same sensitivity seen in $p d r 1 \Delta p d r 3 \Delta$ mutants. Three 


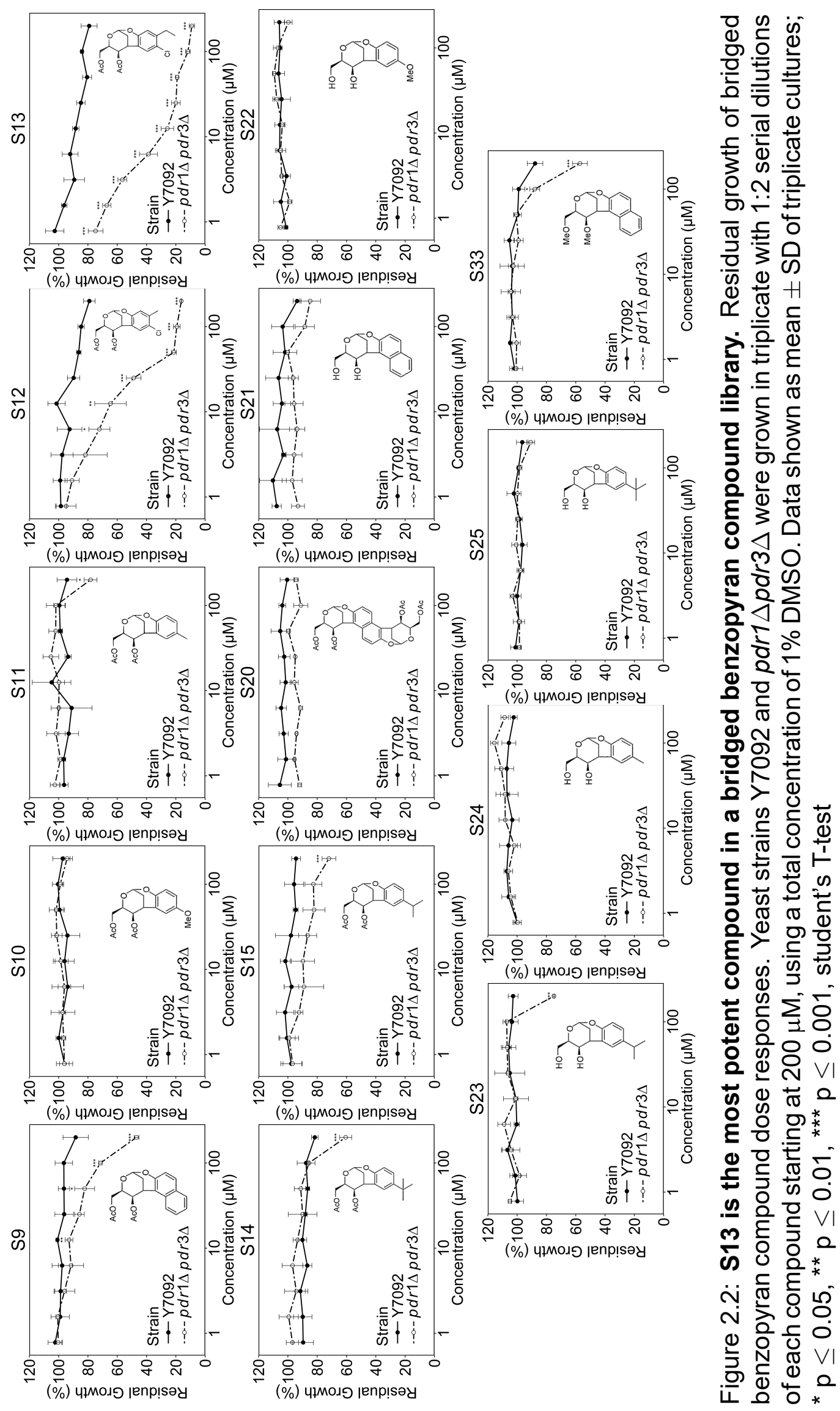




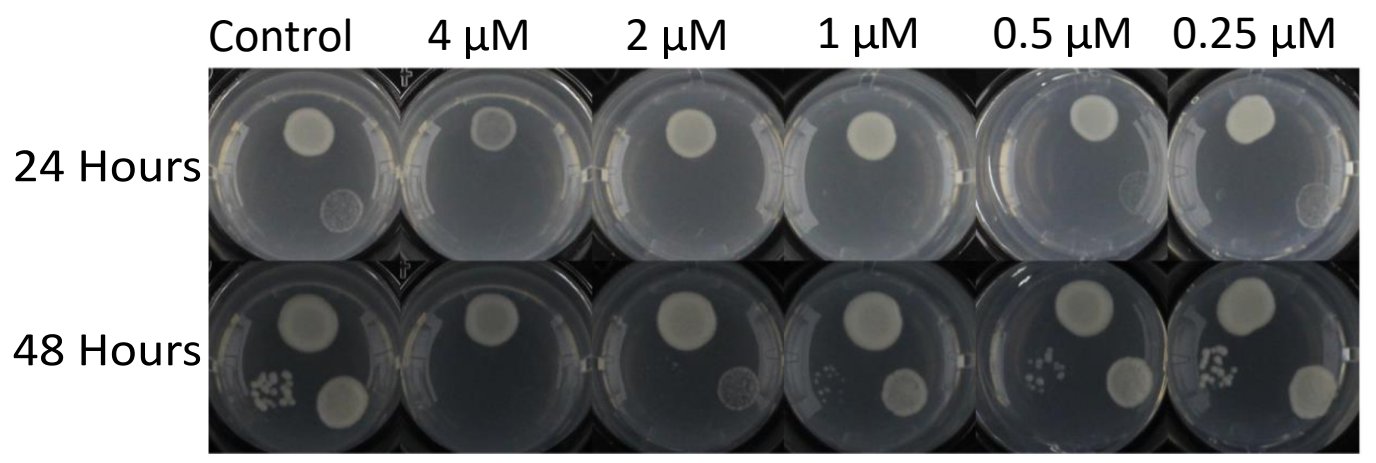

Figure 2.3: $\mathbf{S 1 3}$ is bioactive in solid media. $p d r 1 \Delta p d r 3 \Delta$ was spotted at $1 \times 10^{8}, 1 \times 10^{6}$ and $1 \times 10^{4}$ cells/mL onto agar with or without $\mathrm{S} 13$ (4, 2, $1,0.5$ and $0.25 \mu \mathrm{M})$ and incubated for 48 hours, with photographed at 24 and 48 hours.

ABC-transporter mutants: $p d r 5 \Delta$, snq2 $\Delta$ and yor1 $\Delta$ were treated with S13. All three deletion mutants showed increased sensitivity to S13 compared to the wild-type. However, snq2 $\Delta$ (Fig 2.4A) and yor1 $\Delta$ (Fig 2.4B) both showed significantly less sensitivity to $\mathrm{S} 13$ treatment relative to the $p d r 1 \Delta$ pdr3 $\Delta$ mutant. On the other hand $p d r 5 \Delta$ showed no significant differences to $\mathrm{S} 13$ treatment compared to $p d r 1 \Delta p d r 3 \Delta$ at any of the concentrations tested (Fig 2.4C). These results indicate that $\mathrm{S} 13$ is predominately a Pdr5p substrate, however it is likely $S n q 2 p$ and Yor1p both efflux the compound but to a lesser extent. The lack of significant differences in $\mathrm{S} 13$ sensitivity between $p d r 1 \Delta p d r 3 \Delta$ and $p d r 5 \Delta$, indicates that the increased sensitivity of $p d r 1 \Delta p d r 3 \Delta$ compared to the wild-type is due to S13 efflux from the cell.

\subsubsection{The benzopyran compound library is cytostatic}

In order to determine whether or not the $\mathrm{S} 13$ is cytotoxic or cytostatic, a dose response was performed by treating with the same concentrations used in Figure 2.2. The maximum concentration was not used due to precipitation of compounds at this concentration. Cells were treated for 16 hours with S13 and spotted onto YPD agar and grown for 
A

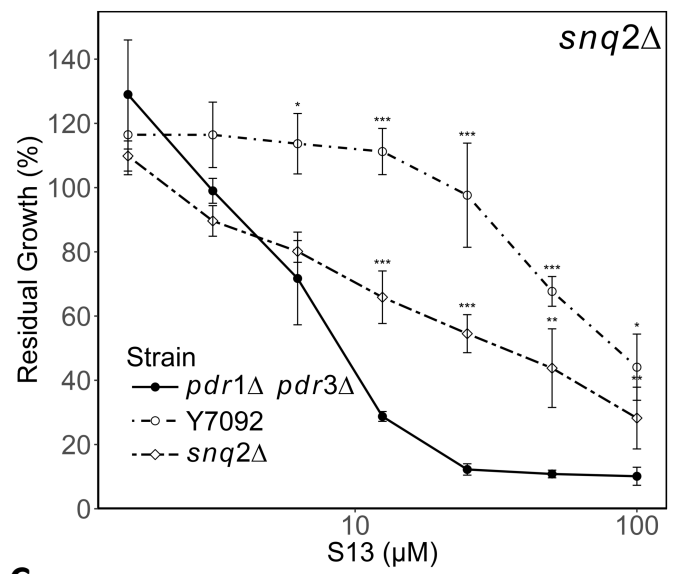

C

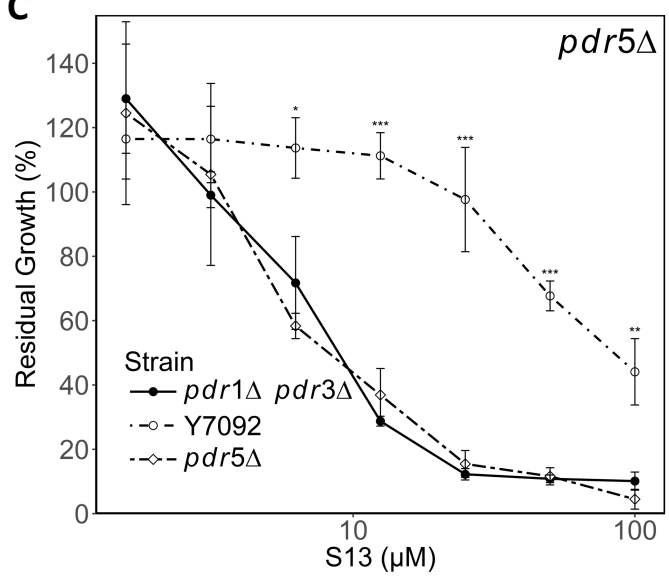

B

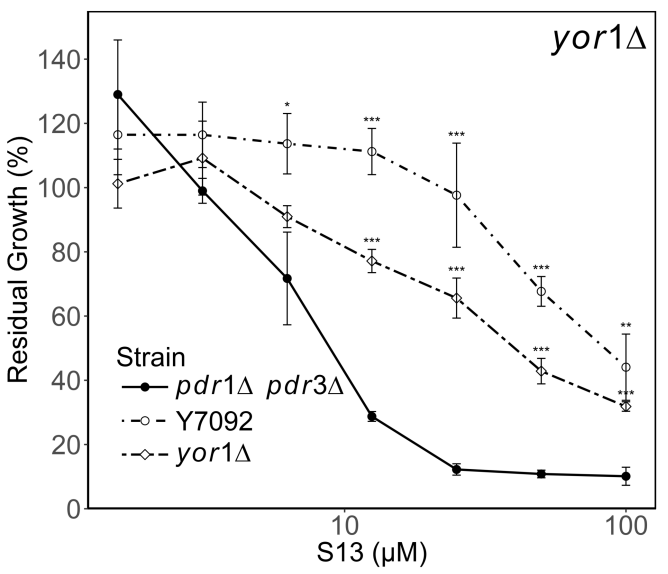

Figure 2.4: $\mathbf{S} 13$ is pdr5p substrate. Residual growth of $\mathrm{Y} 7092$, $p d r 1 \Delta p d r 3 \Delta, s n q 2 \Delta(\mathbf{A}), y o r 1 \Delta(\mathbf{B})$ and $p d r 5 \Delta(\mathbf{C})$ grown in the presence of increasing concentrations of $S 13$. Data shown as mean \pm SD of triplicate cultures, significance compared to $p d r 1 \Delta p d r 3 \Delta ;{ }^{*} p \leq 0.05,{ }^{* *} p \leq 0.01$, ${ }^{* * *} \mathrm{p} \leq 0.001$, student's T-test. 
$\mathrm{S} 13(\mu \mathrm{M})$
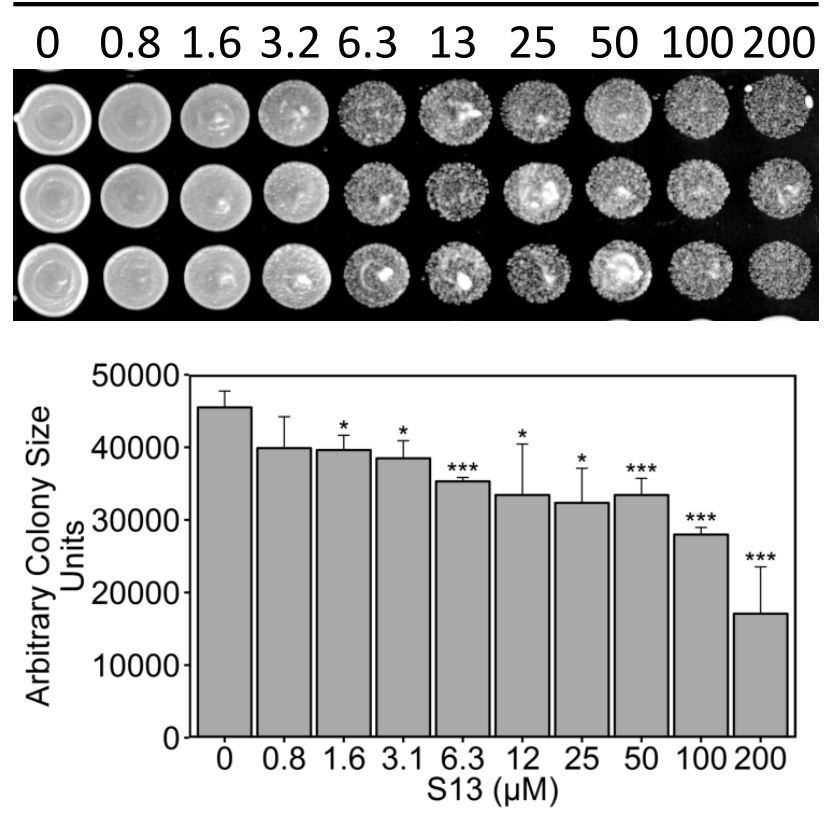

Figure 2.5: $\mathbf{S} 13$ is cytotoxic. Dose response showing $p d r 1 \Delta p d r 3 \Delta$ treated with $\mathrm{S} 13$ at concentrations ranging from fully inhibitory to not inhibitory. Cells were treated with each compound in SC broth at a range of concentrations, then washed and pinned onto YPD agar and grown at $30^{\circ} \mathrm{C}$. Photographs were taken at 24 hours after pinning. Data shown as mean \pm SD of triplicate cultures; ${ }^{*} p \leq 0.05,{ }^{* *} p \leq 0.01,{ }^{* * *} p \leq 0.001$, student's T-test relative to $0 \mu \mathrm{M}$.

24 hours. It was assumed that if $S 13$ was cytotoxic then there would be no growth at the highest concentrations due to cell death. Likewise, if S13 was cytostatic, then there would be slower growth at the higher compound concentrations due to fewer cells being present but colonies would still form over time. Even at $200 \mu \mathrm{M}$, the highest concentration, S13 was not completely toxic as there was cell growth at every spot (Fig. 2.5). However, there was significantly smaller colonies at higher concentrations. S13 showed the greatest growth inhibition with concentrations as low as $1.6 \mu \mathrm{M}$ showing significantly less growth compared to the control at all concentrations but the lowest tested ( 0.8 $\mu \mathrm{M})$. 


\subsubsection{S13 treatment induces upregulation of ergosterol biosynthesis proteins}

As high-throughput microscopy has been used previously to determine protein abundance and localisation changes in response to chemical perturbation (Bircham et al., 2011; Tkach et al., 2012), this method was utilised to determine changes in the proteome due to treatment with S13. Therefore to perform a high-throughput microscopy screen, a GFP library had to be constructed with the $p d r 1 \Delta p d r 3 \Delta$ background. First, PDR1 and PDR3 were deleted from a wild-type strain with a double-RFP construct containing mCherry (a nuclear marker) and RedStar2 (a cytoplasmic marker) (gift from Namal Coorey in our lab), using a $\mathrm{Nat}^{R}$ and a URA3 cassette respectively. This newly made $p d r 1 \Delta p d r 3 \Delta$ strain containing a double-RFP construct was used as the query strain for the Synthetic Genetic Array in which the query strain was mated into a library of yeast strains, each with a different protein tagged with a GFP at the carboxyl-terminal. The end result was a library of approximately 4,100 strains with a pdr1 $\Delta p d r 3 \Delta$ background, each containing a unique genome integrated GFP-tagged protein and a double-RFP construct for use in high-throughput microscopy.

Increasing drug concentrations can lead to off target effects due to target saturation (Marton et al., 1998). The $p d r 1 \Delta p d r 3 \Delta$ GFP collection was treated with $10 \mu \mathrm{M} \mathrm{S13}$, which induces approximately $75 \%$ inhibition, in order to ensure S13 induced a strong phenotype in six hours and not to saturate yeast with $\mathrm{S} 13$. This concentration was chosen due to the large amount of inhibition exhibited, so that S13 induced phenotypes should be visible after only six hours of treatment. The entire library was treated with or without $10 \mu \mathrm{M}$ S13 for 6 hours visualised using a Perkin Elmer OPERA 
high-throughput confocal microscope. Cells were simultaneously excited by a 488 and 561 laser to visualise both the GFP and RFP respectively. The initial screen was performed in singleton, with each strain only having a single well tested. A total of three fields of view (images from different locations within the well), were taken for each strain in a 384 well plate. Automated image analysis was performed using Acapella software, which used the cytoplasmic and nuclear RFPs to recognise cells and quantify the GFP intensity at a single cell level (Bircham et al., 2011).

When cells are treated with a compound it is expected that the majority of proteins do not change in abundance therefore, GFP signals should remain constant for these strains (Tkach et al., 2012). Accordingly, treated and non-treated GFP signals should form a linear regression when plotted against each other. Cells with lowly abundant GFP signals may exhibit auto-fluorescence, therefore potentially showing change in intensity when none is present (Breker et al., 2013). GFP strains that had a fluorescence value less than the lowest intensity value plus $1.5 x$ the median absolute deviation in both the control and $S 13$ treatment were removed from the analysis. Strains that had fewer than 25 cells per strain for either the control or treated were also omitted, leaving 3,029 strains for analysis.To explore the $\$ 13$ screen data, logged median control GFP intensity and logged median treated intensity from the remaining 3,029 strains were compared. The graph shows a strong linear relationship $\left(r^{2}=0.97\right)$ between both the treated and control indicating fluorescence levels did not deviate significantly therefore any changes are likely authentic (Fig. 2.6).

Automated image analysis identified proteins that were upregulated, proteins that were downregulated and proteins with altered 


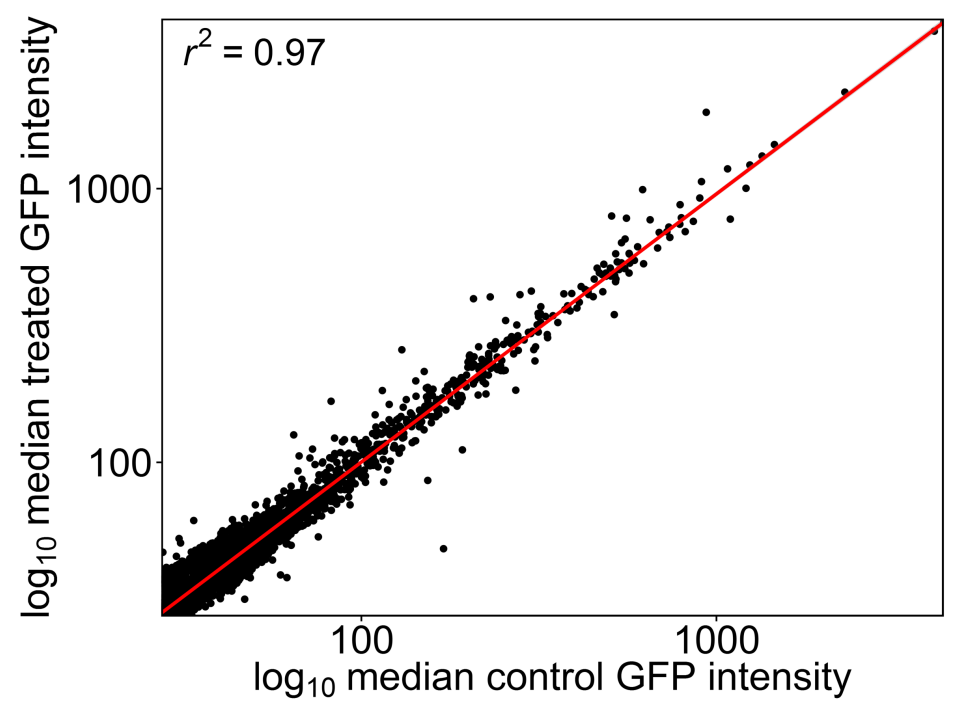

Figure 2.6: Control-Treated GFP intensity. Control and treated GFP intensities for each strain were logged and compared. Strains with less GFP intensity than the strain with the lowest intensity GFP plus $1.5 x$ median absolute deviation or contained less than 25 cells were omitted. A total of 3,029 strains were compared between treated and control.

localisation. As high-throughput assays inherently contain increased false discovery rate (e.g., false positives), strains that were either upregulated or re-localised were pinned to a separate plate and validated. Confirmations were performed by using the same microscope parameters used for the initial screen but two replicates were used instead of one. Each pair-wise comparison between control and treated duplicates was performed using the same automated analysis conducted in the initial screen as well as a secondary method to confirm the original results (Fig. 3.2). Each of these strains was also treated with $\mathrm{S} 12$ to determine any phenotypic differences to $\mathrm{S} 13$ treatments Both $\mathrm{S} 13$ and $\mathrm{S} 12$ treatments showed a high amount of concordance in regards to the proteins upregulated due to treatment (Fig. 2.7). 13 strains showed a 1.2 fold increase in both $\mathrm{S} 12$ and $\mathrm{S} 13$ with there 5 and 4 unique strains respectively.

The median GFP for each treatment and control was 
normalised to their respective median RFP. GFP intensity values from strains with a 1.2 fold increase in intensity were then logged and visualised using a heat map (Fig. 2.8). Nearly half of the 16 upregulated proteins were involved the ergosterol biosynthesis (ERG3, ERG5, ERG28, ERG10, ERG11, ERG13, ERG25, ERG27, ERG28 and MVD1) (Fig. 2.8). The upregulated genes were involved throughout the synthesis of ergosterol (Fig. 2.9), and showed dose dependent upregulation (Fig. 2.10). Yeast treated with $\mathrm{S} 13$ showed most upregulation of ergosterol biosynthesis proteins at $10 \mu \mathrm{M}$ and $5 \mu \mathrm{M}$ after 6 hours treatment, whilst for all proteins $1.5 \mu \mathrm{M}$ shows no significant upregulation. Treatment with $20 \mu \mathrm{M}$ S12 displays similar upregulation patterns to $10 \mu \mathrm{M}$ S13 treatment. These data indicate that both $\mathrm{S} 12$ and $\mathrm{S} 13$ upregulate ergosterol biosynthesis proteins and for $S 13$ the level of upregulation is dependent on concentration.

To determine the interactions between the genes upregulated by $\mathrm{S} 13$ treatment, GeneMania was used to plot network diagrams and determine enrichment and interactions. The steroid metabolic process was significantly enriched (false discovery rate $=3.74 \times 10^{-15}$ ) with 10 out of the possible 16 proteins upregulated with $S 13$ treatment (Fig. 2.11). There was no significant enrichment other than sterol biosynthesis found in proteins upregulated with $\mathrm{S} 13$ treatment. Proteins that were upregulated but not involved in ergosterol biosynthesis include Sam2p, involved in the transfer of an adenosyl group onto methionine, Tir1p, a cell wall mannoprotein, Aft2, involved in the removal of damaged sterols and Yhb1, involved in the oxidative and nitrosative stress responses (Table 2.7). As expected, these proteins showed a large amount of genetic (Fig. 2.11A) and physical (Fig. 2.11B) interactions as well as co-localisation 


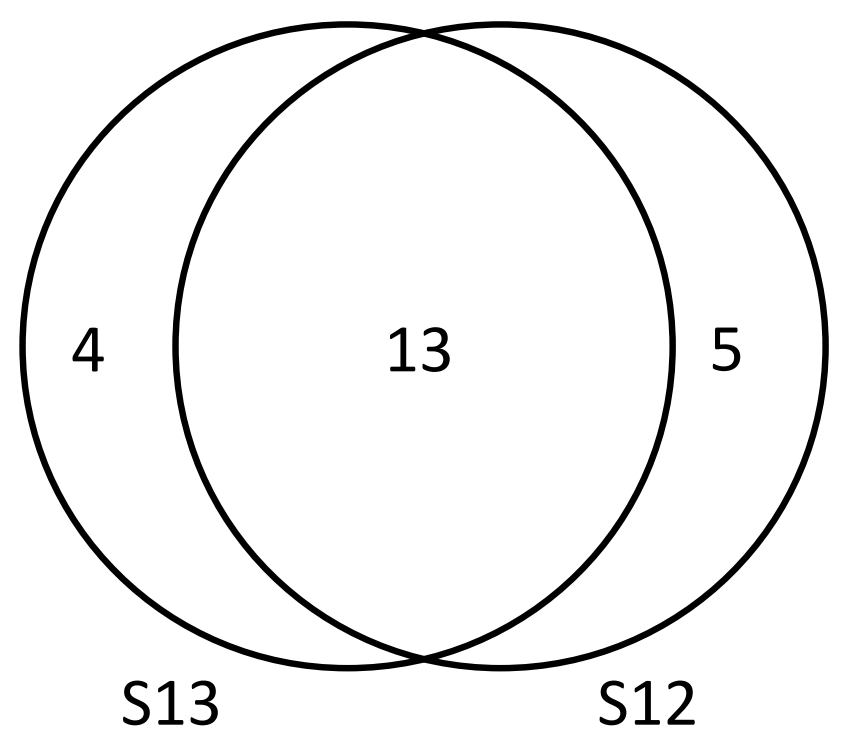

Figure 2.7: S13 and S12 show high concordance between upregulated genesVenn diagram showing number of strains that had 1.2 fold increase in GFP intensity in S13 and S12 treatments

(Fig. $2.11 \mathrm{C}$ ) due to the ergosterol biosynthetic proteins being involved in the same biological process. A number of the genes have human homologues, however the genes involved in the later steps of ergosterol biosynthesis do not have a human homologue (Table. 2.7). Whilst these genes do not have human homologues, the sterol biosynthesis pathway is conserved between yeast and mammals (Nielsen, 2009).

\subsubsection{S13 treatment increases vacuole size}

The high-throughput microscopy screen showed two clear phenotypes involving the vacuole. The first phenotype was that the vacuole was more prominent in S13 and S12 treated cells. GFP-proteins that localised to the vacuole membrane showed a more defined vacuolar membrane when treated with S13 (Fig. 2.12A). Neither Ypq1-GFP, a cationic amino acid transporter (Jzgou et al., 2012), nor Cot1-GFP, a vacuole membrane zinc transporter (Conklin et al., 1994), show any change in abundance between the treated and control. Control cells showed slightly fragmented vacuole morphology yet in treated this 


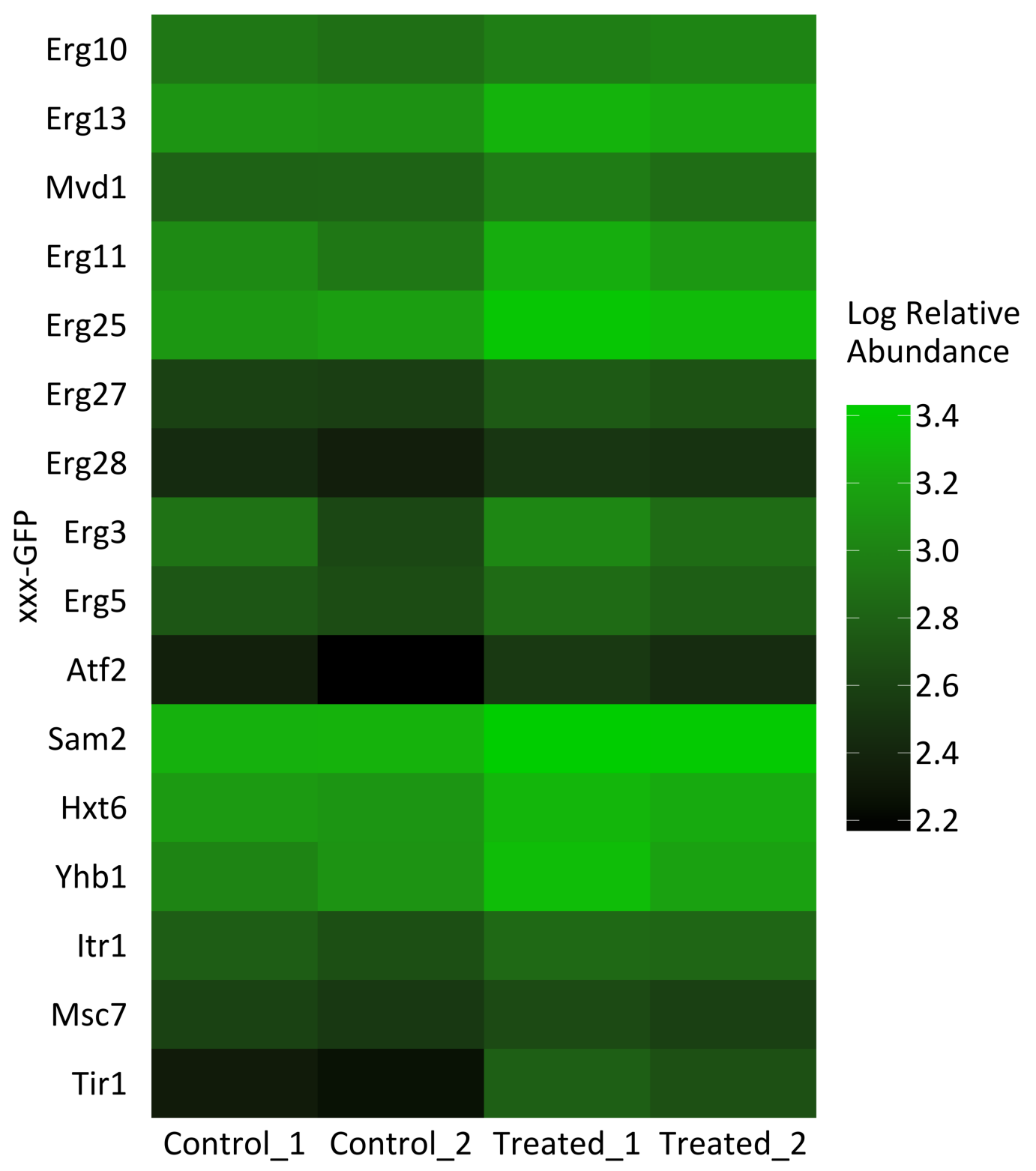

Figure 2.8: $\mathbf{S 1 3}$ treatment induced upregulation of ergosterol biosynthesis genes. Total GFP intensity values for each strain were normalised to their respective RFP intensity value, then logged and visualised in a heat map for each control and treated replicate. 


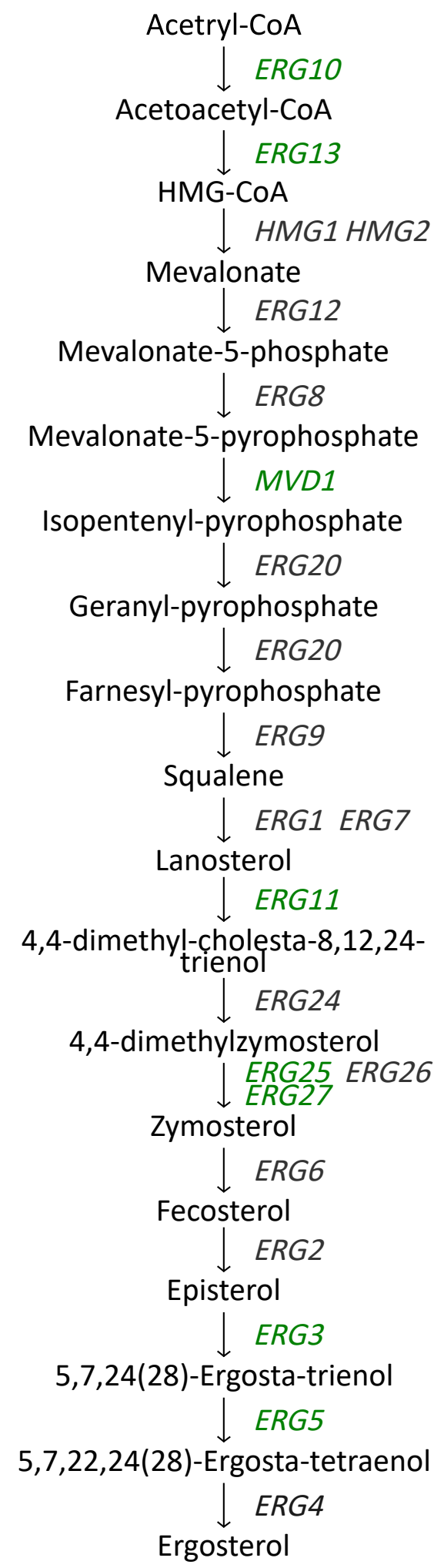

Figure 2.9: Ergosterol biosynthesis pathway showing genes upregulated in $\mathbf{S 1 3}$ treatment. Ergosterol biosynthesis pathway highlighting genes with a 1.2 fold GFP intensity increase during S13 treatment in green. 


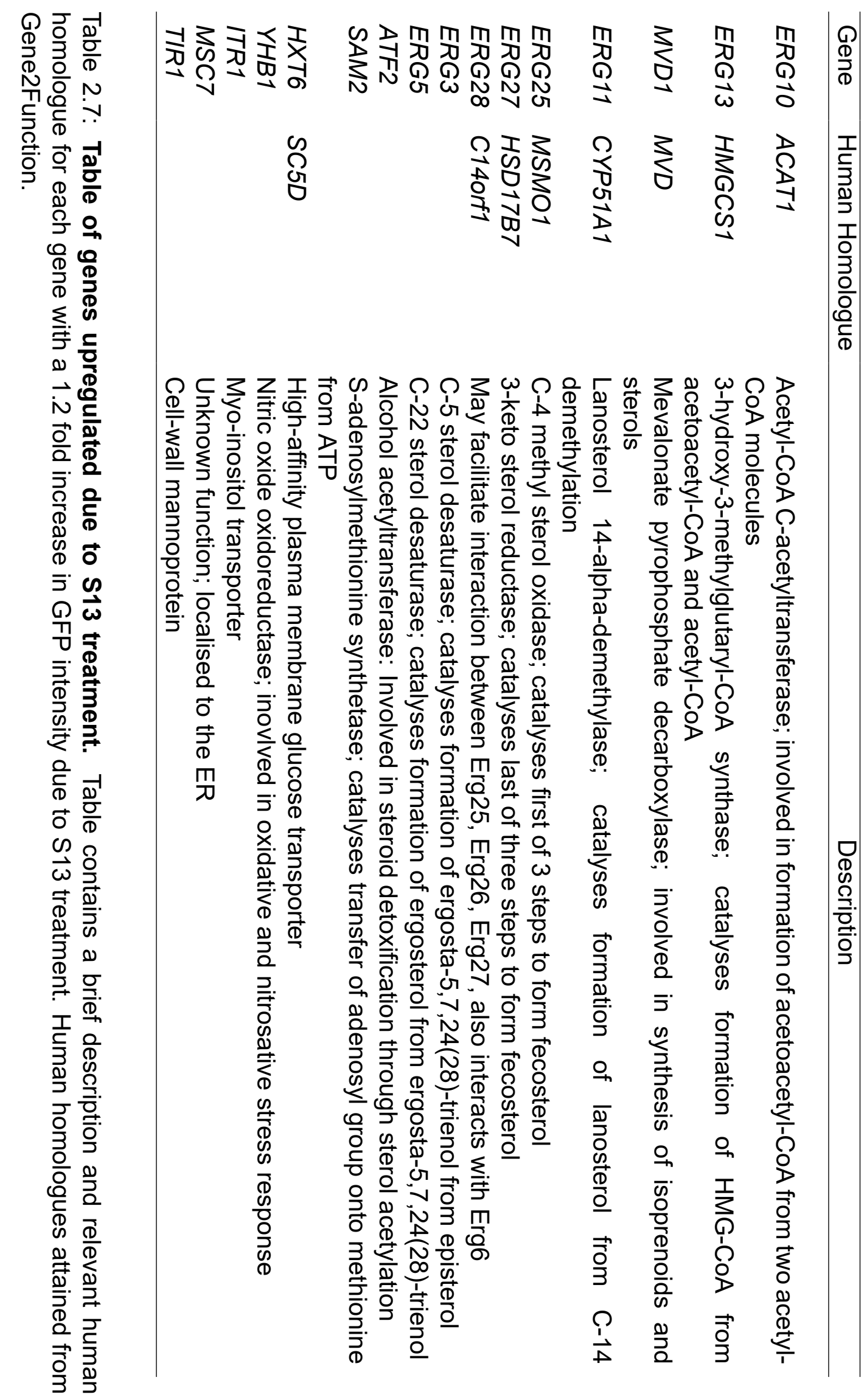




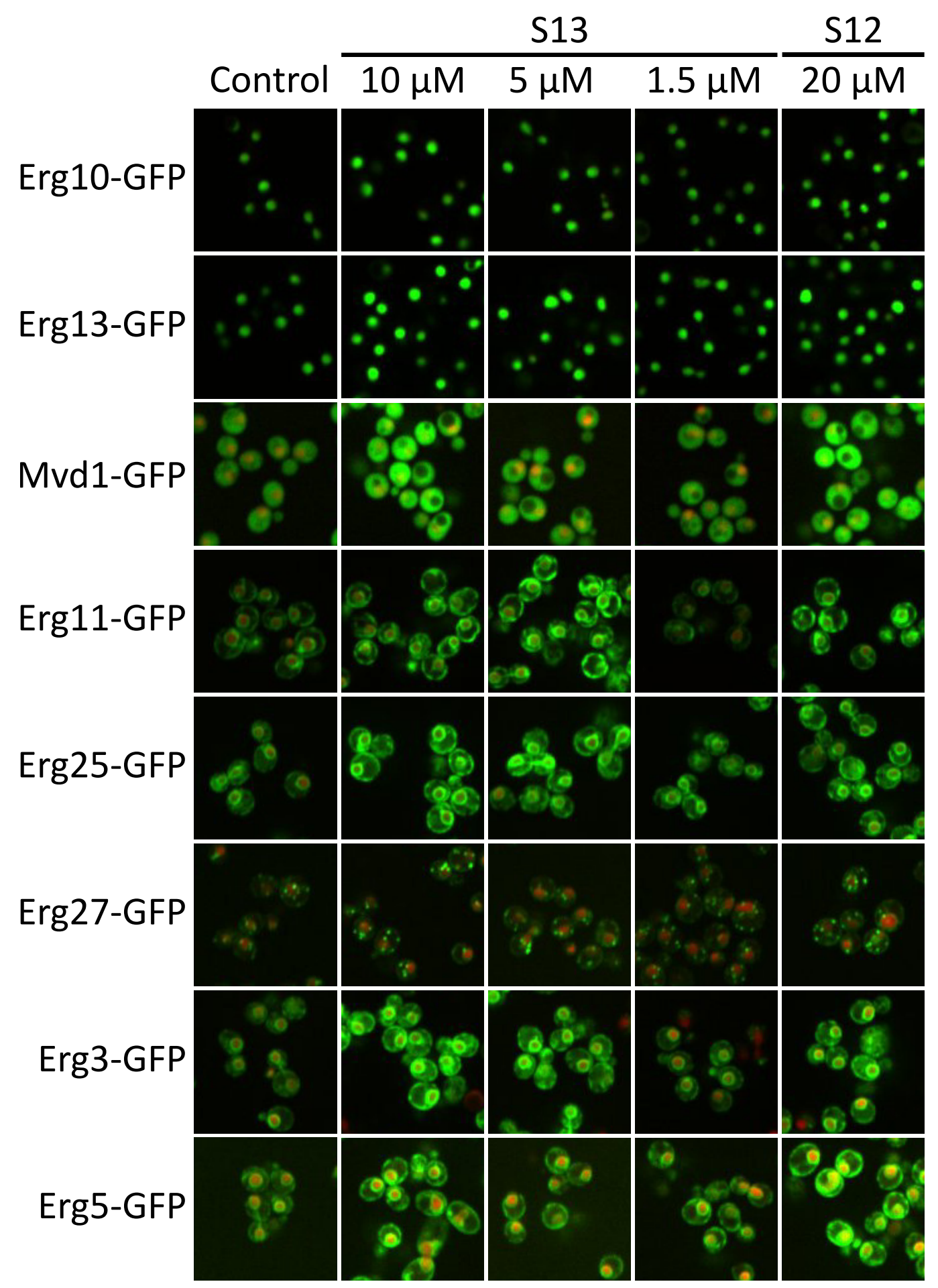

Figure 2.10: $\mathbf{S} 13$ and $\mathbf{S 1 2}$ treatment upregulates genes involved in ergosterol biosynthesis Ergosterol biosynthesis pdr1 $\Delta p d r 3 \Delta$ GFP strains were treated with $\mathrm{S} 13(10 \mu \mathrm{M}, 5 \mu \mathrm{M}$ and $1.5 \mu \mathrm{M})$ and $\mathrm{S} 12(20 \mu \mathrm{M})$ for 6 hours, then visualised using a Perkin Elmer Opera high-throughput confocal microscope. Each treatment was normalised to the RFP in the control frame 


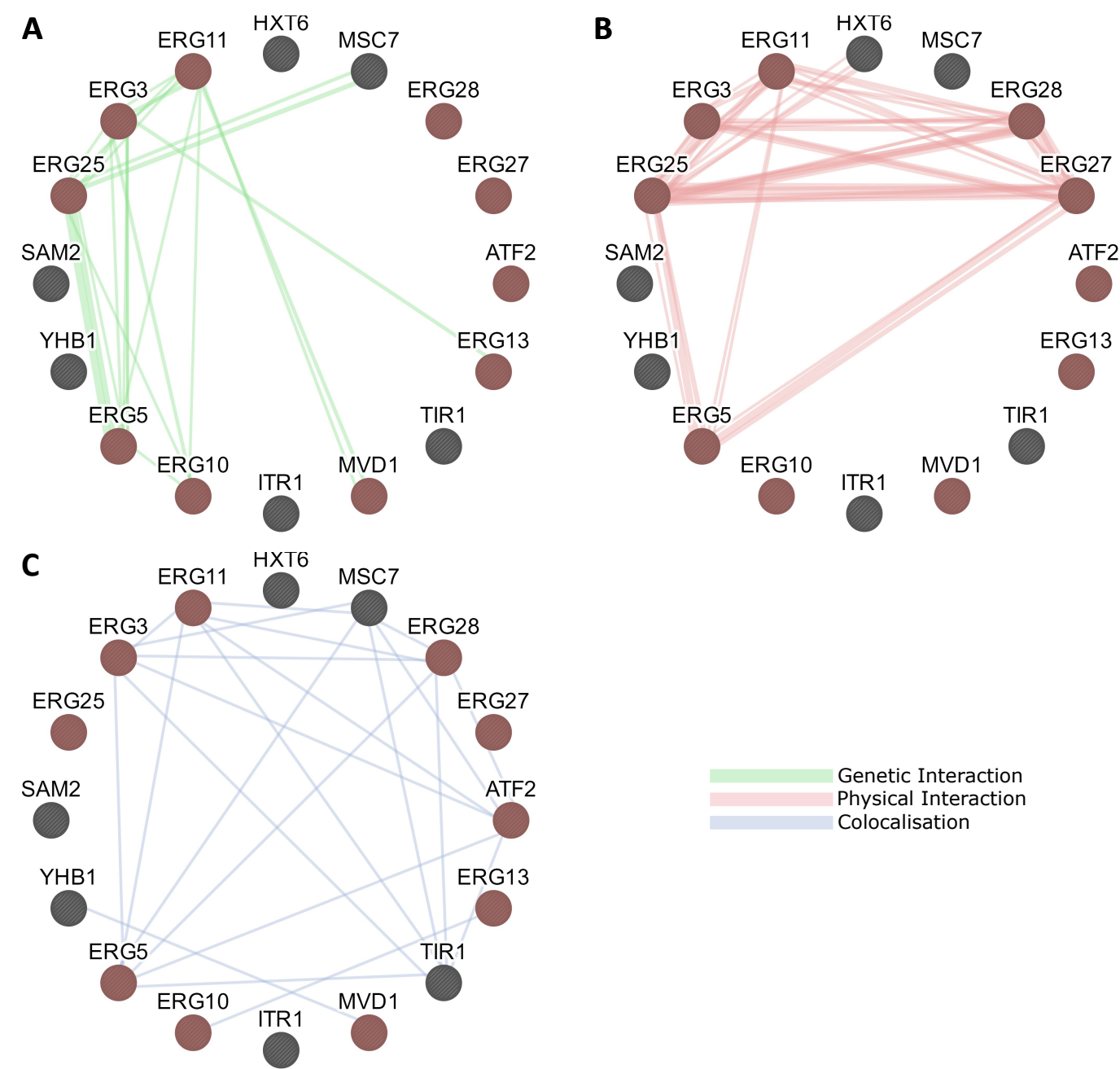

Figure 2.11: Network summaries of S13 screen. Network diagrams showing (A) genetic interactions, (B) physical interactions, and (C) colocalisation for proteins that had a 1.2 fold increase in GFP intensity due to S13 treatment. Nodes coloured red indicate proteins involved with steroid metabolic processes (false discovery rate $=3.74 \times 10^{-15}$ ). Network diagrams and enrichment were made using Gene Mania. 
phenotype is abolished with one distinct vacuole being presented in the majority of cells. Both Ypq1-GFP and Cot1-GFP show distinct vacuolar membranes in S13 treatments at $10 \mu \mathrm{M}$ and $5 \mu \mathrm{M}$ as well as $20 \mu \mathrm{M}$ S12 treatment. Cot1-GFP showed clear vacuole membranes at $1.5 \mu \mathrm{M}$, whilst Ypq1-GFP showed moderate membrane localisation. An increased number of punctate Cot1-GFP structures were seen in $10 \mu \mathrm{M}$ and $5 \mu \mathrm{M}$ $\mathrm{S} 13$ treatments but not $1.5 \mu \mathrm{M}$ or $\mathrm{S} 12$ treatment. These results were backed up by cytoplasmic GFP-tagged proteins, such as Eno1-GFP (a phosphopyruvate hydratase that catalyses formation of phosphoenolpyruvate), which showed a more prominent non-fluorescent space for the vacuole in $\mathrm{S} 13$ treated cells at all concentrations and compounds tested (Fig. 2.12B). Due to the normalisation methods used to display images it can appear like the nucleus is extra-cellular. However, this is due to the GFP intensity drowning out the cytoplasmic RFP marker (Fig. 3.1).

The other phenotype saw a number of proteins, especially plasma membrane transporters, localised to the vacuolar lumen (Fig. 2.13). Thi7-GFP, a thiamine transporter (Singleton, 1997), and Fet4-GFP, a low affinity iron transporter (Dix et al., 1994), showed an increase in localisation to the vacuole lumen at all concentrations of S13 and S12 treated. However, not all plasma membrane transporters showed the same vacuolar localisation phenotype, for example, Hxt6-GFP, a high-affinity glucose transporter (Reifenberger et al., 1995), did not show the same degree of vacuolar lumen localisation that other membrane transporters showed. These data indicate that S13 treatment increases the size of yeast's vacuole and this may be related to increased protein localisation to the vacuole. 


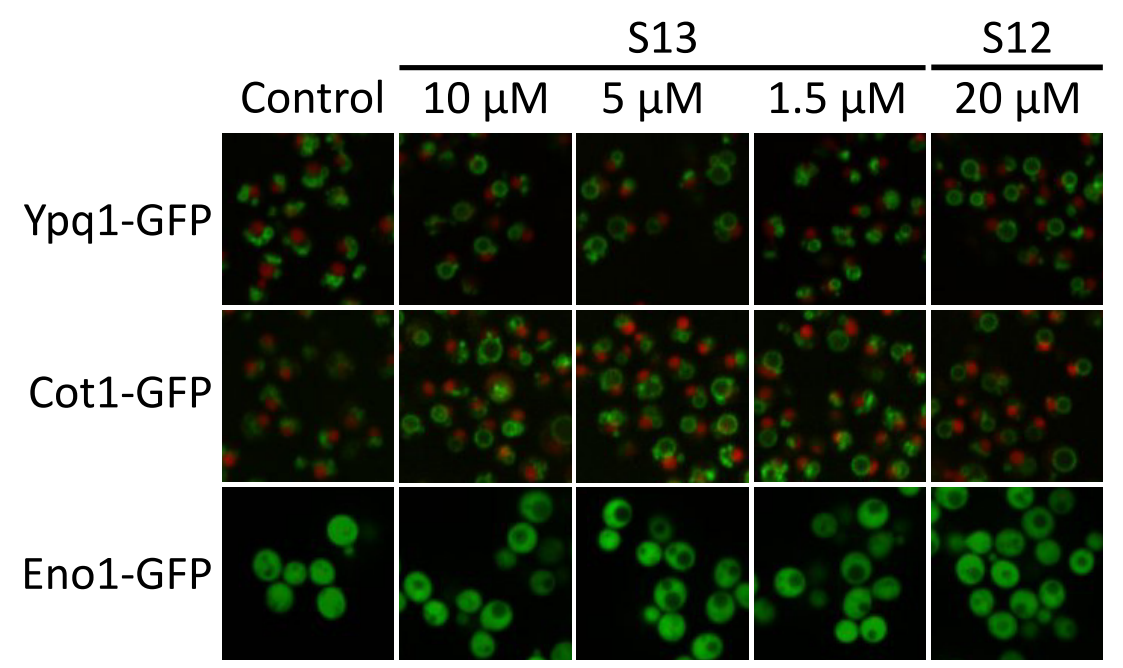

Figure 2.12: $\mathbf{S} 13$ and $\mathbf{S} 12$ treatment increases prominence of the vacuole membrane. Vacuole membrane $p d r 1 \Delta p d r 3 \Delta$ GFP strains Ypq1GFP and Cot1-GFP, and cytoplasmic GFP strain Eno1-GFP were treated with S13 $(10 \mu \mathrm{M}, 5 \mu \mathrm{M}$ and $1.5 \mu \mathrm{M})$ and $\mathrm{S} 12(20 \mu \mathrm{M})$ for 6 hours, then visualised using a Perkin Elmer Opera high-throughput confocal microscope. Each treatment was normalised to the RFP in the control frame.

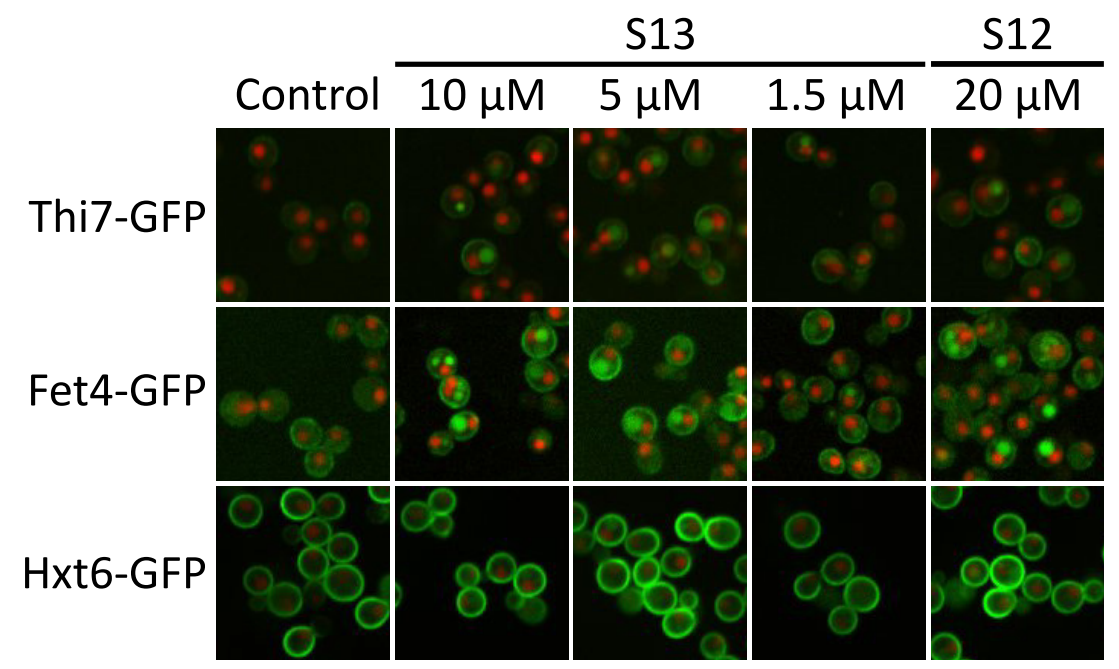

Figure 2.13: $\mathbf{S 1 3}$ and $\mathbf{S 1 2}$ treatment increases localisation of membrane transporters to vacuole lumen. Plasma membrane pdr1 $\Delta p d r 3 \Delta$ GFP strains Thi7-GFP, Fet41-GFP and Hxt6-GFP were treated with $\mathrm{S} 13(10 \mu \mathrm{M}, 5 \mu \mathrm{M}$ and $1.5 \mu \mathrm{M})$ and $\mathrm{S} 12(20 \mu \mathrm{M})$ for 6 hours, then visualised using a Perkin Elmer Opera high-throughput confocal microscope. Each treatment was normalised to the RFP in the control frame. 


\subsubsection{S13 treatment does not alter cell wall or membrane morphology}

Ergosterol is a vital component of the fungal plasma membrane, as shown by many of the genes involved with ergosterol biosynthesis pathway being essential, making them key targets for antifungals (Tsay and Robinson, 1991; Yoshida and Aoyama, 1987). A number of genes involved in ergosterol biosynthesis were upregulated (Fig. 2.10). Filipin staining was performed to determine whether there was a change in ergosterol distribution in the plasma membrane. Filipin specifically binds to un-esterified cholesterol (in mammals) and ergosterol (in yeast) and is commonly used to visualise sterol defects (Fei et al., 2008; Hankins et al., 2015). Cells were grown with and without 5 MM S13 for 16 hours and visualised using fluorescent microscopy. 16 hours was chosen to give cells time to accumulate any defects that $S 13$ may be inducing. There was no change in ergosterol distribution in cells treated with S13 compared to control cells (Fig. 2.14A).

Ergosterol is also involved in the dynamic homeostasis of the plasma membrane (Guan et al., 2009) calcofluor white staining was also performed to determine whether $\mathrm{S} 13$ treatment induced changes in cell wall morphology. Calcofluor white specifically binds to chitin in the cell wall (Elorza et al., 1983). Cells were again treated with $5 \mu \mathrm{M} S 13$ for 16 hours and visualised using fluorescent microscopy. No changes were seen in the chitin distribution of the cell wall under S13 treatment (Fig. 2.14B). Together, these data indicate that $\mathrm{S} 13$ is not interfering with ergosterol and chitin in the plasma membrane.

To determine whether the increased expression of ergosterol biosynthesis proteins is involved in resistance to $\mathbf{S 1 3}$, a number of 
A

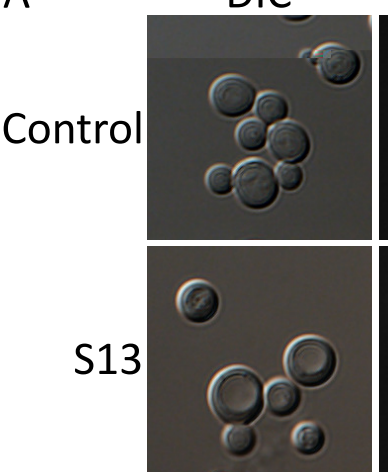

Filipin
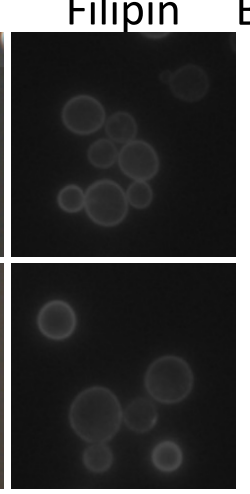
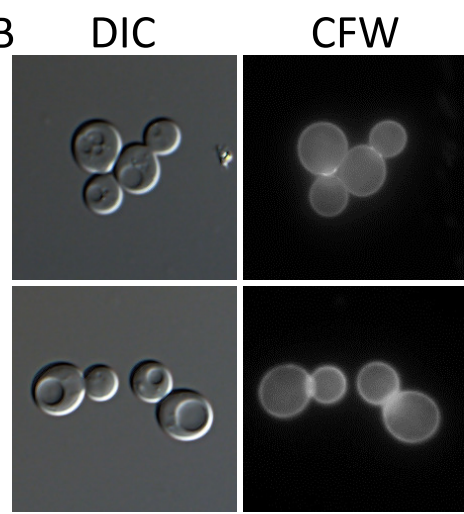

Figure 2.14: $\mathbf{S 1 3}$ has no affect on ergosterol or chitin distribution. pdr1 $\Delta p d r 3 \Delta$ cells were treated with or without $5 \mu \mathrm{M} \mathrm{S13}$ for 16 hours and stained with either $100 \mu \mathrm{g} / \mathrm{mL}$ filipin (A) or $0.1 \mathrm{mg} / \mathrm{mL}$ Calcofluor-White (CFW) (B) and visualised using a fluorescence microscope.

ergosterol biosynthetic mutants were treated with S13. Cells were treated with $1.5 \mu \mathrm{M}$ S13, which is a minimally inhibitory concentration and residual growth was calculated. erg3 $\Delta$, erg5 $\Delta$ and $\operatorname{erg} 24 \Delta$ all showed similar residual growth to the wild-type (Fig. 2.15). However, erg2 $\Delta$ showed significantly increased growth compared to the wild-type and the control with approximately $130 \%$ residual growth. erg $6 \Delta$ was sensitive to S13 treatment showing a $15 \%$ increase in inhibition compared to the wild-type. These results suggest that ergosterol biosynthesis is involved in the growth inhibition caused by $\mathrm{S} 13$.

\subsubsection{S13 treatment induces GFP-Atg8 localisation to the vacuole but autophagy is not required for inhibition}

Macroautophagy (herein referred to as autophagy) involves the formation of a double layer membrane vesicle termed the autophagosome. The autophagosome fuses with the vacuole releasing cytoplasmic content for degradation by the hydrolases in the acidic vacuolar lumen. Autophagosome formation involves the recruitment of various autophagy related (Atg) proteins such as Atg1p, Atg8p, Atg13p 


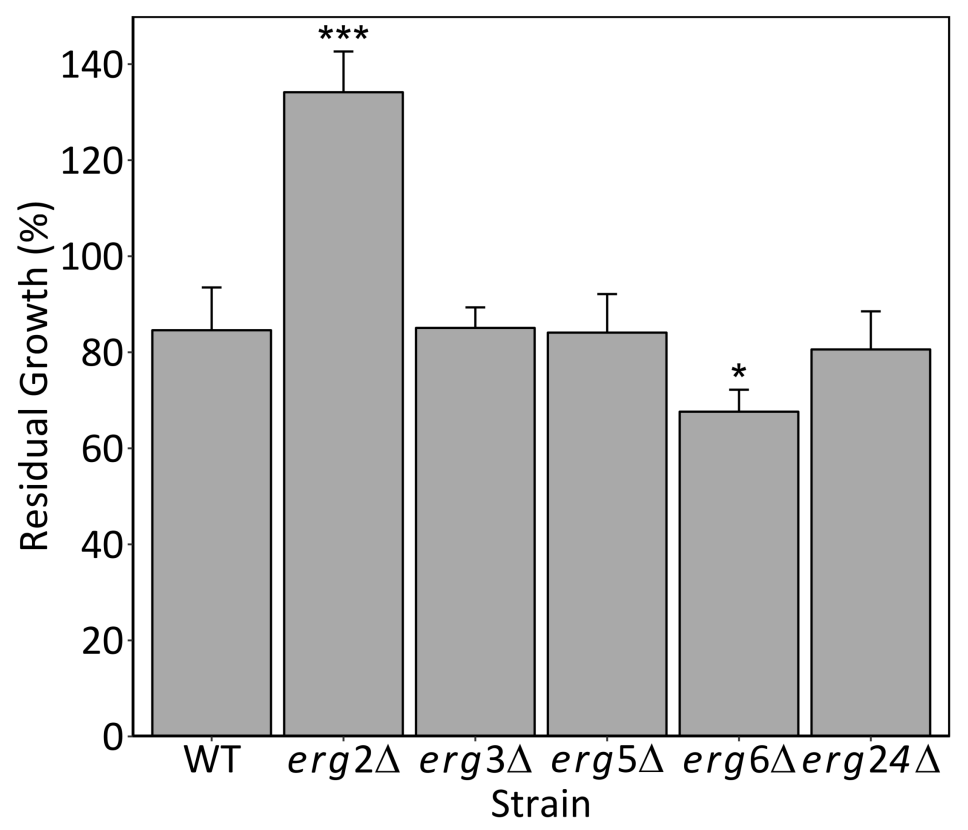

Figure 2.15: Ergosterol biosynthesis genes are invovled in the mechanism for S13. Residual growth of $p d r 1 \Delta p d r 3 \Delta$ (WT) strains containing ergosterol biosynthesis gene deletions treated with or without $1.5 \mu \mathrm{M}$ S13. Data shown as mean \pm SD of triplicate cultures; * $p \leq 0.05$, ${ }^{* *} p \leq 0.01,{ }^{* * *} p \leq 0.001$, student's T-test relative to WT

(Orsi et al., 2012; Scott et al., 2000). Increased autophagy due to chemical perturbation, such as by rapamycin treatment, has been shown to increase vacuole size in S. cerevisiae (Chan and W. F. Marshall, 2014). GFP-Atg8 was used as a proxy for autophagy induction to determine whether autophagy could be involved in the increase in vacuole size and the mislocalisation of plasma membrane transporters to the vacuolar lumen.

A $p d r 1 \Delta p d r 3 \Delta$ strain was transformed with a plasmid containing a GFP-Atg8 construct. GFP-Atg8 is frequently used as a marker for autophagy as it localises to the cytoplasm during growth in rich media but re-localises to the vacuole when autophagy is induced (Shintani and Klionsky, 2004). pdr1 $\Delta p d r 3 \Delta$ cells expressing GFP-Atg8 were treated with 5 and $1.5 \mu \mathrm{M} \mathrm{S13}$ for 16 hours in SC-Ura media and 
visualised. Cells treated with 1.5 or $5 \mu \mathrm{M} \mathrm{S13}$ showed approximately $60 \%$ and $80 \%$ of cells with GFP-Atg8 localisation in the vacuole respectively (Fig $2.16 \mathrm{~A} \& \mathrm{~B}$ ). This was in marked contrast with control cells that only showed $6 \%$ of cells with GFP-Atg8 localisation to the vacuole. This result indicates that $\mathrm{S} 13$ treatment induces increased localisation of GFP-Atg8 to the vacuole.

Autophagy requires autophagosomes to fuse with the vacuole membrane, releasing its contents for degradation (Xie and Klionsky, 2007). A number of gene deletions involved in vesicle fusion at the vacuole were treated with $\mathrm{S} 13$. Mon $1 \mathrm{p}$ and $\mathrm{Ccz} 1 \mathrm{p}$ form a heterodimeric guanine nucleotide exchange factor that acts upon the GTPase Ypt7p via longin domains (Cabrera et al., 2014; kucharczyk et al., 2000; Meiling-Wesse et al., 2002; Wang et al., 2003). Deletion of either CCZ1 or MON1 inhibits autophagy via reduced fusion of both CVT pathway vesicles and autophagosomes at the vacuole (kucharczyk et al., 2000; Meiling-Wesse et al., 2002). Vam3p and Vam7p are t-SNARE proteins that are involved in the docking and fusion of transport intermediates at the vacuole (Nair, Jotwani, et al., 2011; Sato et al., 1998). Deletion of MON1 or CCZ1 show significant resistance to $S 13$ treatment with nearly no inhibition present at a $1.5 \mu \mathrm{M}$ treatment compared to $35 \%$ in the control (Fig. 2.18). vam $3 \Delta$ and $\operatorname{vam} 7 \Delta$ also showed significant resistance to $\mathrm{S} 13$ treatment with $10 \%$ inhibition at $1.5 \mu \mathrm{M}$ of $\mathrm{S} 13$ (Fig. 2.18). These data show that reducing vesicle fusion at the vacuole resists S13 induced growth defects, indicating that vesicular fusion in some way mediates the mechanism of action of S13.

If $\mathrm{S} 13$ resistance is due to inhibition of autophagy then gene deletions directly involved in autophagy should show a similar phenotype. 


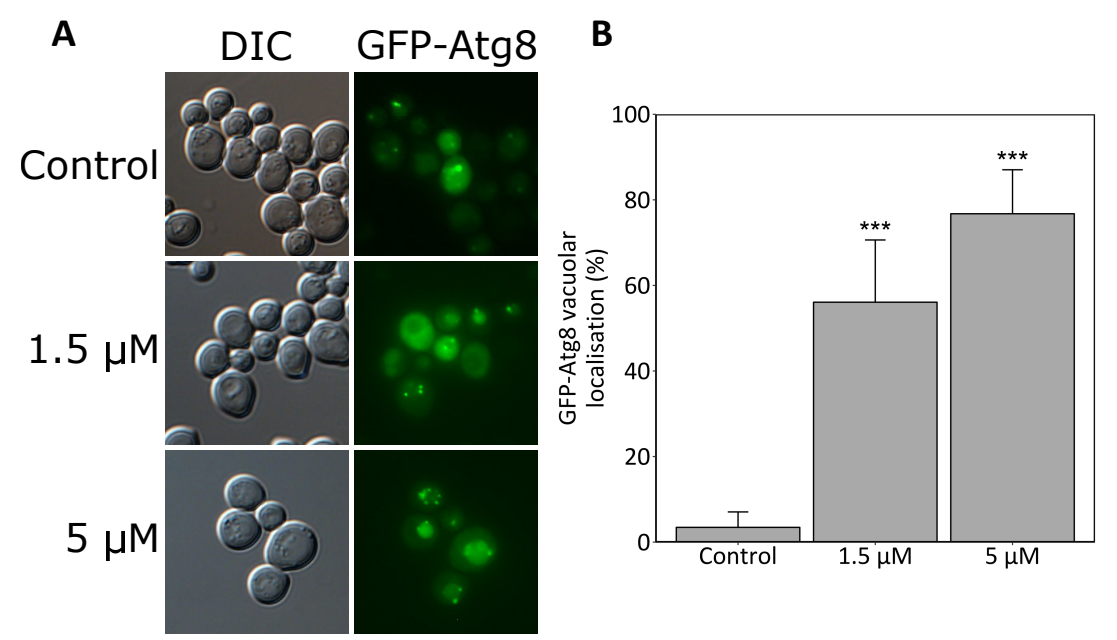

Figure 2.16: $\mathbf{S 1 3}$ treatment induces increased localisation of GFP. Atg8 to the vacuole Percentage of (A) pdr1 $1 \Delta$ pdr3 $\Delta$ GFP-Atg8 cells treated with or without $S 13(1.5 \mu \mathrm{M}$ and $5 \mu \mathrm{M})$ for 16 hours showing GFPAtg8 localised to the vacuole. (B) The proportion of cells with GFP-Atg8 localised to the vacuole were counted, with at least 500 cells were counted per treatment. Cells that had no fluorescent signal were omitted.

A number of strains containing gene deletions involved in the formation of the autophagosome were treated with S13 in order to determine whether autophagy is involved in the mechanism of action of S13. Strains lacking ATG1, ATG9, ATG13 and ATG14 are unable to form the autophagosome and thus also required for autophagy (Orsi et al., 2012; Scott et al., 2000). Strains deficient in autophagy showed no change in sensitivity to S13 with all strains showing approximately $30 \%$ growth inhibition (Fig. 2.18). These results indicate that formation of the autophagosome is not involved in the bioactivity of S13. These data indicate that vesicular fusion at the vacuole is required for $\$ 13$ induced growth inhibition; however it is not due to abolishing autophagosome fusion at the vacuole.

\subsubsection{S13 treatment does not induce ER stress}

The unfolded protein response (UPR) is also involved in inducing autophagy (Yorimitsu et al., 2006). Therefore, the UPR may be a mechanism to explain the increased autophagy with $\$ 13$ treatment. 


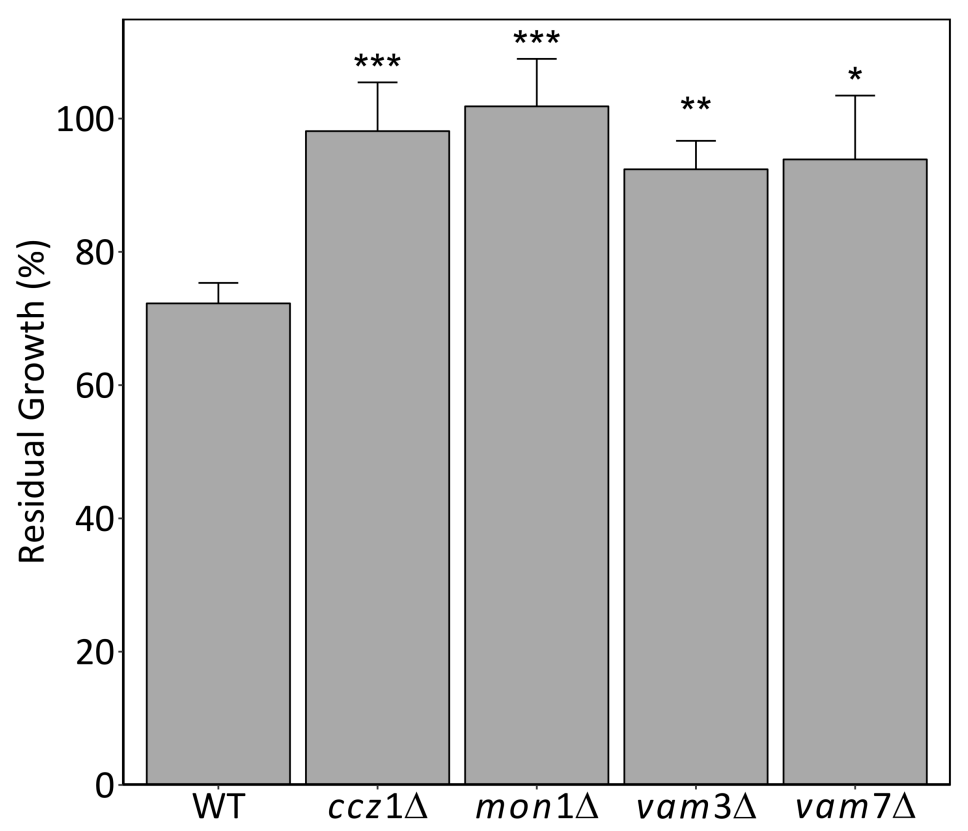

Figure 2.17: Deletion of genes involved with vacuolar vesicle fusion rescues growth of cells treated with S13. Residual growth of midlog $p d r 1 \Delta p d r 3 \Delta$ triple gene deletions involved in vesicular fusion at the vacuole compared treated with $1.5 \mu \mathrm{M} \mathrm{S} 13$ to the wild-type $p d r 1 \Delta p d r 3 \Delta$. Data shown as mean $\pm S D$ of triplicate cultures; ${ }^{*} p \leq 0.05,{ }^{* *} p \leq 0.01$, ${ }^{* * *} \mathrm{p} \leq 0.001$, student's T-test relative to WT.

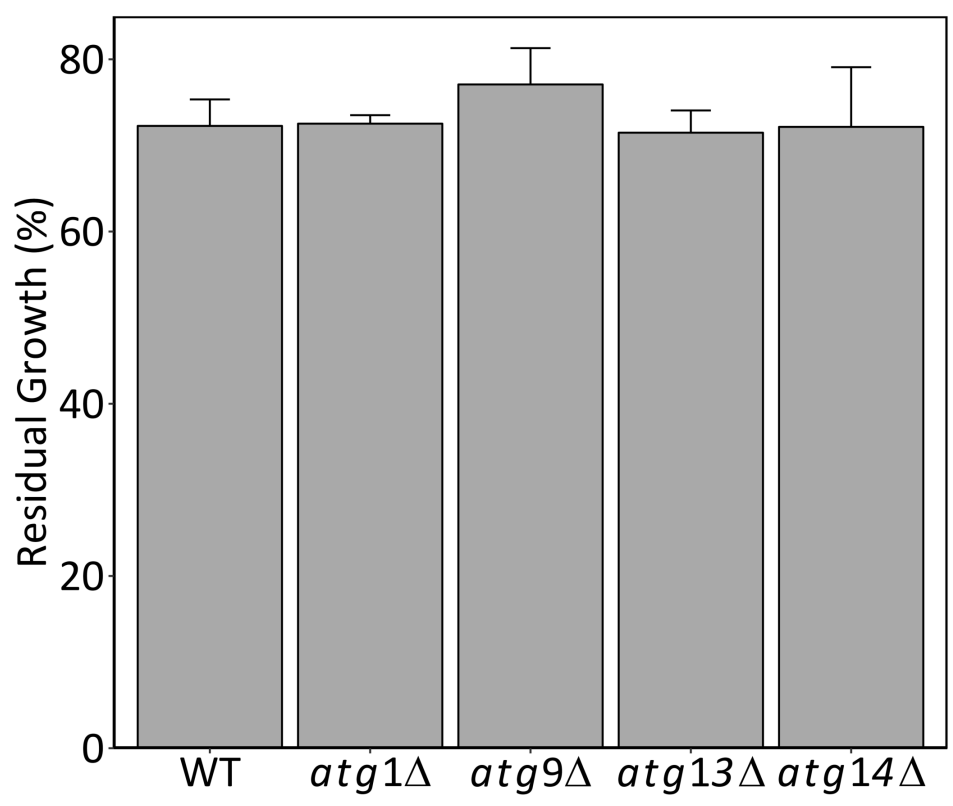

Figure 2.18: Deletion of $A T G$ genes has no affect on $\mathbf{S} 13$ sensitivity. Residual growth of mid-log $p d r 1 \Delta p d r 3 \Delta$ triple gene deletions involved in autophagosome formation treated with $1.5 \mu \mathrm{M} \mathrm{S} 13$ compared to the wildtype $p d r 1 \Delta p d r 3 \Delta$. Data shown as mean \pm SD of triplicate cultures. 
Ergosterol has been shown to work synergistically with saturated fatty acids to induce ER stress (Pineau et al., 2009). As there was an increase in ergosterol biosynthetic protein abundance (Fig. 2.10), there may also be an increase in ER stress caused by an increase in ergosterol accumulation within the endoplasmic reticulum. Peter Bircham from our lab constructed a cassette containing three unfolded protein response elements (UPRE) attached to a GFP, allowing the ER stress phenotype to be visualised (Bircham, 2014). This cassette was transformed into a pdr1 $\Delta p d r 3 \Delta$ strain to determine whether $\mathrm{S} 13$ treatment induces ER stress. Cells were treated for 6 hours with or without $10 \mu \mathrm{M} \mathrm{S13}$ and visualised. There was no significant differences in GFP intensity between treated samples and untreated (Fig. 2.19). However, there was a large increase in fluorescence upon treatment with tunicamycin, indicating the UPRE was expressed in response to ER stress.

The UPR can be induced by the initiation of HAC1 splicing by the endoribonuclease Ire1p (Sidrauski and Walter, 1997). Hac1p forms a homodimer and activates the UPR by binding to UPREs inducing the expression of genes that mediate the UPR (Cox and Walter, 1996; Nikawa, 1996). The pdr1 $\Delta p d r 3 \Delta$ strain containing a deletion in IRE1 was treated with $1.5 \mu \mathrm{M}$ S13. If S13 induced ER stress, ire $1 \Delta$ mutants would be sensitive to $S 13$ treatment as the UPR would not be activated. IRE1 mutants cells showed no change in sensitivity to $S 13$ treatment (Fig. 2.19B). These data collectively suggest that $S 13$ treatment does not induce ER stress.

\subsubsection{S13 induces an increase in vacuolar $\mathrm{pH}$}

Cells with increased vacuolar $\mathrm{pH}$ display increased vacuolar protein accumulation coincident with an increase in vacuole size (Baars 


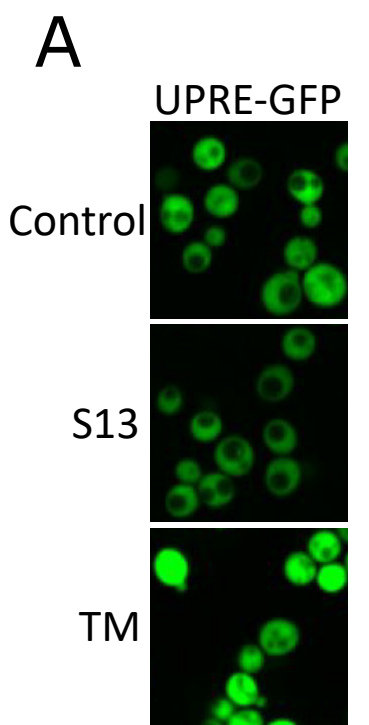

\section{B}

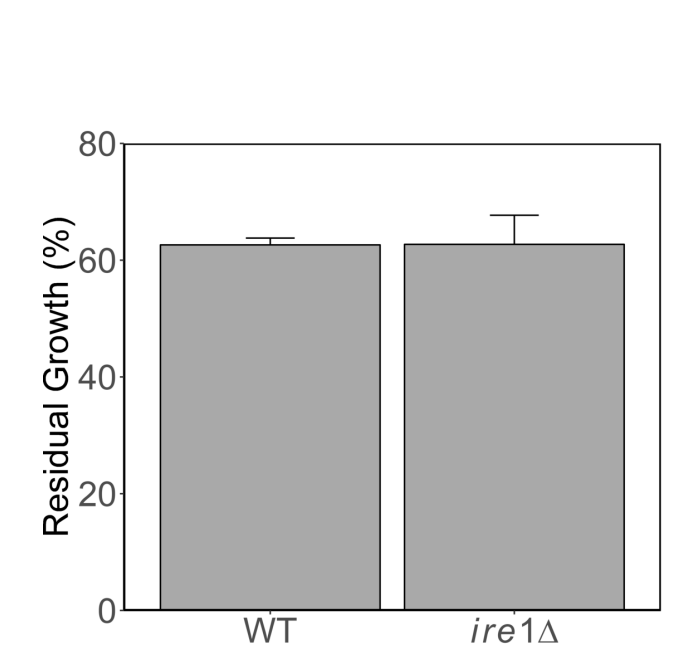

Figure 2.19: $\mathbf{S} 13$ does not induce ER stress. (A) $p d r 1 \Delta p d r 3 \Delta$ cells containing a UPRE-GFP construct were treated with or without $10 \mu \mathrm{M}$ S13 for 6 hours and visualised using a Perkin Elmer OPERA highthroughput confocal microscope. (B) Wild-type (WT) pdr1 $1 \Delta$ pdr3 $\Delta$ cells and $p d r 1 \Delta p d r 3 \Delta$ ire $1 \Delta$ cells were treated with or without $1.5 \mu \mathrm{M} \mathrm{S13}$ and residual growth calculated based on vehicle controls. Data shown as mean $\pm \mathrm{SD}$ of triplicate cultures.

et al., 2007; Mauvezin et al., 2015). S13 treatment resulted in an increase protein mislocalisation to the vacuole lumen (Fig. 2.13). To determine whether $\mathrm{S} 13$ is increasing $\mathrm{pH}$ in the vacuole, cells were stained with chloroquine. Chloroquine is a lipophilic drug used to treat malaria that localises to acidic organelles and fluoresces when excited with light in the ultraviolet spectra (Watanabe et al., 2005). Cells were treated with $10 \mu \mathrm{M}$ S13 for 6 hours and then incubated with $10 \mathrm{mM}$ chloroquine for 20 minutes as previously described (Watanabe et al., 2005). Chloroquine staining in control cells was localised to the vacuole (Fig. 2.20). It has been previously shown that daughter cells have greater vacuolar acidification than their mother cells (Watanabe et al., 2005). This was seen in the control cells verifying that the stain worked as intended. Cells treated with $10 \mu \mathrm{M} \mathrm{S13}$ showed little to no vacuolar localisation of 
chloroquine, indicating that the vacuoles in $\mathrm{S13}$ treated cells have increased $\mathrm{pH}$.

Disruption of either the vacuolar-ATPase (V-ATPase) or ergosterol biosynthesis pathway has been shown to increase the $\mathrm{pH}$ of the yeast vacuole (Brett et al., 2011). The V-ATPase $\mathrm{V}_{1}$ subunit vma1A as well as $\operatorname{erg} 2 \Delta$ and $\operatorname{erg} 6 \Delta$ were grown overnight, subcultured for 6 hours, and then stained with chloroquine (Fig. 2.20). The vma1 $\Delta$ mutant showed no localisation of chloroquine to the vacuole. Both erg $2 \Delta$ and $\operatorname{erg} 6 \Delta$ showed reduced localisation of chloroquine to the vacuole. However, chloroquine localised to a separate non-vacuolar organelle in erg6 $\Delta$ mutants. These results confirm that disruption of V-ATPase functionality and deletion of ergosterol genes increases the $\mathrm{pH}$ of the yeast vacuole.

Cells without functional V-ATPase complexes have reduced growth in $\mathrm{pH} 7$ media, yet grow normally on slightly acidic media $(\mathrm{pH} 5.5)$ (H. Nelson and N. Nelson, 1990). In order to determine whether S13 was more potent on buffered media, pdr1 $\Delta$ pdr3 $\Delta$ cells were grown in SC media with HEPES ( $\mathrm{pH} 7)$ and SC media without HEPES buffer ( $\mathrm{pH}$ 5.3). Yeast treated in buffered SC media showed significantly greater sensitivity to $\mathrm{S} 13$ than yeast grown in more acidic media (Fig. 2.21). These data also suggest that $\mathrm{S} 13$ treatment is causing an increase in $\mathrm{pH}$ within the vacuole. 


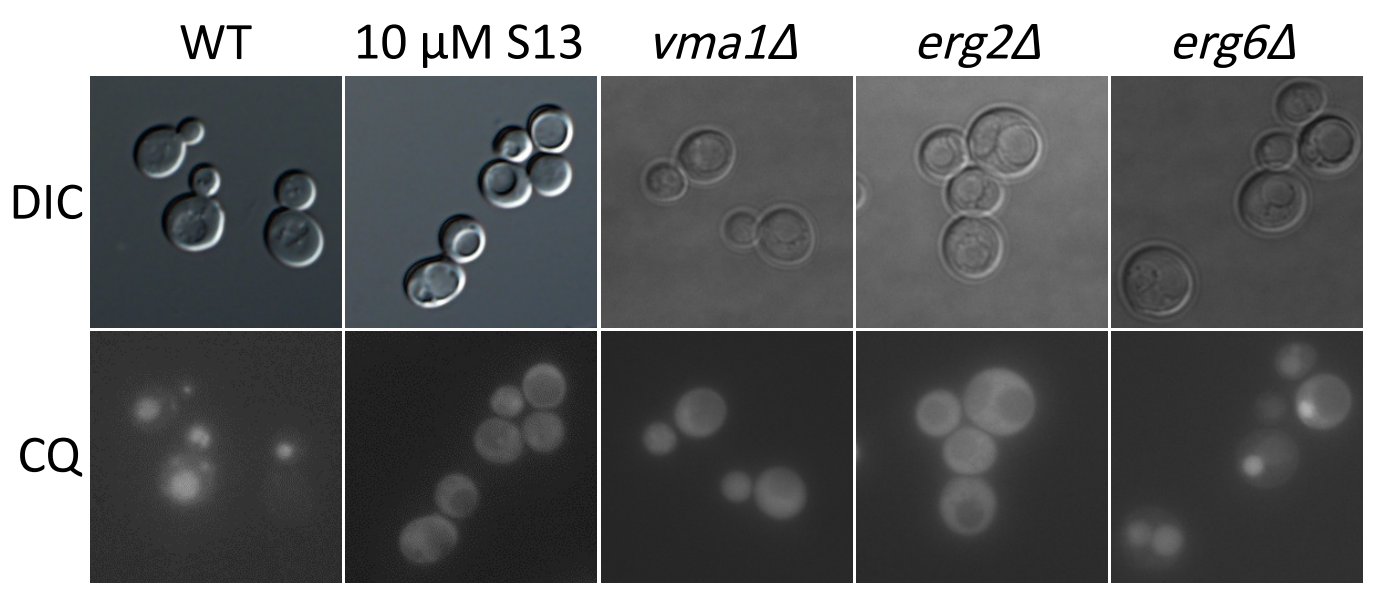

Figure 2.20: S13 treatment increases vacuolar pH. pdr1 $\Delta p d r 3 \Delta$ cells and $p d r 1 \Delta p d r 3 \Delta$ triple deletions, vma1 $\Delta$, erg $2 \Delta$ and erg $6 \Delta$ were treated with or without $10 \mu \mathrm{M} \mathrm{S13}$ for 6 hours and stained with chloroquine (CQ) to visualise acidified organelles. Triple deletion strains were grown same as the $p d r 1 \Delta p d r 3 \Delta$ wild-type without $\mathrm{S} 13$ treatment. Cells were visualised under a fluorescence microscope.

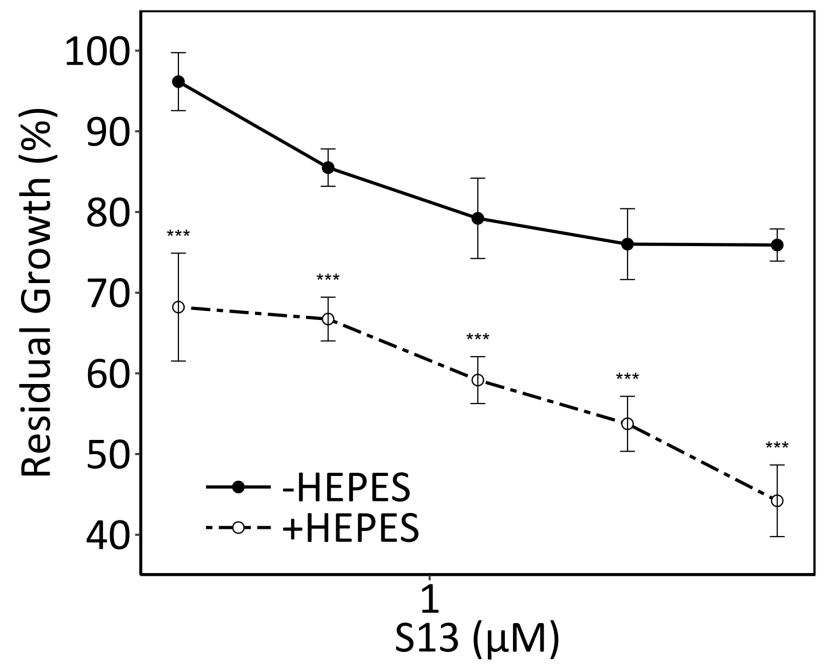

Figure 2.21: $\mathbf{S 1 3}$ is more potent at a neutral $\mathbf{p H}$. pdr1 $\Delta p d r 3 \Delta$ cells were treated with increasing concentrations of S13 in SC media with HEPES (pH 7 ) and SC media without HEPES buffer ( $\mathrm{pH}$ 5.3). Data shown as mean \pm SD of triplicate cultures; ${ }^{*} p \leq 0.05,{ }^{* *} p \leq 0.01,{ }^{* * *} p \leq 0.001$, student's T-test relative to WT. 


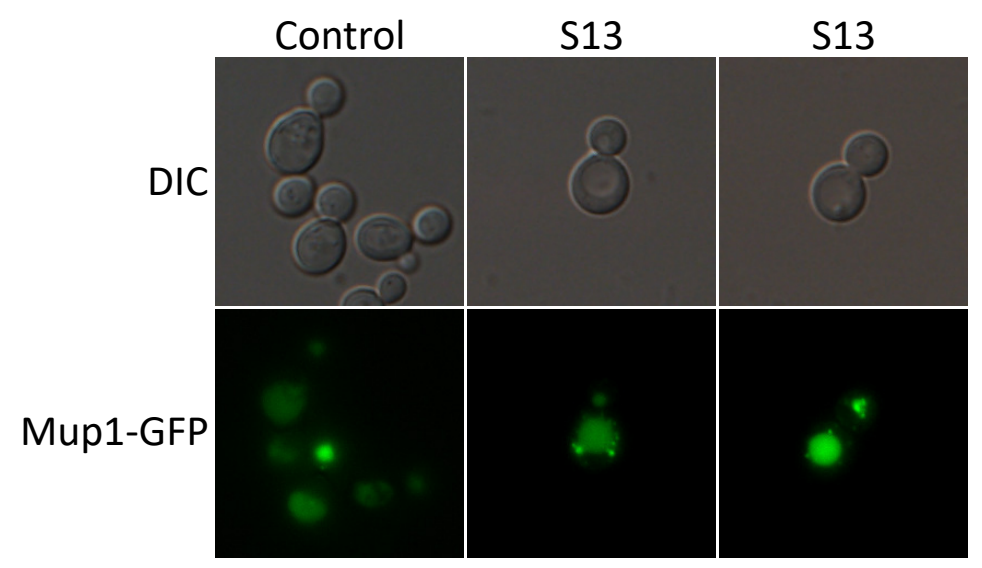

Figure 2.22: S13 treatment partially inhibits MVB fusion at the vacuole. $p d r 1 \Delta p d r 3 \Delta$ cells were transformed with a Mup1-GFP expression plasmid and treated with or without $10 \mu \mathrm{M}$ S13 for 6 hours and visualised using a fluorescent microscope.

\subsubsection{S13 does not inhibit endocytosis but potentially inhibits vesicle fusion at the vacuole} Increasing lumenal $\mathrm{pH}$ in the vacuole decreases vesicular fusion with the vacuole membrane (Yamamoto et al., 1998). Mup1p is a high-affinity methionine transport protein (Isnard et al., 1996). When grown on media containing methionine Mup1p is transported from the plasma membrane to the vacuole via the MVB pathway, which targets proteins for degradation (Teis et al., 2008). As increasing vacuolar $\mathrm{pH}$ decreases vesicular fusion it was expected that treating cells with a Mup1-GFP would increase the number of MVBs seen in the cytoplasm (Bayer et al., 2003). To determine whether vesicles were being inhibited from fusing at the vacuole membrane $p d r 1 \Delta p d r 3 \Delta$ cells were transformed with a Mup1-GFP expression plasmid and treated with 10 $\mu \mathrm{M}$ S13 for 6 hours. Both the control and S13 treated cells showed Mup1-GFP localisation to the vacuole (Fig. 2.22). However, cells treated with S13 showed greater number of punctate GFP structures in the cytoplasm surrounding the vacuole, which are likely to be MVBs 
containing Mup1-GFP. These data indicate that S13 treatment partially inhibits rather than abolishes MVB fusion at the vacuole.

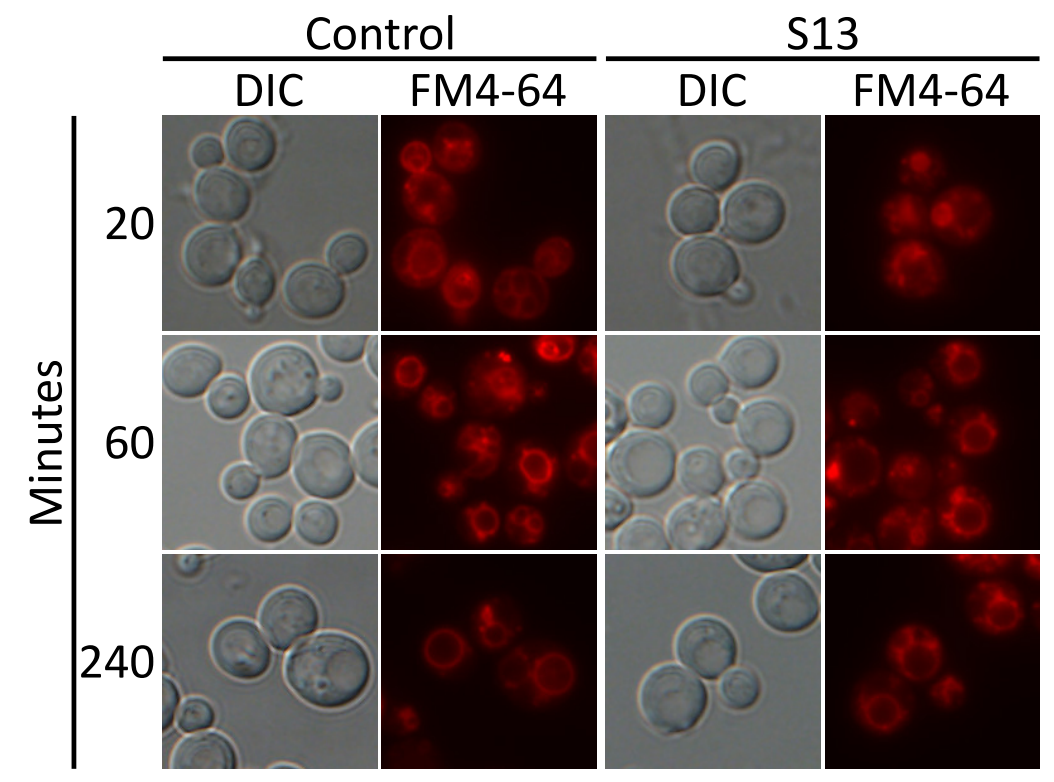

Figure 2.23: S13 inhibits FM4-64 localisation to the vacuole. pdr1 $1 \Delta$ pdr3 $\Delta$ cells were treated with $10 \mu \mathrm{M}$ S13 for 6 hours and stained with FM4-64 at a final concentration of $25.6 \mu \mathrm{M}$. Cells were visualised after 20, 60 and 240 minutes using a fluorescent microscope.

There are multiple vesicular transport pathways that lead to the vacuole (Conibear and Stevens, 1998; Lynch-Day and Klionsky, 2010; Muller et al., 2015). FM4-64 is a synthetic dye that is endocytosed and transported to the vacuole membrane (Vida and Emr, 1995). Since Mup1-GFP containing vesicles accumulated outside of the vacuole (Fig. 2.22), it was hypothesised that endocytosed vesicles would show the same phenotype. If vesicular fusion is impaired in endocytic vesicles then FM4-46 should be taken up by the cell but not localise completely to the vacuole membrane. $p d r 1 \Delta p d r 3 \Delta$ cells were treated with or without 10 $\mu \mathrm{M}$ S13 for 6 hours and stained with FM4-64. The majority of FM4-64 localised to the vacuole membrane after 60 minutes of staining in the control and complete localisation was reached at 240 minutes (Fig. 2.23). After 60 minutes of staining in treated cells, FM4-64 was localised to the 
vacuole, however punctate spots of the stain were still visible in the majority of cells. After 240 minutes FM4-64 was still localised to the vacuole as well as the cytoplasm surrounding the vacuole. Interestingly after 20 minutes FM4-64 is localised to a non-vacuolar compartment in S13 treated cells. As FM4-64 was endocytosed but did not completely reach the vacuolar membrane in $\mathrm{S} 13$ treated cells, it can be concluded that $\mathrm{S} 13$ does not fully inhibit endocytosis but does interfere with localisation to the vacuole membrane. 


\subsection{Discussion}

\subsubsection{Summary of Focused Compound Phenotypic Screen}

Screening of compounds against $S$. cerevisiae for bio-activity gives an unbiased perspective on a novel drug's mechanism of action. In this study a focused compound library containing a core benzopyran scaffold was screened against two yeast strains, a wild-type Y7092 and pdr1 $\Delta$ pdr3 $\Delta$ in a Y7092 background. PDR1 and PDR3 encode transcription factors that control the expression of a variety of $A B C$-transporters involved in the efflux of xenobiotics (Mamnun et al., 2002; Schuller et al., 2007). The deletion of PDR1 and PDR3 increased the bioactivity of the focused compound library compared to the wild-type Y7092. S13 and S12 were shown to be significantly more potent than other compounds in the focused benzopyran library in the $p d r 1 \Delta p d r 3 \Delta$ background.

\subsubsection{Chlorination as a means of increasing potency}

Altering functional groups around a core scaffold is a method of modulating bioactivity. By linking the structure-activity relationship (SAR) of a molecule to the phenotype, it is possible to tune the bioactivity through subtle chemical modification of the molecule at sites that affect bioactivity. Chlorinating compounds increases the steric and electronic nature at that position and in many cases the binding affinity (Iltzsch et al., 1995). Halogens, such as chloride, are able to form hydrogen bonds with a number of amino acid side chains. For example hydrogen bonds are formed between the hydroxyl, carboxylate, sulfur, and nitrogen groups found in many amino acids. The addition of halogens to a 
compound has been used widely in drug discovery to increase efficacy, though typically added during lead optimisation (Hardegger et al., 2011; Jorgensen and Schyman, 2012; Wilcken et al., 2012). Both S12 and S13 contain a chloride group para to the ether oxygen in the benzopyran structure, which are not present in other molecules from the library. These two compounds are substantially more bioactive than all other compounds within the library, which rationally can be attributed to the introduction of the chlorine atom.

\subsubsection{Vacuolar deacidification as a mechanism of action}

Vacuoles are large acidic organelles involved in autophagy that house lipases, hydrolases and proteases (Hecht et al., 2014). Vacuolar acidification is controlled by V-ATPases, which use ATP to pump hydrogen ions into the vacuole to retain an acidic environment $(H$. Nelson and N. Nelson, 1990). Inhibition or deletion of the V-ATPase increases vacuole size in yeast by abolishing vacuolar fission (Baars et al., 2007). Inhibition of V-ATPases through treatment with bafilomycin has been shown to inhibit vesicular fusion at the vacuole/lysosome and to decrease digestion of proteins in the lumen of the vacuole/lysosome (Yamamoto et al., 1998). S13 treatment increased the $\mathrm{pH}$ in the vacuole as well as increased its size. A number of plasma membrane transporters aggregated in the vacuolar lumen when cells were treated with $\mathbf{S 1 3}$. Following S13 treatment cells showed increased numbers of cytoplasmic MVBs, in line with a decrease in vesicle fusion at the vacuole membrane. The abolishment of chloroquine staining the vacuole during $\mathrm{S} 13$ treatment in conjunction with the greater sensitivity in neutral media and decreased vesicular fusion at the vacuole indicate that $\mathrm{S} 13$ is increasing the $\mathrm{pH}$ in the vacuole lumen. 


\subsubsection{S13 induced autophagy}

Autophagy is a cell's recycling pathway used to break down proteins and other macromolecules, which gets degraded via hydrolases, lipases and proteases in the vacuole (lysosome in mammals) (Hecht et al., 2014). GFP-LC3 (in mammals) and GFP-Atg8 (in yeast) localise to the vacuole when autophagy is induced and are well established methods of measuring autophagic flux (Cheong and Klionsky, 2008; Kabeya, 2000). The GFP-Atg8 and GFP-LC3 structures are cleaved in the vacuole, but still emit a signal when excited allowing visualisation within the vacuole (Shintani and Klionsky, 2004). Cells treated with the potent V-ATPase inhibitor bafilomycin $A_{I}$ have been shown to increase the localisation of GFP-LC3 to the lysosome, however the level of undigested GFP-LC3 is also increased indicating that the GFP-tagged protein is not being broken down (Ni et al., 2011; Slobodkin and Elazar, 2013; Yamamoto et al., 1998). Bafilomycin $A_{I}$ treatment is commonly used to inhibit autophagy and been shown to decrease protein degradation in the lysosomes of cultured cells (Yamamoto et al., 1998; Yoshimori et al., 1991). Therefore GFP-Atg8 cannot be used as a sole method of measuring autophagic flux. S13 treatment induced a substantial increase in GFP-Atg8 localisation to the vacuole, however the increase in vacuolar $\mathrm{pH}$ and the lack of sensitivity in atg mutants suggest that autophagy is potentially inhibited.

\subsubsection{Ergosterol's involvement in vacuolar pH}

Ergoterol is the main sterol found in yeast's membrane, which is formed in a pathway that is largely conserved from yeast to humans (Nielsen, 2009). Deletion of ERG genes increases the vacuolar $\mathrm{pH}$ in yeast, much like VMA mutants (Brett et al., 2011; Zhang et al., 2010). 
Inhibition of Erg11p by ketoconazole has been shown to upregulate a number of genes involved in the final steps of ergosterol biosynthesis including ERG3, ERG11 and ERG25 (Yu et al., 2007). Deletions of ergosterol biosynthesis genes show post-internalisation endocytic defects, unlike treatment with VMA inhibitors, which inhibited endocytosis (Heese-Peck, 2002; Perzov et al., 2002). S13 treatment resulted in a upregulation of a number of genes involved in ergosterol biosynthesis upregulated as well as phenotypes indicating an increase in vacuolar $\mathrm{pH}$. The chloroquine phenotype was also similar to the phenotype seen in the erg2 $\Delta$ mutant but not the erg6s, which showed an increase in a non-vacuolar organelle. ERG6 mutants have exaggerated class $\mathrm{E}$ compartments that have been shown to accumulate quinacrine, which stains the vacuole in the same manner as chloroquine (Raymond et al., 1992; Umebayashi and Nakano, 2003). ERG2 deletion was also resistant to $\mathrm{S} 13$ treatment whereas ERG6 deletion was sensitive. Deletion of ERG6 has been shown to increase sensitivity to small molecule drugs by increasing passive diffusion across the membrane, in an $A B C$-transporter independent process (Emter et al., 2002). FM4-64 did not completely localise to the vacuole membrane in $\mathbf{S 1 3}$ treated cells as punctate patches of the stain were visible surrounding the vacuole. Ergosterol biosynthesis mutants, unlike V-ATPase inhibitor treated cells, are able to endocytose FM4-64 (Heese-Peck, 2002), however, FM4-64 does not completely localise to the vacuole membrane, much like in S13 treatment. Contrastingly, erg mutants showed fragmented vacuoles whereas S13 treated cells showed one large vacuole (Heese-Peck, 2002), however these results do not rule out the possibility that $\$ 13$ is targeting ergosterol biosynthesis genes. 


\subsubsection{Potential uses}

Presented here is a novel benzopyran that increases vacuolar $\mathrm{pH}$ by an unknown mechanism. The processes required to acidify the vacuole and the lysosome are conserved in yeast to humans (N. Nelson et al., 2000). Autophagy is a key target for cancer therapy due to being implicated in many forms of cancer, e.g., ras-dependent cancers have been described as "autophagy addicted" due to their requirement for autophagy (Guo et al., 2011; White, 2015). V-ATPase inhibitors have shown promise in the treatment of various cancers due to its ability to inhibit autophagy. For example bafolomycin $A_{I}$ induces apoptosis in B-cell acute lymphoblastic leukemia and osteosarcoma cells (Yuan et al., 2015). Deacidification of the vacuole modulates resistance to various cancer therapies (Lozupone et al., 2015; McAfee et al., 2012; von Schwarzenberg et al., 2014). S13 described above is a novel compound that decreases vacuolar acidity, which could be used to deacidify lysosomes for the treatment of cancer or to augment established cancer therapies. 


\subsection{Conclusion}

To conclude, a novel focused compound library was synthesised by Sandile Simelane with a core benzopyran scaffold. A phenotypic screen was performed using $S$. cerevisiae as a model organism to determine inhibitory effect of the compound library on growth. The phenotypic screen was conducted using two strains of yeast, a Y7092 wild-type and a $p d r 1 \Delta p d r 3 \Delta$ strain hypersensitive to xenobiotics. The compound library was found to be more potent in the $p d r 1 \Delta p d r 3 \Delta$ background. S13 was found to be the most potent compound within the benzopyran library and was shown to be a Pdr5p substrate. High-throughput microscopy of 4,100 strains, each with a different GFP-tagged protein, was utilized to determine proteins that increased in abundance or changed localization in response to perturbation with $\mathrm{S} 13$. Following treatment with $\mathbf{S 1 3}$, the yeast vacuole increased in size due to an aggregation of proteins in the vacuolar lumen. The increase in vacuole size was coincident with a decrease in vacuolar acidity whereby the stain chloroquine, which accumulates in acidic organelles, showed no localisation to the vacuole in $\mathrm{S} 13$ treated cells. There was also a decrease in vesicular fusion at the vacuolar membrane and potentially disrupted autophagy due to the decrease in acidity. Several proteins involved in ergosterol biosynthesis were also upregulated. Together, these results reveal a novel bridged benzopyran that increases vacuolar size and $\mathrm{pH}$ through an epistatic mechanism involving ergosterol biosynthesis (Fig. 2.24). 

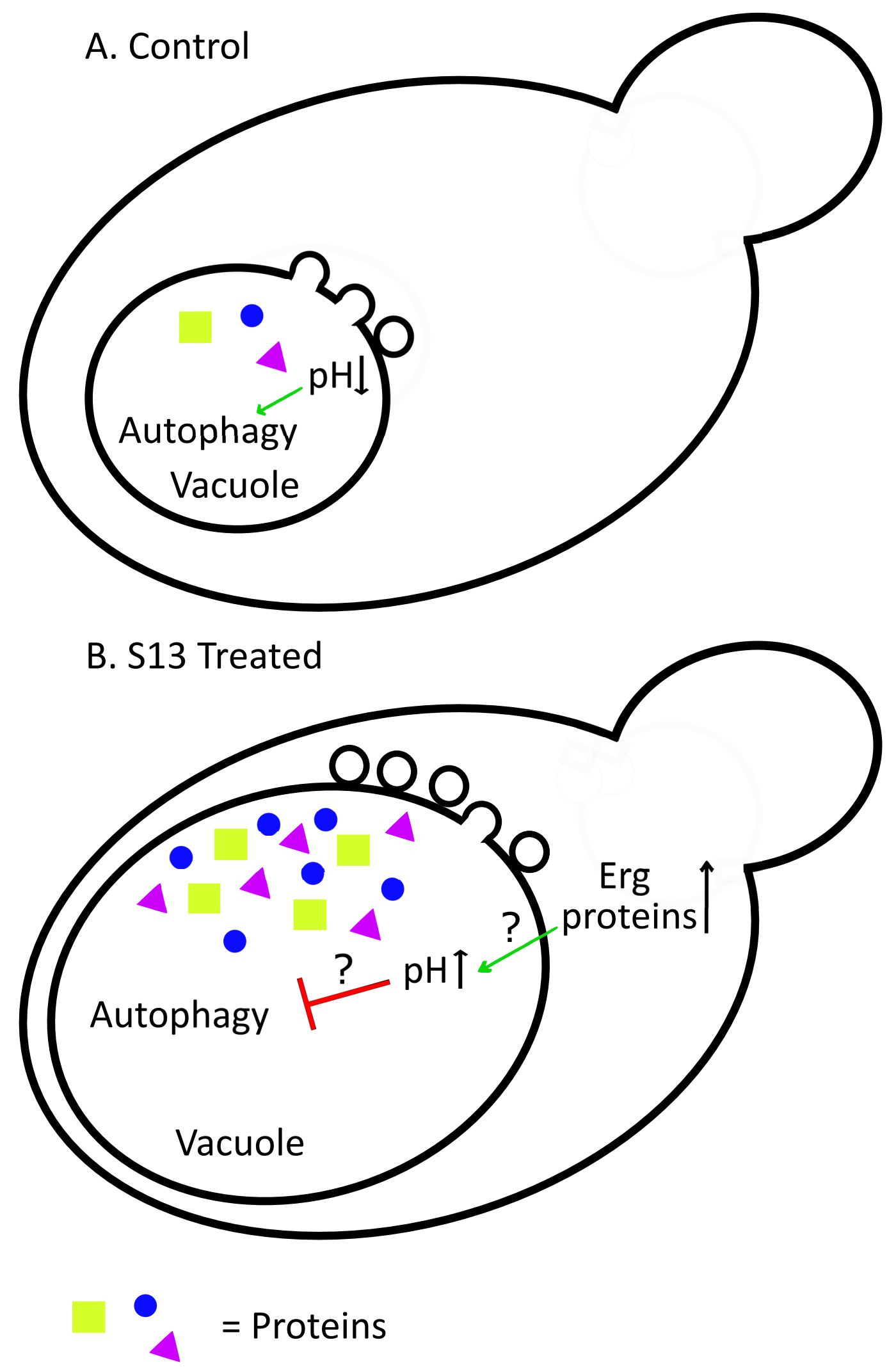

Figure 2.24: Proposed S13 mechanism of action. Schematic of an untreated $p d r 1 \Delta p d r 3 \Delta$ cell and a $p d r 1 \Delta p d r 3 \Delta$ cell treated with $\mathrm{S} 13$. 


\subsection{Future Directions}

In this thesis, a novel benzopyran compound was shown to upregulate proteins involved in ergosterol biosynthesis, potentially alter autophagic flux and increase the vacuolar $\mathrm{pH}$. However due to the time limitations that a Masters degree imposes, there were a number of questions left unanswered by this study. The following experiments should shed light on these unanswered questions.

\subsubsection{Quantifying vacuolar $\mathrm{pH}$ increase}

As it is not known by what means $\mathrm{S} 13$ is increasing the vacuole $\mathrm{pH}$, this needs to be determined in the future. Firstly, a more quantitative dye such as 2,7-bis(carboxyethyl)-5(6)-carboxyfluorescein (BCECF) or 5(6)-Carboxy-2,7-dichlorofluorescein diacetate (cDCFDA) needs to be used to quantify the extent that $\mathrm{S} 13$ is increasing the $\mathrm{pH}$ in the vacuole (Ali, 2003; Ho et al., 2015). BCECF and cDCFDA are sequestered into the vacuole and $\mathrm{pH}$ can be measured via fluorescence emitted by each compound relative to a standard curve. Using either of these probes will allow for quantification of the $\mathrm{pH}$ increase that $\mathrm{S} 13$ induces on the vacuole.

\subsubsection{Measuring autophagic flux}

Atg8-PE or GFP-Atg8 levels will be measured to confirm that S13 inhibits autophagy. Atg8 is conjugated to phosphatidylethanolamine (PE) during autophagosome formation and can therefore be used to measure autophagy induction (Nair, Thumm, et al., 2011). GFP-Atg8 localises to the vacuole during autophagy and is cleaved to GFP and Atg8 if autophagy is occurring normally. Free GFP can be measured due to its stability in the vacuole, allowing autophagic flux to be measured 
(Shintani and Klionsky, 2004). The Pho8 $\Delta 60$ assay can be used to measure autophagy in a quantitative manner (Noda and Klionsky, 2008). Pho8 is the only vacuolar alkaline phosphatase in yeast. Pho8 $\Delta 60$ is a truncated version of the Pho8 protein that cannot localise to the ER and instead localises to the cytoplasm (Noda, Matsuura, et al., 1995). Pho8 $\Delta 60$ is non-specifically taken up by the autophagosome and transported to the vacuole where it is proteolytically activated, therefore allowing its alkaline phosphatase activity to be a measure of autophagy. If S13 is inhibiting breakdown in the vacuole, we expect that Atg8-PE levels will be normal but there will be a decrease in free GFP and alkaline phosphatase activity relative to the control under autophagic conditions.

\subsubsection{Quantifying ergosterol and its intermediates}

The levels of ergosterol and its intermediates will be measured to determine whether ergosterol biosynthesis is being affected by $\mathrm{S} 13$ treatment. To do this $p d r 1 \Delta p d r 3 \Delta$ cells will be treated with $\mathrm{S} 13$ at varying concentrations for set periods of time and total sterols will be extracted. Sterol extracts will be measured using GC-MS to determine where (if anywhere) in the pathway is being inhibited by $S 13$ (Veen et al., 2003). If $\mathrm{S} 13$ is inhibiting ergosterol biosynthesis at a specific point then it is expected that the relevant intermediate will accumulate in treated cells.

\subsubsection{Determining a target of S13}

The specific target of S13 remains unknown. In order to prove what the target of S13 is the the heterozygous deletion collection will be used. The heterozygous deletion library can be perturbed by chemical stresses to determine proteins that require two copies to resist treatment, i.e., happloinsufficient. This methods has been used to find the target for drugs such as the immunosuppressant rapamycin (Heitman et al., 1991). 
A pdr1 1 pdr3 $\Delta$ query strain will be mated with a library of heterozygous deletion mutants making them sensitive to S13. This library will be pooled and screened against S13 at a $1.5 \mu \mathrm{M}$. DNA will be isolated from the pool and sequenced or run on a microarray to determine strains that are hypersensitive to $\mathrm{S} 13$ implicating them in the mechanism of action of S13 (Smith, Ammar, et al., 2010).

\subsubsection{Translation into mammalian cell lines}

This work in yeast needs to be translated into mammalian cells. S13 will be screened for activity in human cells using cell lines that require autophagy for survival such as those from ras-activated cancers (Guo et al., 2011). If the bioactivity in yeast is conserved, S13 will be anti-cancer via decreased autophagy.

\subsubsection{Further structure activity relationship research}

Based on the chlorine being the unique feature of $\mathrm{S} 13$, chlorination of this class of compound clearly demonstrated the importance of the halogen for potency. Future work in developing the potency would be to vary the position of the chloride atom, further investigate other alkyl chain substituents (S12 is methyl, S13 ethyl), and compare the potency of the same structure but substituted with alternative halogens (e.g., $\mathrm{F}, \mathrm{Br}$ ). 


\section{Chapter 3}

Appendix 


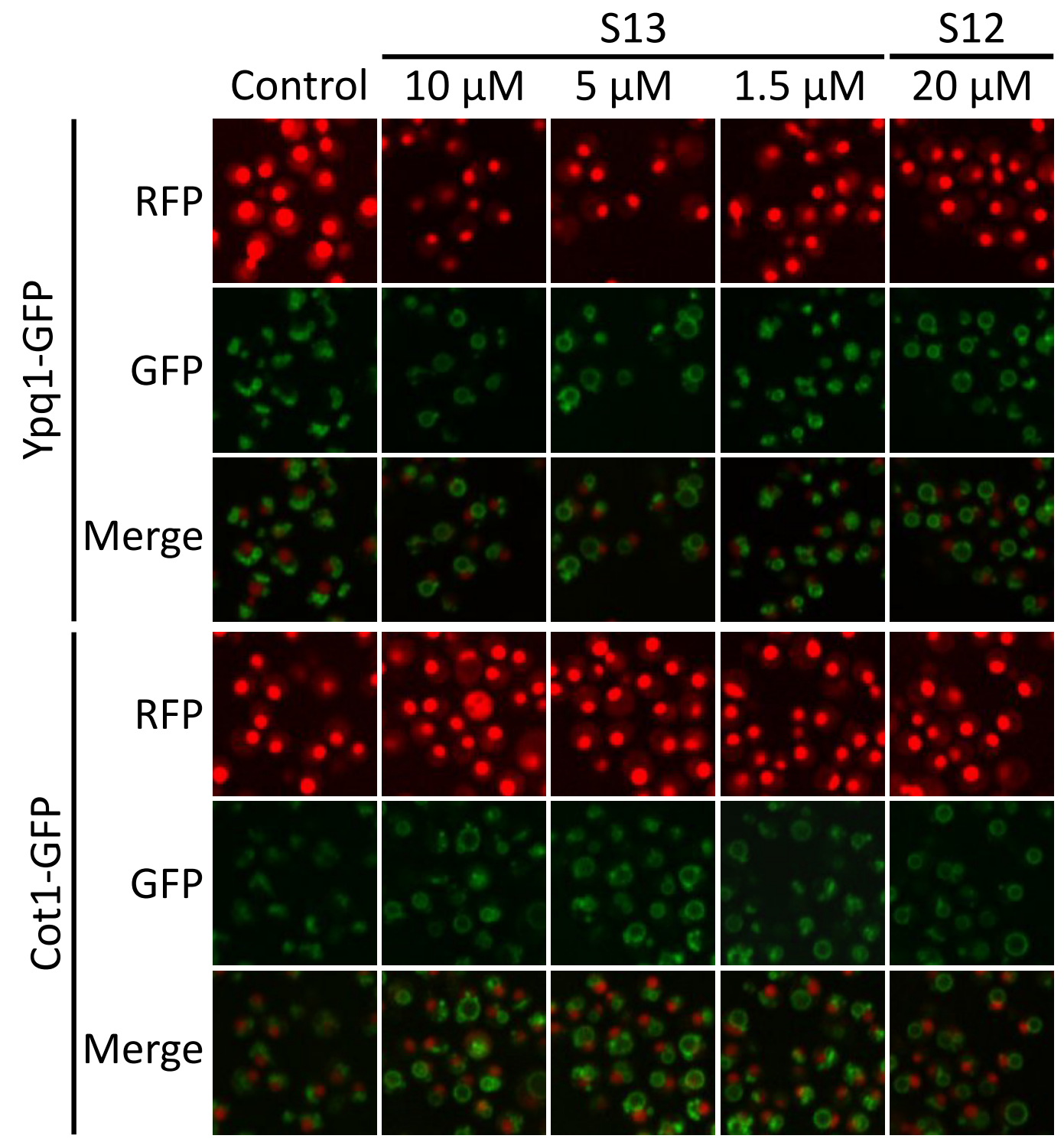

Figure 3.1: RFP and GFP channel for Ypq1-GFP and Cot1-GFP. Ypq1GFP and Cot1-GFP were treated for 6 hours with or without $S 13(10,5,1.5$ $\mu)$ or $\$ 12(20 \mu)$ and visualised using a Perkin Elmer Opera high-throughput confocal microscope. Shown is the RFP and GFP channels separated as well as the merged to visualise the cell outline in regards to the GFP localisation. 


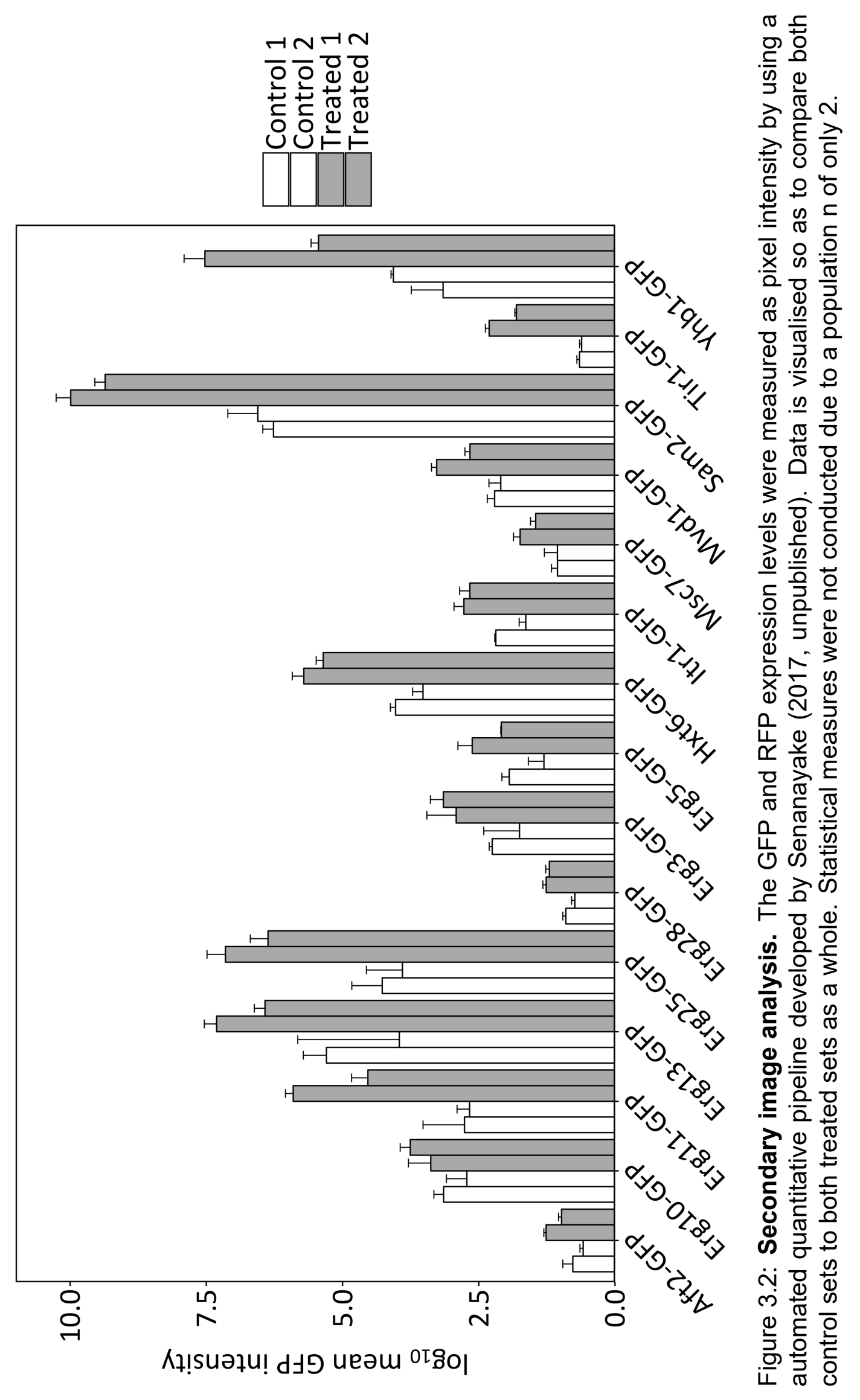




\section{Bibliography}

Adams, R., C. L. Worth, S. Guenther, M. Dunkel, R. Lehmann, and $R$. Preissner (2012). Binding Sites in Membrane Proteins Diversity, Druggability and Prospects. In: European Journal of Cell Biology 91, 326-339.

Alam, A. N., N. H. Alam, T. Ahmed, and D. A. Sack (1990). Randomised Double Blind Trial of Single Dose Doxycycline for Treating Cholera in Adults. In: BMJ 300, 1619-1621.

Ali, R. (2003). Inhibition of Sodium/Proton Exchange by a Rab-GTPaseActivating Protein Regulates Endosomal Traffic in Yeast. In: Journal of Biological Chemistry 279, 4498-4506.

Ashburner, M. et al. (2000). Gene Ontology: Tool for the Unification of Biology. In: Nature Genetics 25, 25-29.

Baars, T. L., S. Petri, C. Peters, and A. Mayer (2007). Role of the V-ATPase in Regulation of the Vacuolar Fission Fusion Equilibrium. In: Molecular Biology of the Cell 18, 3873-3882.

Ballard, T., J. Richards, A. Wolfe, and C. Melander (2008). Synthesis and Antibiofilm Activity of a Second-Generation Reverse-Amide Oroidin Library: A Structure-Activity Relationship Study. In: Chemistry - A European Journal 14, 10745-10761.

Balzi, E., W. Chen, S. Ulaszewski, E. Capieaux, and A. Goffeau (1987). The Multidrug Resistance Gene PDR1 from Saccharomyces Cerevisiae. In: The Journal of Biological Chemistry 262, 16871-16879.

Bauer, R. A., J. M. Wurst, and D. S. Tan (2010). Expanding the Range of 'Druggable' Targets with Natural Product-Based Libraries: An Academic Perspective. In: Current Opinion in Chemical Biology 14, 308-314.

Bayer, M. J., C. Reese, S. Bfffdfffdhler, C. Peters, and A. Mayer (2003). Vacuole Membrane Fusion: $V_{0}$ Functions after Trans-SNARE Pairing and Is Coupled to the $\mathrm{Ca}^{2+}$-Releasing Channel. In: The Journal of Cell Biology 162, 211-222.

Bemis, G. W. and M. A. Murcko (1996). The Properties of Known Drugs. 1. Molecular Frameworks. In: Journal of Medicinal Chemistry 39, 2887-2893.

Bircham, P. W., D. R. Maass, C. A. Roberts, P. Y. Kiew, Y. S. Low, M. Yegambaram, J. Matthews, C. A. Jack, and P. H. Atkinson (2011). Secretory Pathway Genes Assessed by High-Throughput Microscopy and Synthetic Genetic Array Analysis. In: Molecular BioSystems 7, 2589.

Bircham, P. W. (2014). The Use of High-Throughput Microscopy in the Characterisation of Phenotypes Associated with the Unfolded Protein Response in Saccharomyces Cerevisiae.

Botstein, D. and G. R. Fink (2011). Yeast: An Experimental Organism for 21st Century Biology. In: Genetics 189, 695-704. 
Bradley, D. V. and R. J. Cazort (1970 Jan-Feb). Relief of Bladder Spasm by Flavoxate. A Comparative Study. In: The Journal of Clinical Pharmacology and the Journal of New Drugs 10, 65-68.

Breker, M., M. Gymrek, and M. Schuldiner (2013). A Novel Single-Cell Screening Platform Reveals Proteome Plasticity during Yeast Stress Responses. In: The Journal of Cell Biology 200, 839-850.

Brett, C. L., L. Kallay, Z. Hua, R. Green, A. Chyou, Y. Zhang, T. R. Graham, M. Donowitz, and R. Rao (2011). Genome-Wide Analysis Reveals the Vacuolar $\mathrm{pH}$-Stat of Saccharomyces Cerevisiae. In: PLoS ONE 6. Ed. by M. Kaeberlein, e17619.

Cabrera, M., M. Nordmann, A. Perz, D. Schmedt, A. Gerondopoulos, F. Barr, J. Piehler, S. Engelbrecht-Vandr, and C. Ungermann (2014). The Mon1-Ccz1 GEF Activates the Rab7 GTPase Ypt7 via a LonginFold-Rab Interface and Association with PI3P-Positive Membranes. In: Journal of Cell Science 127 (Pt 5), 1043-1051.

Chan, Y.-H. M. and W. F. Marshall (2014). Organelle Size Scaling of the Budding Yeast Vacuole Is Tuned by Membrane Trafficking Rates. In: Biophysical Journal 106, 1986-1996.

Charest, M. G. (2005). A Convergent Enantioselective Route to Structurally Diverse 6-Deoxytetracycline Antibiotics. In: Science 308, 395-398.

Cheng, J.-T. (2000). Review: Drug Therapy in Chinese Traditional Medicine. In: The Journal of Clinical Pharmacology 40, 445-450.

Cheong, H. and D. J. Klionsky (2008). Chapter 1 Biochemical Methods to Monitor Autophagy-Related Processes in Yeast. In: Methods in Enzymology. Vol. 451. Elsevier, 1-26.

Chong, Y. T., M. J. Cox, and B. Andrews (2012). Proteome-Wide Screens in Saccharomyces Cerevisiae Using the Yeast GFP Collection. In: Advances in Systems Biology. Ed. by I. I. Goryanin and A. B. Goryachev. Vol. 736. New York, NY: Springer New York, 169-178.

Chong, Y., J. Koh, H. Friesen, S. Kaluarachchi Duffy, M. Cox, A. Moses, J. Moffat, C. Boone, and B. Andrews (2015). Yeast Proteome Dynamics from Single Cell Imaging and Automated Analysis. In: Cell 161, 1413-1424.

Conibear, E. and T. H. Stevens (1998). Multiple Sorting Pathways between the Late Golgi and the Vacuole in Yeast. In: Biochimica et Biophysica Acta (BBA) - Molecular Cell Research 1404 (1-2), 211-230.

Conklin, D., M. Culbertson, and C. Kung (1994). Interactions between Gene Products Involved in Divalent Cation Transport in Saccharomyces Cerevisiae. In: MGG Molecular \& General Genetics 244.

Coorey, N. V. C., J. H. Matthews, D. S. Bellows, and P. H. Atkinson (2015). Pleiotropic Drug-Resistance Attenuated Genomic Library Improves Elucidation of Drug Mechanisms. In: Mol. BioSyst.

Corcoran, M. L., W. G. Stetler-Stevenson, P. D. Brown, and L. M. Wahl (1992). Interleukin 4 Inhibition of Prostaglandin E2 Synthesis Blocks Interstitial Collagenase and 92-kDa Type IV Collagenase/Gelatinase Production by Human Monocytes. In: The Journal of Biological Chemistry 267, 515-519.

Costanzo, M. et al. (2016). A Global Genetic Interaction Network Maps a Wiring Diagram of Cellular Function. In: Science 353, aaf1420-aaf1420.

Cox, J. S. and P. Walter (1996). A Novel Mechanism for Regulating Activity of a Transcription Factor That Controls the Unfolded Protein Response. In: Cell 87, 391-404. 
De Boer, R. A., A. A. Voors, and D. J. van Veldhuisen (2007). Nebivolol: Third-Generation $\beta$-Blockade. In: Expert Opinion on Pharmacotherapy 8, 1539-1550.

Delaveau, T., A. Delahodde, E. Carvajal, J. Subik, and C. Jacq (1994). PDR3, a New Yeast Regulatory Gene, Is Homologous toPDR1 and Controls the Multidrug Resistance Phenomenon. In: MGG Molecular \& General Genetics 244, 501-511.

DeRisi, J., B. van den Hazel, P. Marc, E. Balzi, P. Brown, C. Jacq, and A. Goffeau (2000). Genome Microarray Analysis of Transcriptional Activation in Multidrug Resistance Yeast Mutants. In: FEBS Letters 470, 156-160.

Dix, D. R., J. T. Bridgham, M. A. Broderius, C. A. Byersdorfer, and D. J. Eide (1994). The FET4 Gene Encodes the Low Affinity Fe(II) Transport Protein of Saccharomyces Cerevisiae. In: The Journal of Biological Chemistry 269, 26092-26099.

Dobzhansky, T. (1946). Genetics of Natural Populations. Xiii. Recombination and Variability in Populations of Drosophila Pseudoobscura. In: Genetics 31, 269-290.

Duarte, C. D., E. J. Barreiro, and C. A. M. Fraga (2007). Privileged Structures: A Useful Concept for the Rational Design of New Lead Drug Candidates. In: Mini Reviews in Medicinal Chemistry 7, 1108-1119.

Elorza, M. V., H. Rico, and R. Sentandreu (1983). Calcofluor White Alters the Assembly of Chitin Fibrils in Saccharomyces Cerevisiae and Candida Albicans Cells. In: Microbiology 129, 1577-1582.

Emter, R., A. Heese-Peck, and A. Kralli (2002). ERG6 and PDR5 Regulate Small Lipophilic Drug Accumulation in Yeast Cells via Distinct Mechanisms. In: FEBS Letters 521 (1-3), 57-61.

Estrada, A. F., G. Muruganandam, C. Prescianotto-Baschong, and A. Spang (2015). The ArfGAP2/3 Glo3 and Ergosterol Collaborate in Transport of a Subset of Cargoes. In: Biology Open 4, 792-802.

Eugster, A. (2004). Ent5p Is Required with Ent3p and Vps27p for Ubiquitin-Dependent Protein Sorting into the Multivesicular Body. In: Molecular Biology of the Cell 15, 3031-3041.

Evans, B. E., K. E. Rittle, M. G. Bock, R. M. DiPardo, R. M. Freidinger, W. L. Whitter, G. F. Lundell, D. F. Veber, and P. S. Anderson (1988). Methods for Drug Discovery: Development of Potent, Selective, Orally Effective Cholecystokinin Antagonists. In: Journal of Medicinal Chemistry 31, 2235-2246.

Fei, W., G. Alfaro, B.-P. Muthusamy, Z. Klaassen, T. R. Graham, H. Yang, and C. T. Beh (2008). Genome-Wide Analysis of Sterol-Lipid Storage and Trafficking in Saccharomyces Cerevisiae. In: Eukaryotic Cell 7, 401-414.

Feng, B. Y. and B. K. Shoichet (2006). A Detergent-Based Assay for the Detection of Promiscuous Inhibitors. In: Nature Protocols 1, 550-553.

Ferguson, J., Z. De Los Santos, N. Devi, E. Van Meir, S. Zingales, and B. Wang (2017). Examining the Structure-Activity Relationship of Benzopyran-Based Inhibitors of the Hypoxia Inducible Factor-1 Pathway. In: Bioorganic \& Medicinal Chemistry Letters 27, 1731-1736.

Fleming, A. (1929). On the Antibacterial Action of Cultures of a Penicillium, with Special Reference to Their Use in the Isolation of B. Influenz. In: British journal of experimental pathology 10, 226-236. 
Gasch, A. P., P. T. Spellman, C. M. Kao, O. Carmel-Harel, M. B. Eisen, G. Storz, D. Botstein, and P. O. Brown (2000). Genomic Expression Programs in the Response of Yeast Cells to Environmental Changes. In: Molecular Biology of the Cell 11, 4241-4257.

Gavin, A.-C. et al. (2006). Proteome Survey Reveals Modularity of the Yeast Cell Machinery. In: Nature 440, 631-636.

Ghaemmaghami, S., W.-K. Huh, K. Bower, R. W. Howson, A. Belle, N. Dephoure, E. K. O'Shea, and J. S. Weissman (2003). Global Analysis of Protein Expression in Yeast. In: Nature 425, 737-741.

Giaever, G. and C. Nislow (2014). The Yeast Deletion Collection: A Decade of Functional Genomics. In: Genetics 197, 451-465.

Giaever, G., A. M. Chu, et al. (2002). Functional Profiling of the Saccharomyces Cerevisiae Genome. In: Nature 418, 387-391.

Gietz, R. D. and R. H. Schiestl (2007). Quick and Easy Yeast Transformation Using the LiAc/SS Carrier DNA/PEG Method. In: Nature Protocols 2, 35-37.

Goffeau, A. et al. (1996). Life with 6000 Genes. In: Science (New York, N.Y.) 274, 546, 563-567.

Guan, X. L. et al. (2009). Functional Interactions between Sphingolipids and Sterols in Biological Membranes Regulating Cell Physiology. In: Molecular Biology of the Cell 20, 2083-2095.

Guo, J. Y. et al. (2011). Activated Ras Requires Autophagy to Maintain Oxidative Metabolism and Tumorigenesis. In: Genes \& Development 25, 460-470.

Handfield, L.-F., Y. T. Chong, J. Simmons, B. J. Andrews, and A. M. Moses (2013). Unsupervised Clustering of Subcellular Protein Expression Patterns in High-Throughput Microscopy Images Reveals Protein Complexes and Functional Relationships between Proteins. In: PLoS Computational Biology 9. Ed. by R. F. Murphy, e1003085.

Hankins, H. M., Y. Y. Sere, N. S. Diab, A. K. Menon, and T. R. Graham (2015). Phosphatidylserine Translocation at the Yeast Trans-Golgi Network Regulates Protein Sorting into Exocytic Vesicles. In: Molecular Biology of the Cell 26, 4674-4685.

Hardegger, L. A. et al. (2011). Halogen Bonding at the Active Sites of Human Cathepsin L and MEK1 Kinase: Efficient Interactions in Different Environments. In:

Harrison, R. K. (2016). Phase II and Phase III Failures: 2013-2015. In: Nature Reviews Drug Discovery 15, 817-818.

Harvey, A. L., R. Edrada-Ebel, and R. J. Quinn (2015). The Re-Emergence of Natural Products for Drug Discovery in the Genomics Era. In: Nature Reviews Drug Discovery 14, 111-129.

Hata, M. and G. R. Marshall (2006). Do Benzodiazepines Mimic ReverseTurn Structures? In: Journal of Computer-Aided Molecular Design 20, 321-331.

Hecht, K. A., A. F. O'Donnell, and J. L. Brodsky (2014). The Proteolytic Landscape of the Yeast Vacuole. In: Cellular Logistics 4, e28023.

Heese-Peck, A. (2002). Multiple Functions of Sterols in Yeast Endocytosis. In: Molecular Biology of the Cell 13, 2664-2680.

Heim, R., A. B. Cubitt, and R. Y. Tsien (1995). Improved Green Fluorescence. In: Nature 373, 663-664.

Heinicke, S., M. S. Livstone, C. Lu, R. Oughtred, F. Kang, S. V. Angiuoli, O. White, D. Botstein, and K. Dolinski (2007). The Princeton Protein 
Orthology Database (P-POD): A Comparative Genomics Analysis Tool for Biologists. In: PLoS ONE 2. Ed. by B. Snel, e766.

Heitman, J., N. R. Movva, and M. N. Hall (1991). Targets for Cell Cycle Arrest by the Immunosuppressant Rapamycin in Yeast. In: Science; Washington 253, 905.

Henkel, T., R. M. Brunne, H. Mller, and F. Reichel (1999). Statistical Investigation into the Structural Complementarity of Natural Products and Synthetic Compounds. In: Angewandte Chemie International Edition 38, 643-647.

Hert, J., J. J. Irwin, C. Laggner, M. J. Keiser, and B. K. Shoichet (2009). Quantifying Biogenic Bias in Screening Libraries. In: Nature Chemical Biology 5, 479-483.

Hill, J., K. A. Donald, D. E. Griffiths, and G. Donald (1991). DMSO-Enhanced Whole Cell Yeast Transformation. In: Nucleic Acids Research 19, 5791.

Hillenmeyer, M. E. et al. (2008). The Chemical Genomic Portrait of Yeast: Uncovering a Phenotype for All Genes. In: Science 320, 362-365.

Hirsh, J., J. E. Dalen, D. Deykin, and L. Poller (1992). Oral Anticoagulants. Mechanism of Action, Clinical Effectiveness, and Optimal Therapeutic Range. In: Chest 102 (4 Suppl), 312S-326S.

Ho, C. Y., C. H. Choy, C. A. Wattson, D. E. Johnson, and R. J. Botelho (2015). The Fab1/PIKfyve Phosphoinositide Phosphate Kinase Is Not Necessary to Maintain the $\mathrm{pH}$ of Lysosomes and of the Yeast Vacuole. In: Journal of Biological Chemistry 290, 9919-9928.

Hu, W., Z. Guo, F. Chu, A. Bai, X. Yi, G. Cheng, and J. Li (2003). Synthesis and Biological Evaluation of Substituted 2-Sulfonyl-Phenyl-3-Phenyl-Indoles: A New Series of Selective COX-2 Inhibitors. In: Bioorganic \& Medicinal Chemistry 11, 1153-1160.

Hughes, T. R. (2002). Yeast and Drug Discovery. In: Functional \& Integrative Genomics 2 (4-5), 199-211.

Huh, W.-K., J. V. Falvo, L. C. Gerke, A. S. Carroll, R. W. Howson, J. S. Weissman, and E. K. O'Shea (2003). Global Analysis of Protein Localization in Budding Yeast. In: Nature 425, 686-691.

Iltzsch, M. H., S. S. Uber, K. O. Tankersley, and M. H. el Kouni (1995). Structure-Activity Relationship for the Binding of Nucleoside Ligands to Adenosine Kinase from Toxoplasma Gondii. In: Biochemical Pharmacology 49, 1501-1512.

Isnard, A. D., D. Thomas, and Y. Surdin-Kerjan (1996). The Study of Methionine Uptake in Saccharomyces Cerevisiae Reveals a New Family of Amino Acid Permeases. In: Journal of Molecular Biology 262, 473-484.

Jenner, E. (1801). An Inquiry Into the Causes and Effects of the Variolae Vaccinae: A Disease Discovered in Some of the Western Counties of England, Particularly Gloucestershire, and Known by the Name of the Cow Pox. Google-Books-ID: HJEAAAAcAAJ. author. 212.

Jzgou, A. et al. (2012). Heptahelical Protein PQLC2 Is a Lysosomal Cationic Amino Acid Exporter Underlying the Action of Cysteamine in Cystinosis Therapy. In: Proceedings of the National Academy of Sciences of the United States of America 109, E3434-3443.

Jorgensen, W. L. and P. Schyman (2012). Treatment of Halogen Bonding in the OPLS-AA Force Field: Application to Potent Anti-HIV Agents. In: Journal of Chemical Theory and Computation 8, 3895-3901. 
Kabeya, Y. (2000). LC3, a Mammalian Homologue of Yeast Apg8p, Is Localized in Autophagosome Membranes after Processing. In: The EMBO Journal 19, 5720-5728.

Kamada, Y., T. Funakoshi, T. Shintani, K. Nagano, M. Ohsumi, and Y. Ohsumi (2000). Tor-Mediated Induction of Autophagy via an Apg1 Protein Kinase Complex. In: The Journal of Cell Biology 150, 1507-1513.

Khurana, V., D. F. Tardiff, C. Y. Chung, and S. Lindquist (2015). Toward Stem Cell-Based Phenotypic Screens for Neurodegenerative Diseases. In: Nature Reviews. Neurology 11, 339-350.

Klionsky, D. J. et al. (2016). Guidelines for the Use and Interpretation of Assays for Monitoring Autophagy (3rd Edition). In: Autophagy 12, 1-222.

Ko, S. K., H. J. Jang, E. Kim, and S. B. Park (2006). Concise and DiversityOriented Synthesis of Novel Scaffolds Embedded with Privileged Benzopyran Motif. In: Chemical Communications, 2962.

kucharczyk, R., S. Dupre, S. Avaro, R. Haguenauer-Tsapis, P. P. Sonimski, and J. Rytka (2000). The Novel Protein Ccz1p Required for Vacuolar Assembly in Saccharomyces Cerevisiae Functions in the Same Transport Pathway as Ypt7p. In: Journal of Cell Science 113 Pt 23, 4301-4311.

Kumar, A., S. Srivastava, G. Gupta, V. Chaturvedi, S. Sinha, and R. Srivastava (2011). Natural Product Inspired Diversity Oriented Synthesis of Tetrahydroquinoline Scaffolds as Antitubercular Agent. In: ACS Combinatorial Science 13, 65-71.

Landgraf, D., B. Okumus, P. Chien, T. A. Baker, and J. Paulsson (2012). Segregation of Molecules at Cell Division Reveals Native Protein Localization. In: Nature Methods 9, 480-482.

Lee, M.-L. and G. Schneider (2001). Scaffold Architecture and Pharmacophoric Properties of Natural Products and Trade Drugs: Application in the Design of Natural Product-Based Combinatorial Libraries. In: Journal of Combinatorial Chemistry 3, 284-289.

Ligon, B. (2004). Penicillin: Its Discovery and Early Development. In: Seminars in Pediatric Infectious Diseases 15, 52-57.

Lindstrom, D. L. and D. E. Gottschling (2009). The Mother Enrichment Program: A Genetic System for Facile Replicative Life Span Analysis in Saccharomyces Cerevisiae. In: Genetics 183, 413-422, 1SI-13SI.

Lipinski, C. A., F. Lombardo, B. W. Dominy, and P. J. Feeney (2001). Experimental and Computational Approaches to Estimate Solubility and Permeability in Drug Discovery and Development Settings. In: Advanced Drug Delivery Reviews 46 (1-3), 3-26.

Lozupone, F. et al. (2015). TM9SF4 Is a Novel V-ATPase-Interacting Protein That Modulates Tumor pH Alterations Associated with Drug Resistance and Invasiveness of Colon Cancer Cells. In: Oncogene 34, 5163-5174.

Lynch-Day, M. A. and D. J. Klionsky (2010). The Cvt Pathway as a Model for Selective Autophagy. In: FEBS Letters 584, 1359-1366.

Mamnun, Y. M., R. Pandjaitan, Y. Mah, A. Delahodde, and K. Kuchler (2002). The Yeast Zinc Finger Regulators Pdr1p and Pdr3p Control Pleiotropic Drug Resistance (PDR) as Homo- and Heterodimers in Vivo: Regulation of Yeast Pleiotropic Drug Resistance (PDR). In: Molecular Microbiology 46, 1429-1440. 
Martin, L., M. Hutchens, and C. Hawkins (2017). Trial Watch: Clinical Trial Cycle Times Continue to Increase despite Industry Efforts. In: Nature Reviews Drug Discovery 16, 157-157.

Marton, M. J. et al. (1998). Drug Target Validation and Identification of Secondary Drug Target Effects Using DNA Microarrays. In: Nature Medicine 4, 1293-1301.

Mattiazzi Usaj, M., E. B. Styles, A. J. Verster, H. Friesen, C. Boone, and B. J. Andrews (2016). High-Content Screening for Quantitative Cell Biology. In: Trends in Cell Biology 26, 598-611.

Mauvezin, C., P. Nagy, G. Juhsz, and T. P. Neufeld (2015). Autophagosome-lysosome Fusion is Independent of V-ATPase-Mediated Acidification. In: Nature Communications 6, 7007.

Mayor, S. (2011). Tree That Provides Paclitaxel Is Put on List of Endangered Species. In: BMJ 343 (nov15 3), d7411-d7411.

McAfee, Q. et al. (2012). Autophagy Inhibitor Lys05 Has Single-Agent Antitumor Activity and Reproduces the Phenotype of a Genetic Autophagy Deficiency. In: Proceedings of the National Academy of Sciences 109, 8253-8258.

McIntosh, M., L. J. Cruz, M. W. Hunkapiller, W. R. Gray, and B. M. Olivera (1982). Isolation and Structure of a Peptide Toxin from the Marine Snail Conus Magus. In: Archives of Biochemistry and Biophysics 218, 329-334.

Meiling-Wesse, K., H. Barth, C. Voss, G. Barmark, E. Murn, H. Ronne, and M. Thumm (2002). Yeast Mon1p/Aut12p Functions in Vacuolar Fusion of Autophagosomes and Cvt-Vesicles. In: FEBS Letters 530 (1-3), 174-180.

Milln-Zambrano, G., A. Rodrguez-Gil, X. Peate, L. de Miguel-Jimnez, M. Morillo-Huesca, N. Krogan, and S. Chvez (2013). The Prefoldin Complex Regulates Chromatin Dynamics during Transcription Elongation. In: PLoS Genetics 9. Ed. by C. S. Pikaard, e1003776.

Mullard, A. (2016). R\\&D Returns Continue to Fall. In: Nature Reviews Drug Discovery 16, 9-9.

Muller, M. et al. (2015). The Coordinated Action of the MVB Pathway and Autophagy Ensures Cell Survival during Starvation. In: eLife 4.

Nair, U., A. Jotwani, et al. (2011). SNARE Proteins Are Required for Macroautophagy. In: Cell 146, 290-302.

Nair, U., M. Thumm, D. J. Klionsky, and R. Krick (2011). GFP-Atg8 Protease Protection as a Tool to Monitor Autophagosome Biogenesis. In: Autophagy 7, 1546-1550.

Nelson, H. and N. Nelson (1990). Disruption of Genes Encoding Subunits of Yeast Vacuolar $\mathrm{H}(+)$-ATPase Causes Conditional Lethality. In: Proceedings of the National Academy of Sciences of the United States of America 87, 3503-3507.

Nelson, M. L. and S. B. Levy (2011). The History of the Tetracyclines: The History of the Tetracyclines. In: Annals of the New York Academy of Sciences 1241, 17-32.

Nelson, N., N. Perzov, A. Cohen, K. Hagai, V. Padler, and H. Nelson (2000). The Cellular Biology of Proton-Motive Force Generation by V-ATPases. In: The Journal of Experimental Biology 203 (Pt 1), 89-95.

Newman, D. J. and G. M. Cragg (2016). Natural Products as Sources of New Drugs from 1981 to 2014. In: Journal of Natural Products 79, 629-661. 
Newman, J. R. S., S. Ghaemmaghami, J. Ihmels, D. K. Breslow, M. Noble, J. L. DeRisi, and J. S. Weissman (2006). Single-Cell Proteomic Analysis of S. Cerevisiae Reveals the Architecture of Biological Noise. In: Nature 441, 840-846.

Ni, H.-M., A. Bockus, A. L. Wozniak, K. Jones, S. Weinman, X.-M. Yin, and W.-X. Ding (2011). Dissecting the Dynamic Turnover of GFP-LC3 in the Autolysosome. In: Autophagy 7, 188-204.

Nicolaou, K. C., A. J. Roecker, S. Barluenga, J. A. Pfefferkorn, and G.-Q. Cao (2001). Discovery of Novel Antibacterial Agents Active Against Methicillin-ResistantStaphylococcus Aureus from Combinatorial Benzopyran Libraries. In: ChemBioChem 2, 460-465.

Nielsen, J. (2009). Systems Biology of Lipid Metabolism: From Yeast to Human. In: FEBS Letters 583, 3905-3913.

Nijman, S. M. (2011). Synthetic Lethality: General Principles, Utility and Detection Using Genetic Screens in Human Cells. In: FEBS Letters $585,1-6$.

Nikawa, J. (1996). Saccharomyces Cerevisiae IRE2/HAC1 Is Involved in IRE1-Mediated KAR2 Expression. In: Nucleic Acids Research 24, 4222-4226.

Nilsen, A., A. Halsos, A. Johansen, E. Hansen, E. Torud, D. Moseng, G. Anestad, and G. Storvold (1992). A Double Blind Study of Single Dose Azithromycin and Doxycycline in the Treatment of Chlamydial Urethritis in Males. In: Sexually Transmitted Infections 68, 325-327.

Noda, T., A. Matsuura, Y. Wada, and Y. Ohsumi (1995). Novel System for Monitoring Autophagy in the Yeast Saccharomyces Cerevisiae. In: Biochemical and Biophysical Research Communications 210, 126-132.

Noda, T. and D. J. Klionsky (2008). Chapter 3 The Quantitative Pho8 860 Assay of Nonspecific Autophagy. In: Methods in Enzymology. Vol. 451. Elsevier, 33-42.

Novick, P. and R. Schekman (1979). Secretion and Cell-Surface Growth Are Blocked in a Temperature-Sensitive Mutant of Saccharomyces Cerevisiae. In: Proceedings of the National Academy of Sciences of the United States of America 76, 1858-1862.

Novick, P., C. Field, and R. Schekman (1980). Identification of 23 Complementation Groups Required for Post-Translational Events in the Yeast Secretory Pathway. In: Cell 21, 205-215.

Ohsumi, Y. (2017). The Nobel Prize in Physiology or Medicine 2016. URL: http : / / www . nobelprize . org / nobel _ prizes / medicine / laureates/2016/ (visited on 04/23/2017).

Orsi, A., M. Razi, H. C. Dooley, D. Robinson, A. E. Weston, L. M. Collinson, and S. A. Tooze (2012). Dynamic and Transient Interactions of Atg9 with Autophagosomes, but Not Membrane Integration, Are Required for Autophagy. In: Molecular Biology of the Cell 23, 1860-1873.

Overington, J. P., B. Al-Lazikani, and A. L. Hopkins (2006). How Many Drug Targets Are There? In: Nature Reviews Drug Discovery 5, 993-996.

Parsons, A. B., R. L. Brost, et al. (2004). Integration of Chemical-Genetic and Genetic Interaction Data Links Bioactive Compounds to Cellular Target Pathways. In: Nature Biotechnology 22, 62-69.

Parsons, A. B., A. Lopez, et al. (2006). Exploring the Mode-of-Action of Bioactive Compounds by Chemical-Genetic Profiling in Yeast. In: Cell 126, 611-625. 
Payne, D. J., M. N. Gwynn, D. J. Holmes, and D. L. Pompliano (2007). Drugs for Bad Bugs: Confronting the Challenges of Antibacterial Discovery. In: Nature Reviews Drug Discovery 6, 29-40.

Pentland, A. P., S. D. Shapiro, and H. G. Welgus (1995). Agonist-Induced Expression of Tissue Inhibitor of Metalloproteinases and Metalloproteinases by Human Macrophages is Regulated by Endogenous Prostaglandin E2 Synthesis. In: The Journal of Investigative Dermatology 104, 52-57.

Perkins, R., H. Fang, W. Tong, and W. J. Welsh (2003). QUANTITATIVE STRUCTURE-ACTIVITY RELATIONSHIP METHODS: PERSPECTIVES ON DRUG DISCOVERY AND TOXICOLOGY. In: Environmental Toxicology and Chemistry 22, 1666.

Perzov, N., V. Padler-Karavani, H. Nelson, and N. Nelson (2002). Characterization of Yeast V-ATPase Mutants Lacking Vph1p or Stv1p and the Effect on Endocytosis. In: The Journal of Experimental Biology 205 (Pt 9), 1209-1219.

Petrovska, B. (2012). Historical Review of Medicinal Plants' Usage. In: Pharmacognosy Reviews 6, 1.

Pierce, S. E., E. L. Fung, D. F. Jaramillo, A. M. Chu, R. W. Davis, C. Nislow, and G. Giaever (2006). A Unique and Universal Molecular Barcode Array. In: Nature Methods 3, 601-603.

Pineau, L., J. Colas, S. Dupont, L. Beney, P. Fleurat-Lessard, J.-M. Berjeaud, T. Bergs, and T. Ferreira (2009). Lipid-Induced ER Stress: Synergistic Effects of Sterols and Saturated Fatty Acids. In: Traffic 10, 673-690.

Raymond, C. K., I. Howald-Stevenson, C. A. Vater, and T. H. Stevens (1992). Morphological Classification of the Yeast Vacuolar Protein Sorting Mutants: Evidence for a Prevacuolar Compartment in Class $\mathrm{E}$ Vps Mutants. In: Molecular Biology of the Cell 3, 1389-1402.

Reggiori, F. (2004). Early Stages of the Secretory Pathway, but Not Endosomes, Are Required for Cvt Vesicle and Autophagosome Assembly in Saccharomyces Cerevisiae. In: Molecular Biology of the Cell 15, 2189-2204.

Reifenberger, E., K. Freidel, and M. Ciriacy (1995). Identification of Novel HXT Genes in Saccharomyces Cerevisiae Reveals the Impact of Individual Hexose Transporters on Qlycolytic Flux. In: Molecular Microbiology 16, 157-167.

Rothman, J. E., R. W. Schekman, and T. C. Sudhof (2017). The Nobel Prize in Physiology or Medicine 2013. URL: http : / / www . nobelprize .org / nobel _ prizes / medicine / laureates / 2013/ (visited on 04/23/2017).

Sato, T. K., T. Darsow, and S. D. Emr (1998). Vam7p, a SNAP-25-like Molecule, and Vam3p, a Syntaxin Homolog, Function Together in Yeast Vacuolar Protein Trafficking. In: Molecular and Cellular Biology 18, 5308-5319.

Schuller, C., Y. M. Mamnun, H. Wolfger, N. Rockwell, J. Thorner, and K. Kuchler (2007). Membrane-Active Compounds Activate the Transcription Factors Pdr1 and Pdr3 Connecting Pleiotropic Drug Resistance and Membrane Lipid Homeostasis in Saccharomyces Cerevisiae. In: Molecular Biology of the Cell 18, 4932-4944.

Scott, S. V. et al. (2000). Apg13p and Vac8p Are Part of a Complex of Phosphoproteins That Are Required for Cytoplasm to Vacuole Targeting. In: Journal of Biological Chemistry 275, 25840-25849. 
Shintani, T. and D. J. Klionsky (2004). Cargo Proteins Facilitate the Formation of Transport Vesicles in the Cytoplasm to Vacuole Targeting Pathway. In: Journal of Biological Chemistry 279, 29889-29894.

Sidrauski, C. and P. Walter (1997). The Transmembrane Kinase Ire1p Is a Site-Specific Endonuclease That Initiates mRNA Splicing in the Unfolded Protein Response. In: Cell 90, 1031-1039.

Simelane, S. B., H. H. Kinfe, A. Muller, and D. B. G. Williams (2014). Aluminum Triflate Catalyzed Tandem Reactions of D -Galactal: Toward Chiral Benzopyrans, Chromenes, and Chromans. In: Organic Letters 16, 4543-4545.

Simon, J. A. and A. Bedalov (2004). Opinion: Yeast as a Model System for Anticancer Drug Discovery. In: Nature Reviews Cancer 4, 481-492.

Singleton, C. K. (1997). Identification and Characterization of the Thiamine Transporter Gene of Saccharomyces Cerevisiae. In: Gene 199 (12), 111-121.

Skidmore, R., R. Kovach, C. Walker, J. Thomas, M. Bradshaw, J. Leyden, C. Powala, and R. Ashley (2003). Effects of Subantimicrobial-Dose Doxycycline in the Treatment of Moderate Acne. In: Archives of Dermatology 139.

Slobodkin, M. R. and Z. Elazar (2013). The Atg8 Family: Multifunctional Ubiquitin-like Key Regulators of Autophagy. In: Essays In Biochemistry 55, 51-64.

Smith, A. M., L. E. Heisler, J. Mellor, F. Kaper, M. J. Thompson, M. Chee, F. P. Roth, G. Giaever, and C. Nislow (2009). Quantitative Phenotyping via Deep Barcode Sequencing. In: Genome Research 19, 1836-1842.

Smith, A. M., R. Ammar, C. Nislow, and G. Giaever (2010). A Survey of Yeast Genomic Assays for Drug and Target Discovery. In: Pharmacology \& Therapeutics 127, 156-164.

Song, H., M. Lavoie, X. Fan, H. Tan, G. Liu, P. Xu, Z. Fu, H. W. Paerl, and H. Qian (2017). Allelopathic Interactions of Linoleic Acid and Nitric Oxide Increase the Competitive Ability of Microcystis Aeruginosa. In: The ISME Journal.

Sopko, R. et al. (2006). Mapping Pathways and Phenotypes by Systematic Gene Overexpression. In: Molecular Cell 21, 319-330.

Staats, H. F., S. M. Kirwan, H. W. Choi, C. P. Shelburne, S. N. Abraham, G. Y. C. Leung, and D. Y.-K. Chen (2013). A Mast Cell Degranulation Screening Assay for the Identification of Novel Mast Cell Activating Agents. In: Med. Chem. Commun. 4, 88-94.

Stephens, C. R., J. J. Beereboom, H. H. Rennhard, P. N. Gordon, K. Murai, R. K. Blackwood, and M. S. von Wittenau (1963). 6-Deoxytetracyclines. IV. 1,2 Preparation, C-6 Stereochemistry, and Reactions. In: Journal of the American Chemical Society 85, 2643-2652.

Stringer, D. K. and R. C. Piper (2011). A Single Ubiquitin Is Sufficient for Cargo Protein Entry into MVBs in the Absence of ESCRT Ubiquitination. In: The Journal of Cell Biology 192, 229-242.

Takenaka, T. (2001). Classical vs Reverse Pharmacology in Drug Discovery. In: BJU international 88 Suppl 2, 7-10, discussion 49-50.

Tan, C. et al. (2005). Z. In: Cancer Research 65, 605-612.

Teis, D., S. Saksena, and S. D. Emr (2008). Ordered Assembly of the ESCRT-III Complex on Endosomes Is Required to Sequester 
Cargo during MVB Formation. In: Developmental Cell 15, 578-589.

Tkach, J. M. et al. (2012). Dissecting DNA Damage Response Pathways by Analysing Protein Localization and Abundance Changes during DNA Replication Stress. In: Nature Cell Biology 14, 966-976.

Tong, A. H. Y. (2004). Global Mapping of the Yeast Genetic Interaction Network. In: Science 303, 808-813.

Tong, A. H. Y. and C. Boone (2006). Synthetic Genetic Array Analysis in Saccharomyces Cerevisiae. In: Methods in Molecular Biology (Clifton, N.J.) 313, 171-192.

Tong, A. H. et al. (2001). Systematic Genetic Analysis with Ordered Arrays of Yeast Deletion Mutants. In: Science (New York, N.Y.) 294, 2364-2368.

Tsay, Y. H. and G. W. Robinson (1991). Cloning and Characterization of ERG8, an Essential Gene of Saccharomyces Cerevisiae That Encodes Phosphomevalonate Kinase. In: Molecular and Cellular Biology 11, 620-631.

Uetz, P. et al. (2000). A Comprehensive Analysis of Protein-Protein Interactions in Saccharomyces Cerevisiae. In: Nature 403, 623-627.

Umebayashi, K. and A. Nakano (2003). Ergosterol Is Required for Targeting of Tryptophan Permease to the Yeast Plasma Membrane. In: The Journal of Cell Biology 161, 1117-1131.

Veen, M., U. Stahl, and C. Lang (2003). Combined Overexpression of Genes of the Ergosterol Biosynthetic Pathway Leads to Accumulation of Sterols In. In: FEMS Yeast Research 4, 87-95.

Vezina, C., A. Kudelski, and S. N. Sehgal (1975). Rapamycin (AY-22,989), a New Antifungal Antibiotic. I. Taxonomy of the Producing Streptomycete and Isolation of the Active Principle. In: The Journal of Antibiotics 28, 721-726.

Vida, T. A. and S. D. Emr (1995). A New Vital Stain for Visualizing Vacuolar Membrane Dynamics and Endocytosis in Yeast. In: The Journal of Cell Biology 128, 779-792.

Von Schwarzenberg, K., T. Lajtos, L. Simon, R. Mller, G. Vereb, and A. M. Vollmar (2014). V-ATPase Inhibition Overcomes Trastuzumab Resistance in Breast Cancer. In: Molecular Oncology 8, 9-19.

Wagih, O. and L. Parts (2014). Gitter: A Robust and Accurate Method for Quantification of Colony Sizes From Plate Images. In: G3\&amp;\#58; Genes|Genomes|Genetics 4, 547-552.

Wang, C.-W., P. E. Stromhaug, E. J. Kauffman, L. S. Weisman, and D. J. Klionsky (2003). Yeast Homotypic Vacuole Fusion Requires the Ccz1-Mon1 Complex during the Tethering/Docking Stage. In: The Journal of Cell Biology 163, 973-985.

Wani, M. C., H. L. Taylor, M. E. Wall, P. Coggon, and A. T. McPhail (1971). Plant Antitumor Agents. VI. The Isolation and Structure of Taxol, a Novel Antileukemic and Antitumor Agent from Taxus Brevifolia. In: Journal of the American Chemical Society 93, 2325-2327.

Warde-Farley, D. et al. (2010). The GeneMANIA Prediction Server: Biological Network Integration for Gene Prioritization and Predicting Gene Function. In: Nucleic Acids Research 38 (suppl_2), W214-W220.

Watanabe, $\overline{\mathrm{T}}$., S. Furukawa, K. Kitamoto, A. Takatsuki, R. Hirata, H. Ogihara, and M. Yamasaki (2005). Vacuolar H+-ATPase and Plasma Membrane $\mathrm{H}+-$ ATPase Contribute to the Tolerance against 
High-Pressure Carbon Dioxide Treatment in Saccharomyces Cerevisiae. In: International Journal of Food Microbiology 105, 131-137.

Welsch, M. E., S. A. Snyder, and B. R. Stockwell (2010). Privileged Scaffolds for Library Design and Drug Discovery. In: Current Opinion in Chemical Biology 14, 347-361.

White, E. (2015). The Role for Autophagy in Cancer. In: Journal of Clinical Investigation 125, 42-46.

Wilcken, R., X. Liu, M. O. Zimmermann, T. J. Rutherford, A. R. Fersht, A. C. Joerger, and F. M. Boeckler (2012). Halogen-Enriched Fragment Libraries as Leads for Drug Rescue of Mutant P53. In: Journal of the American Chemical Society 134, 6810-6818.

Winzeler, E. A. (1999). Functional Characterization of the S. Cerevisiae Genome by Gene Deletion and Parallel Analysis. In: Science 285, 901-906.

World Preview 2016, Outlook to 2022. URL: http: //info . evaluategroup. com/rs/607-YGS-364/images/wp16.pdf.

Xie, Z. and D. J. Klionsky (2007). Autophagosome Formation: Core Machinery and Adaptations. In: Nature Cell Biology 9, 1102-1109.

Yamamoto, A., Y. Tagawa, T. Yoshimori, Y. Moriyama, R. Masaki, and Y. Tashiro (1998). Bafilomycin A1 Prevents Maturation of Autophagic Vacuoles by Inhibiting Fusion between Autophagosomes and Lysosomes in Rat Hepatoma Cell Line, H-4-II-E Cells. In: Cell Structure and Function 23, 33-42.

Yorimitsu, T., U. Nair, Z. Yang, and D. J. Klionsky (2006). Endoplasmic Reticulum Stress Triggers Autophagy. In: Journal of Biological Chemistry 281, 30299-30304.

Yoshida, Y. and Y. Aoyama (1987). Interaction of Azole Antifungal Agents with Cytochrome P-45014DM Purified from Saccharomyces Cerevisiae Microsomes. In: Biochemical Pharmacology 36, 229-235.

Yoshimori, T., A. Yamamoto, Y. Moriyama, M. Futai, and Y. Tashiro (1991). Bafilomycin A1, a Specific Inhibitor of Vacuolar-Type $\mathrm{H}(+)$-ATPase, Inhibits Acidification and Protein Degradation in Lysosomes of Cultured Cells. In: The Journal of Biological Chemistry 266, 17707-17712.

Yu, L. et al. (2007). Transcriptional Profiles of the Response to Ketoconazole and Amphotericin B in Trichophyton Rubrum. In: Antimicrobial Agents and Chemotherapy 51, 144-153.

Yuan, N. et al. (2015). Bafilomycin A1 Targets Both Autophagy and Apoptosis Pathways in Pediatric B-Cell Acute Lymphoblastic Leukemia. In: Haematologica 100, 345-356.

Zhang, Y.-Q., S. Gamarra, G. Garcia-Effron, S. Park, D. S. Perlin, and R. Rao (2010). Requirement for Ergosterol in V-ATPase Function Underlies Antifungal Activity of Azole Drugs. In: PLoS Pathogens 6. Ed. by L. E. Cowen, e1000939. 